Florida International University FIU Digital Commons

\title{
Mechanical properties of self-consolidating concrete with pozzolanic materials
}

Indra Prasad Chapagain

Florida International University

DOI: $10.25148 /$ etd.FI14060143

Follow this and additional works at: https://digitalcommons.fiu.edu/etd

Part of the Civil Engineering Commons

\section{Recommended Citation}

Chapagain, Indra Prasad, "Mechanical properties of self-consolidating concrete with pozzolanic materials" (2008). FIU Electronic Theses and Dissertations. 2111.

https://digitalcommons.fiu.edu/etd/2111

This work is brought to you for free and open access by the University Graduate School at FIU Digital Commons. It has been accepted for inclusion in FIU Electronic Theses and Dissertations by an authorized administrator of FIU Digital Commons. For more information, please contact dcc@fiu.edu. 
FLORIDA INTERNATIONAL UNIVERSITY

Miami, Florida

MECHANICAL PROPERTIES OF SELF-CONSOLIDATING CONCRETE WITH

POZZOLANIC MATERIALS

A thesis submitted in partial fulfillment of the

requirements for the degree of

MASTER OF SCIENCE

in

CIVIL ENGINEERING

by

Indra Prasad Chapagain 
To: Interim Dean Amir Mirmiran

College of Engineering and Computing

This thesis, written by Indra Prasad Chapagain, and entitled Mechanical Properties of Self-Consolidating Concrete with Pozzolanic Materials, having been approved in respect to style and intellectual content, is referred to you for judgment.

We have read this thesis and recommend that it be approved.

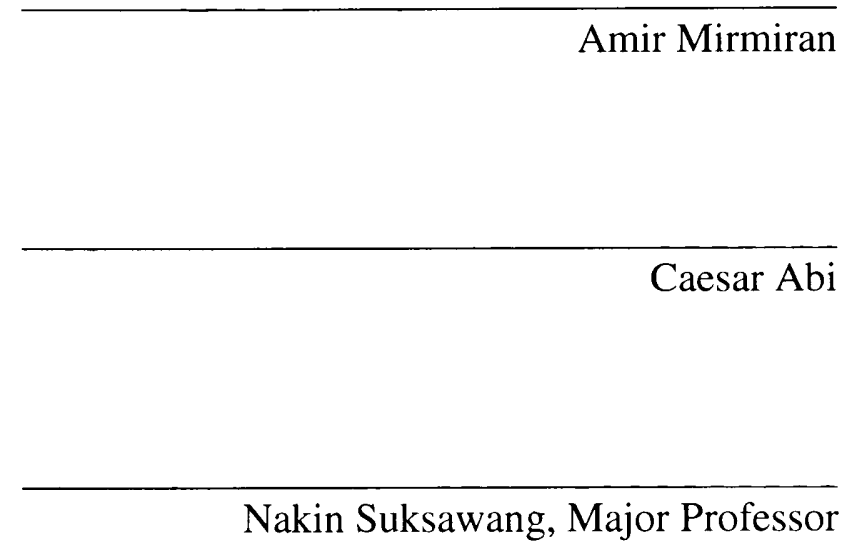

Date of Defense: July 16, 2008

The thesis of Indra Prasad Chapagain is approved.

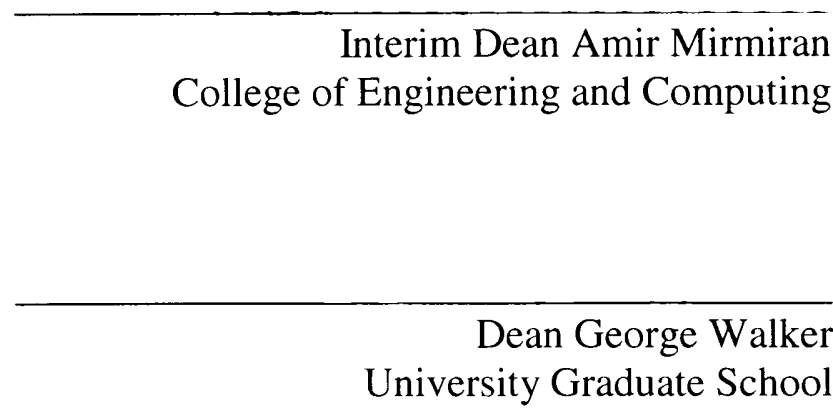

Florida International University, 2008 


\section{DEDICATION}

This thesis is dedicated to Gyanisara Chapagain, Apoorva Chapagain and Kamana Chapagain. 


\section{ACKNOWLEDGMENTS}

I would like to express my genuine gratitude to my Supervisor Professor N. Suksawang for his valuable help, guidance and insights throughout my thesis and experimental works. It was a great opportunity of learning and experience with him. I wish to thank the members of my thesis committee, Professor A. Mirmiran and Professor C. Abi Shdid for their encouragement, valuable time and constructive comments.

I am grateful to Mr. Edgar Polo for all the help in the laboratory. I also wish to thank Mr. Bill Box, Rinker Materials and Mr. Frank Suarez, Grace Construction Products for their help in providing concrete materials for the experiment.

Finally, I could not stop without thanking my wife Gyanisara Chapagain, son Apoorva Chapagain and daughter Kamana Chapagain for sacrificing their family life and encouraging me in my studies. To them I dedicate my thesis. 


\begin{abstract}
OF THE THESIS
MECHANICAL PROPERTIES OF SELF-CONSOLIDATING CONCRETE WITH

POZZOLANIC MATERIALS

by

Indra Prasad Chapagain
\end{abstract}

Florida International University, 2008

Miami, Florida

Professor N. Suksawang, Major Professor

Self-consolidating concrete has been described as the most revolutionary development in concrete technology in several decades with the ability to flow freely through closely spaced reinforcements, expel entrapped air and self compact without vibration. Since it was first developed in Japan in the early 1980's, major development in the chemical admixture technology has made SCC more viable.

An experimental study was conducted to identify the mechanical properties of SCC by optimizing the use of pozzolanic materials and local aggregates with some proposed statistical models. The research was focused to investigate compressive strength, splitting tensile strength, modulus of elasticity and drying shrinkage behavior of concrete. The results were established experimentally and compared with the available SCC research data based on extensive literature study.

Besides the improved mechanical performance, results indicate that the use of pozzolanic materials and local aggregate in SCC is recommended in terms of its cost benefit value. 


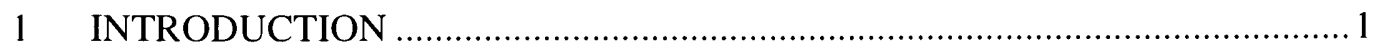

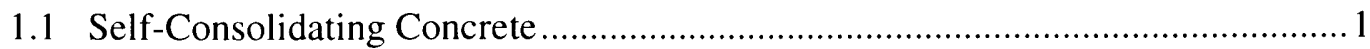

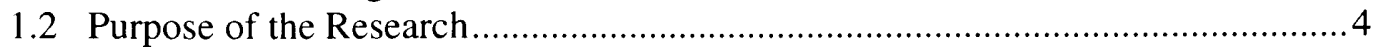

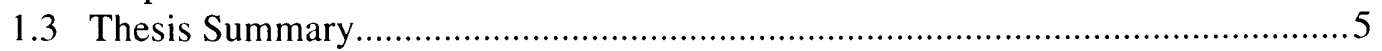

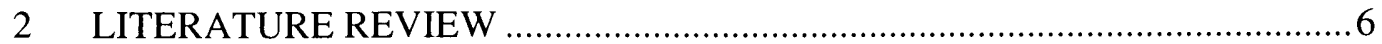

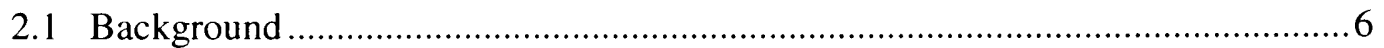

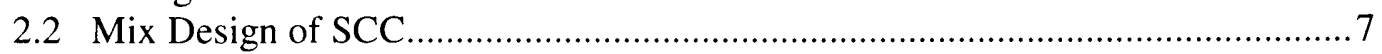

2.3 Influence of Mixing Procedures on the Production of SCC ................................ 9

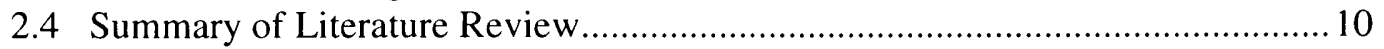

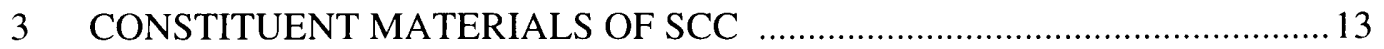

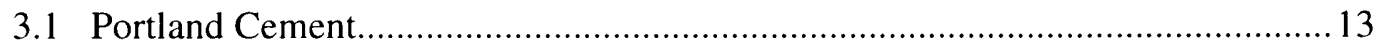

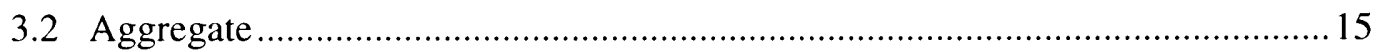

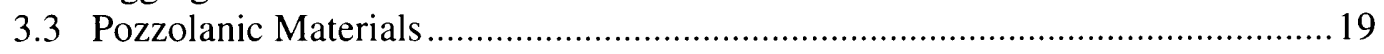

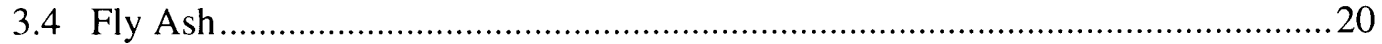

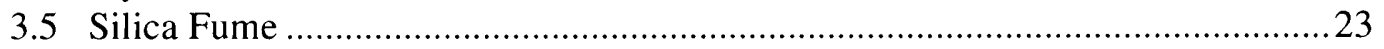

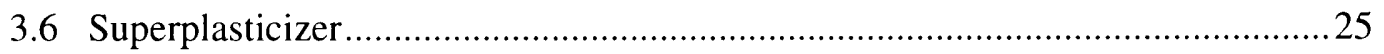

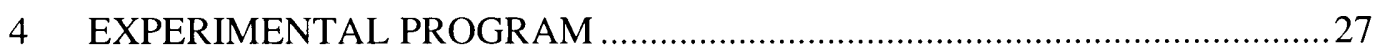

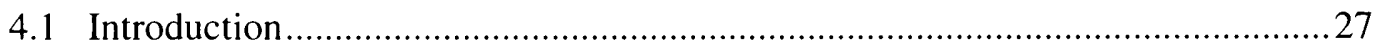

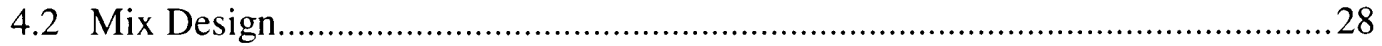

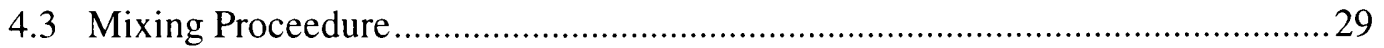

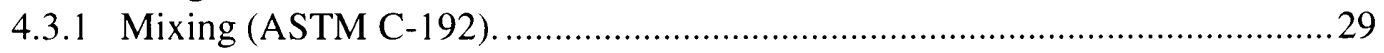

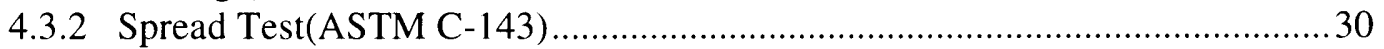

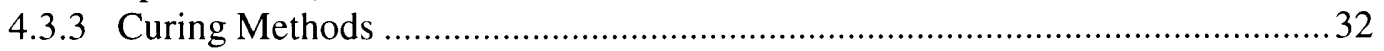

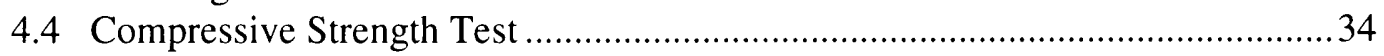

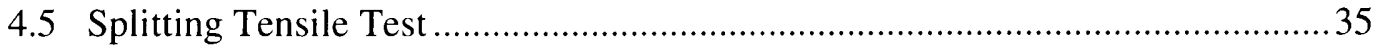

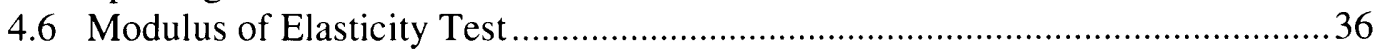

4.7 Drying Shrinkage Test .............................................................................. 41

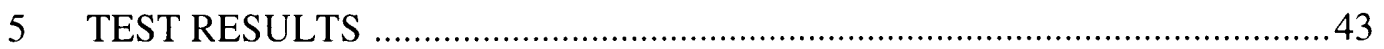

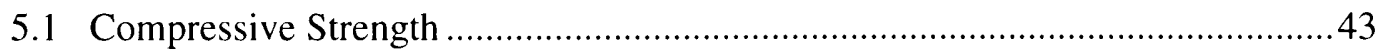

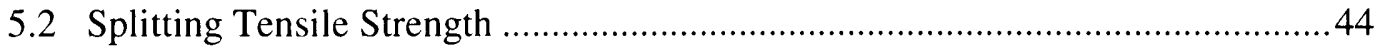

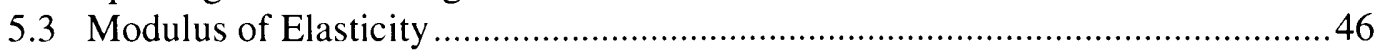

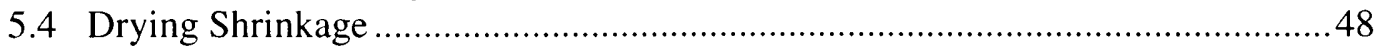

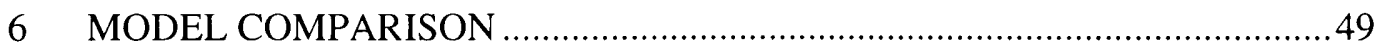

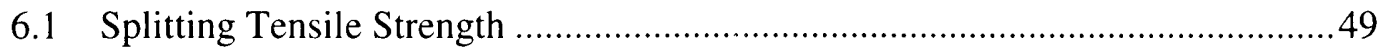

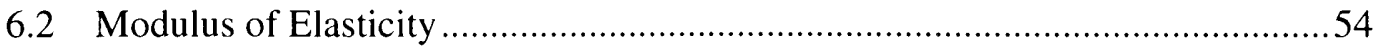


7 CONCLUSIONS...

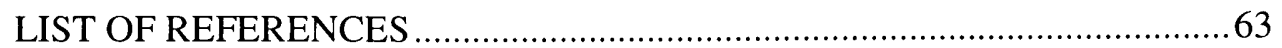

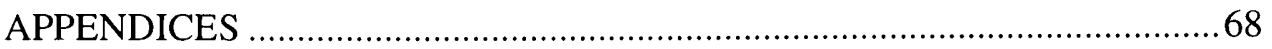


TABLE

PAGE

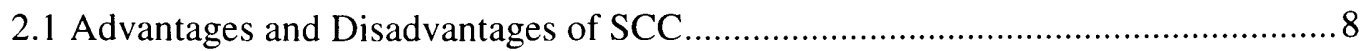

3.1 Composition of Different Types of Portland Cement..................................... 14

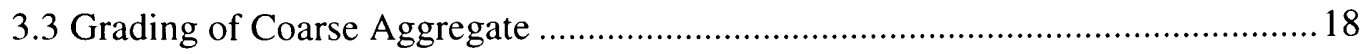

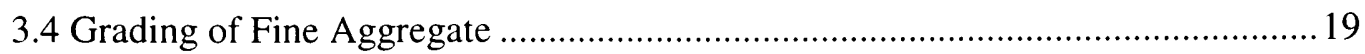

3.5 Typical Chemical Compositions of Fly Ash and Portland Cements ..................21

3.6 Physical and Chemical Properties of Silica Fume (Huang, 1990).......................25

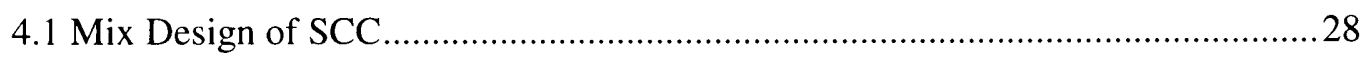

4.2 Trial Mix of Fly Ash, Silica Fume and Ordinary Portland Cement....................29

4.3 Results of the Slump Flow (Spread) Test ................................................. 31

6.1 Selection of Best Equation for Splitting Tensile Strength ................................53

6.3 Selection of Best Equation for Modulus of Elasticity ....................................58

3.2 The Physical and Chemical properties of Portland Cement ............................68

4.3 General Physical and Chemical Properties of Silica Fume ............................. 70

5.1 Compressive Strength Test Results ........................................................ 71

5.2 Splitting Tensile Strength Test Results .................................................... 72

5.3 Modulus of Elasticity Test Results ...................................................... 74

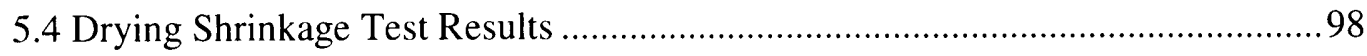

6.2 Calculations of the Percentage Error for the Splitting Tensile Strength.............. 102

6.4 Calculation of Percentage Error for the Modulus of Elasticity........................ 114 


\section{LIST OF FIGURES}

FIGURE

PAGE

3.1 Recommended Values for Coarse and Fine Aggregate Volume ...........................15

3.2 Symmetrical Curves for a Combined Gradation................................................18

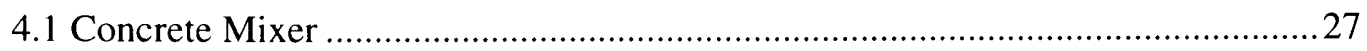

4.2 Typical Slump Flow for Spread Test ................................................................ 31

4.3 Spread Test According to ASTM C-1611 ……………………….........................

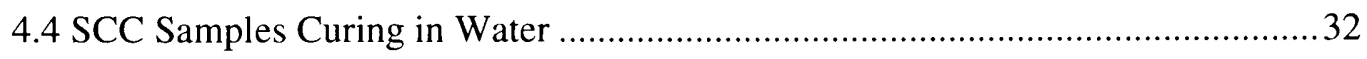

4.5 Samples for Drying Shrinkage Test ..................................................................3

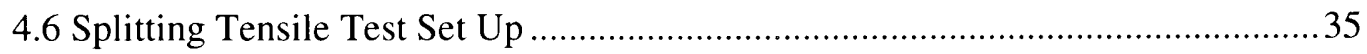

4.7 Strain Gauge for Modulus of Elasticity Test Set Up …………….........................36

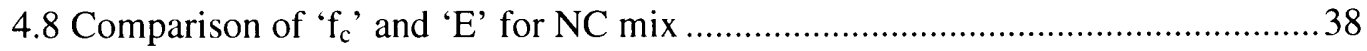

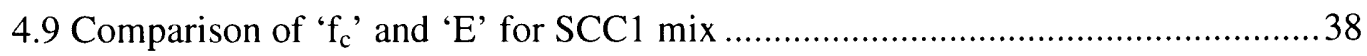

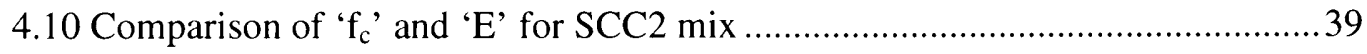

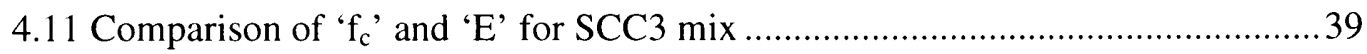

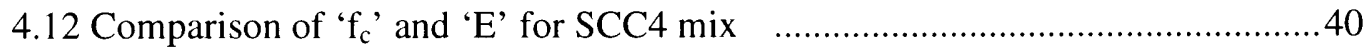

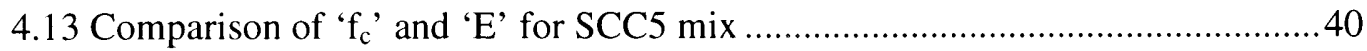

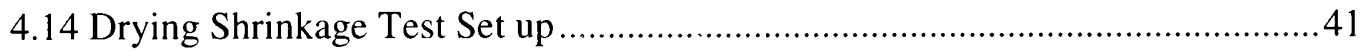

4.15 Samples for Drying Shrinkage Test ............................................................42

5.1 Compressive Strengths for Different Mix Models..............................................43

5.2 Splitting Tensile Strength for Different Mix Models ...........................................44

5.3 Seven day Tensile Test Results with Two Samples............................................45

5.4 Twenty Eight day Tensile Test Results with Two Samples ..................................45

5.5 Modulus of Elasticity for Different Mix Models .............................................46 
5.7 Twenty Eight Days Test Results of Linear Strain for 'E'

5.8 Experimental Result of the Drying Shrinkage vs. Time …..................................48

6.1 Comparison of Splitting Test Result with the Available Research.......................50

6.2 Equation for Splitting Tensile Strength (Regular) ..............................................51

6.3 Equation for Splitting Tensile Strength (Forced through Zero)............................51

6.4 Equations for Splitting Tensile Strength .........................................................52

6.5 Comparison of Modulus of Elasticity Test Results with the Codes ......................55

6.6 Equations for Modulus of Elasticity (Regular) .............................................56

6.7 Equations for Modulus of Elasticity (Forced through Zero) ………......................56

6.8 Equations for Modulus of Elasticity ………….............................................57 
$\mathrm{f}_{\mathrm{c}}=$ Compressive strength

$\mathrm{f}_{\text {st }}=$ Splitting tensile strength

$\mathrm{E}=$ Modulus of elasticity of concrete

$\mathrm{L}=$ Length of specimen

$d=$ Diameter of specimen

$\mathrm{F}=$ Applied force

$w_{c}=$ Density of normal concrete

$\mathrm{oz}=$ Ounce

$\mathrm{W} / \mathrm{b}=\mathrm{W}$ ater binder ratio

$\varepsilon=$ Strain (Longitudinal)

SCC $=$ Self-Consolidating concrete

$\mathrm{NC}=$ Normal concrete

$\mathrm{OPC}=$ Ordinary Portland cement

ASTM $=$ American Society of Testing Materials

$\mathrm{SP}=$ Superplasticizer

$\mathrm{VMA}=\mathrm{Viscosity}$ modifying agent

$\mathrm{AEA}=$ Air entraining admixtures

$\mathrm{LP}=$ Limestone powder

$\mathrm{NA}=$ Not applicable 


\section{CHAPTER 1}

\section{INTRODUCTION}

\subsection{Self-Consolidating Concrete}

Self-consolidating concrete (SCC) can be defined as a fresh concrete that possesses superior flowability under maintained stability (i.e. no segregation), thus allowing self-compaction (Goodier, winter 2002/2003). It is a fluid mixture, which is suitable for placing in complex structures with congested reinforcement without vibration. It is characterized by high powder content. The resulting concrete has an excellent surface finish (Subramanian and Chattopadhyay, 2002).

The development of SCC begun in Japan in 1983 when the aim was to build durable concrete structures with a reduced number of skilled workers. The initial fundamental investigations were carried out at Tokyo University by Ojawa and Maekawa in 1989 (Okamura and Ouchi, 1989).

Opportunities obviously exist for SCC in rapid pavement repair, precast application in highway or bridge construction because of its rapid strength gain, long service life and no noise (therefore making highway night working possible) are all vital to highway construction and repair, and so SCC is an ideal material ( Mullarky and Vanikar).

The mix composition of SCC generally differs from that of a normal concrete through a higher proportion of ultrafines and through the use of highly effective superplasticizers. In principle, there are three approaches to the production of SCC:

- Raising the ultrafines content by addition of fine fractions in the form of fly ash or stone powder. 
- Use of suitable stabilizing additives and or superplasticizer (viscosity agent type);

- Combination of above -mentioned measures (combination type).

Neither the water nor the cement content of SCC differs substantially from those of normal concrete. The water to cement $(\mathrm{W} / \mathrm{C})$ value remains on the normal range between 0.45 and 0.60 . The addition of ultrafines of high specific surface area significantly increases the mortar volume, but at the same time reduces the relative percentage of water in the cement paste. Addition of superplasticizers is therefore essential to give the fresh concrete adequate flowability. Newly developed additives based on polyacrylates and multycarboxylate ethers are particularly suitable in this respect. Concrete additive based on polycarboxylates offer the following advantages for SCC application.

- Significant reduction of the water demand $\mathrm{n}$ the mix

- Little loss of consistency

- Short setting times

- High early strength

- Low tendency to segregation. (Brameshuber, 2001)

SCC that flows into formwork and through reinforcement under the influence of its own weight can be made such that no external vibration is required. Although careful proportioning and batching are needed, SCC can be produced with locally available materials. Concrete with a high slump flow are prone to segregation and bleeding. Tests should be conducted with the material used for a specific project to establish that the SCC flows sufficiently but will not segregate, bleed, or require additional consolidation. Segregation is the tendency for coarse aggregate to separate 
from the sand-cement mortar due to vibration, transportation or handling and bleeding is the water gain due to the settlement of solid materials in concrete. To minimize segregation, a large amount of fine material, a small nominal maximum aggregate (NMA) size, uniform grading, and low water cementitious material ratios are needed or conventional mixtures with viscosity modifying agent (VMA) may be used. To mitigate high drying shrinkage, a large NMA size, a large amount of coarse aggregate, and lower water cement are needed. To avoid an improper air-void system that would reduce freeze-thaw resistance either larger air content or conventional air content with the proper selection of admixtures that will lead to a reduced void size and spacing is needed. (Ozyildirim and Lane, 2003).

Fresh concrete can be described as a particle suspension, although rather complex. The liquid phase is normally defined as either mortar or cement paste. As in all particle suspensions, the balance between flowability and segregation is vital. SCC is extending the flowability, with maintained stability of the suspension, to such a degree that the concrete can flow through openings, fill moulds and consolidate itself without any added external energy input. To achieve this behavior it is necessary to have:

- Appropriate flowability

- Stability(non-segregations)

- No blocking tendency(passing through openings between bars)

The main mechanism to achieve appropriate flowability is a reduction of the interparticle friction with the use of superplaticizing admixtures. The physical and mineralogical properties of the fine particle materials are also very important. The stability is achieved by designing the liquid phase with appropriate rheological 
properties. This is achieved through careful particle packing design and/or the use of viscosity modifying admixtures.

The size and shape of the coarse aggregate as well as the volume of the liquid phase are important factors to prevent blocking for different reinforcement configurations. The type of superplasticizer is of outmost importance. It shall be selected from the requirements needed for each type of product. An accelerator can be needed in the superplasticizer for example for walls so that the surface finishing can take place at an early age. (Gunnar Rise, 2001).

\subsection{Purpose of the Research}

A large volume of research regarding normal concrete has been performed; a comparatively much smaller quantity of research regarding self-consolidating concrete is available. Inadequate homogeneity of the cast concrete due to poor compaction or segregation may drastically lower the performance of the matured concrete. The strength and durability of concrete can be improved with the addition of pozzolanic materials and chemical admixtures. The pozzolanic materials are finer materials than even Portland cement which reduces porosity and increases its strength and durability.

The purpose of this study is to investigate the behavior and relationship of mechanical properties of diverse SCC mixes with the use of new fillers i.e. pozzolanic materials. In this study, the mechanical properties include compressive strength, tensile splitting strength, modulus of elasticity and shrinkage which are needed for designing reinforced concrete structures. The mixes are based on the proportion used by the 'Core slab Structures', Miami based SCC Plant, Pozzolanic materials in 
different trial proportions are additionally used in these mixes which consist of fly ash and silica fume to reduce shrinkage, permeability and increase durability. Silica fume is capable of reducing permeability and helps to minimize aggregate segregation whereas fly ash significantly improves mechanical properties and durability of concrete. (Xie et al., 2002; Bouzoubaa and Lachemi, 2001; and Ho et al., 2003).

\subsection{Thesis Summary}

Chapter one gives a brief introduction to self-consolidating concrete, purpose of the research and outline of thesis summary. Chapter two presents literature review that includes background of self-consolidating concrete, its mix design, influence of mixing procedures and summary of literature review. Chapter three explains constituent materials of self-consolidating concrete e.g. Portland cement, aggregates, pozzolanic materials and superplasticizer. Chapter four explains the experimental program that includes introduction, material properties, description of each constituent material in accordance with ASTM standard, spread test, compressive strength test, splitting tensile test, modulus of elasticity test and drying shrinkage test. Chapter five covers test results. The test results are summarized for compressive strength, splitting tensile strength, modulus of elasticity and drying shrinkage. Diagrams have been provided for splitting tensile strength vs. percent fly ash, modulus of elasticity vs. percent fly ash and time vs. percent drying shrinkage. Chapter six shows a model comparison of splitting tensile test and modulus of elasticity with the available research and codes such as ACI 318, ACI 363 and Eurocode 2. Chapter seven describes the conclusion of the overall research. 


\section{CHAPTER 2}

\section{LITERATURE REVIEW}

\subsection{Background}

Inadequate homogeneity of the cast concrete due to poor compaction or segregation may drastically lower the performance of mature concrete. SCC has been developed to ensure adequate compaction and facilitate placement of concrete in structures with congested reinforcement and in complex areas where compaction may not be possible. (Bouzoubaa and Lachemi, 2001). It can also be used in situations where it is difficult or impossible to use mechanical compaction for fresh concrete, such as underwater concreting, cast in-situ pile foundations, machine bases and columns and walls with closely spaced reinforcements. The high flowability of SCC makes it possible to fill the formwork without vibration. Since its inception, it has been widely used in large construction in Japan (Okamura and Ouchi, 2003). Recently, this concrete has gained wide use in many countries for different applications and structural configurations (Bouzoubaa Lachemi, 2001).

SCC can also be regarded as "the most revolutionary development in concrete construction for several decades. Originally developed to offset a growing shortage of skilled labor, it is now taken up with enthusiasm across European countries for both site and precast concrete work. (Krieg, Oct. 2003; EFNARC, Feb 2002).

SCC has gained widespread attention in the United States in the last few years for its obvious advantages of savings in labor costs, shortened construction time, better finish and improved work environment (Gaimster and Foord, 2000; Khayat, 1999). 
SCC was developed in Japan in the early 1980's. The roots of the development were dictated by three main factors, one being the need for flowing concrete to compensate proper filling within the intricate reinforcement design in seismic members. The others are the decreasing number of skilled craftsmen in Japan and the need to reduce the cost and time of construction. With the growing use of concrete in special architectural configurations and closely spaced reinforcing bars, it is very important to produce concrete that ensures proper filling ability, good structural performance, and adequate durability (Hayakawa et al., 1993).

\subsection{Mix Design of SCC}

In order to understand the mix design and its phenomena in connection with the properties and quality of SCC, we need to be familiar with the tests and results, research and experiments that have been done to date. An attempt has been made to cover up multiple tests with varieties of mixes, so as to make a finer distinction with the comparison.

The basic components for the mix composition of SCC are the same as used in conventional concrete. However, to obtain the required properties of fresh concrete, in SCC a higher proportion of ultra fine materials and the incorporation of chemical admixtures, in particularly an effective superplasticizer, are necessary. Ordinary and approved fillers are fly ash, limestone powder, blast furnace slag, and silica fume and quartzite powder (Holschemacher and Klug, 2002). Fillers are fine particles than Portland cement, which helps in reducing porosity and improves durability and strength of concrete.

The result in mixes compared to conventional workability concrete, contain: 
- Lower coarse aggregate contents

- Increased paste contents

- High power (materials $<0.125 \mathrm{~mm}$ ) contents,

- Low water/powder ratios

- High superplasticizer doses

- (Sometimes) a viscosity-modifying agent.

SCC is based on a new concept that fulfils the deficiencies of normal concrete. It has proved beneficial economically because of a number of reasons:

Table 2.1 Advantages and Disadvantages of SCC

\begin{tabular}{|c|c|}
\hline Advantages & Disadvantages \\
\hline $\begin{array}{l}\text { - } \text { Faster construction } \\
\text { - } \text { Reduction in manpower } \\
\text { - Uniform consistency of } \\
\text { concrete } \\
\text { - Easier placing } \\
\text { - Greater flexibility in design } \\
\text { - Better surface finishing } \\
\text { - Increased bond strength } \\
\text { - Improved durability } \\
\text { - Reduced noise levels, due to } \\
\text { - } \text { absence of vibration } \\
\text { Safe working environment }\end{array}$ & $\begin{array}{l}\text { - Greater quality-assurance effort in } \\
\text { production } \\
\text { - Higher costs for materials for the } \\
\text { plasticizers and additives } \\
\text { - Properties are not well known } \\
\text { - Can only be used on flat surfaces } \\
\text { - Non-uniform formwork pressure }\end{array}$ \\
\hline
\end{tabular}

(Krieg 2003, and ENFARC 2002, Leiberum 2002) 


\subsection{Influence of Mixing Procedures on the Production of SCC}

The mixing procedure is critical in producing concrete of the desired properties. All materials are weighed preciously and added in a sequence to the mixture. The sequence of mixing must allow sufficient time for the thorough mixing of all the ingredients without losing moisture due to wind and temperature effects.

Besides technical problems as for example the composition, there are as well administrative barriers in the foreground. During the SCC's production in mixtures, it is necessary to produce a concrete which has good flow qualities and a high passing and form filling quality with an excellent cohesion quality. According to Beitzel, $\mathrm{H}$. there is three groups of mixing parameters:

System technical:

- mixing space,

- mixing tools,

- Process rate

$\underline{\text { Service technical: }}$

- Dosage sequence

- Mixing time

- Length of cycle

Concrete technical:

- Material items

- Various characteristics, (Beitzel, H., 2001) 


\subsection{Summary of Literature Review}

The mechanical properties and qualities of SCC mainly depend on its mix design within the recommended standard tests. There are many factors that are still unknown for the better strength and modulus of elasticity. Materials, its quality and proportion are the root three factors that change the behavior of mechanical properties of concrete. Size, fineness modulus (grading) and quantity of fine and coarse aggregate, w/b ratio, cement and chemical are the known factors that are responsible to change the property of SCC. Hence, an approach have been made to cover up a wide range of mix design from different world class literatures, seminars and even local plant to obtain and compare especially the mechanical properties. Some important summary and conclusions have been drawn with respect to the performance of SCC.

- Specifications and guidelines for SCC- EFNARC, 2002 has proposed a crushed aggregate for a better mechanical property of SCC, whereas Petersson O., 1997 suggests opposite one, with the proof of experiment and result, the higher compressive strength obtained for mixes is explained by a better quality of the natural rounded 4/10 aggregate compared to the semi crushed 4/10.

- If the concrete design is not a densely reinforced one, we can ignore the flowability requirement using greater size and quantity of aggregates (by balancing segregation adding viscosity modifying admixtures) so as to increase the strength parameter of SCC, as suggested by Ouchi, Nakamura, Osterson, Hallberg, and Lwin, 2003 ISHPC.

- The equal use of course and fine aggregate tends to reach highest possible compressive strength of SCC (Petersson O. 1997, Swedish Cement and concrete Research Institute). 
- The coarse aggregate chosen for SCC is typically rounded small aggregate particles that enhance the flowability and deformability. The smaller aggregate size is also less likely to segregate from the paste. The coarse particles increase the strength of concrete reducing the flowability. The most common max aggregate size used in SCC is in the range of 16-20mm (Peterson O., 1998) depending on the type of construction.

- To minimize segregation, a large amount of fine material, a small nominal maximum aggregate (NMA) size, uniform grading, and low water cementitious material ratios are needed or conventional mixtures with viscosity modifying agent (VMA) may be used. To shrinkage, a large NMA size, a large amount of coarse aggregate, and lower water cement are needed. (Ozyildirim C., 2003).

- If problems develop due to a poor gradation, alternative aggregates, or special screening of existing aggregates, should be considered. The combined gradation can be used to better control workability, pumpability, shrinkage and other properties of concrete (Steven et.al., 2003)

- The maximum size of coarse aggregate used in concrete has a bearing on the economy of concrete. Usually more water and cement is required for smallsize aggregate than for large sizes, due to an increase in total aggregate surface area (The European Guidelines for SCC, 2005).

- As the aggregates restrain the creep of the concrete paste, the higher the volume of the aggregate and the higher the E-value of the aggregate, the lower the creep will be (The European Guidelines for SCC, 2005). 
- A decrease in the maximum aggregate size which results in a higher paste volume increases the drying shrinkage (The European Guidelines for SCC, 2005). 


\section{CHAPTER 3}

\section{CONSTITUENT MATERIALS OF SCC}

The constituent materials used in the production of SCC are similar to that of the normal vibrated concrete except the reduced aggregate content and increased powder content with the addition of superplasticizer or viscosity modifying agent (VMA).

\subsection{Portland Cement}

Portland cement is mainly consists of limestone and clay. Limestone is first processed to produce calcium oxide which in turn is combined with the metal oxides produced from clay (silica $\mathrm{SiO}_{2}$, alumina $\mathrm{Al}_{2} \mathrm{O}_{3}$, iron oxide $\mathrm{Fe}_{2} \mathrm{O}_{3}$ etc) to generate the primary products of Portland cement. The major components of Portland cement are:

1. Tricalcium silicate $\left(3 \mathrm{CaOSiO}_{2}=\mathrm{C}_{3} \mathrm{~S}\right)$

2. Dicalcium silicate $\left(2 \mathrm{CaOSiO}_{2}=\mathrm{C}_{2} \mathrm{~S}\right)$

3. Tricalcium aluminate $\left(3 \mathrm{CaOAl}_{2} \mathrm{O}_{3}=\mathrm{C}_{3} \mathrm{~A}\right)$

4. Tetracalcium aluminoferrite $\left(4 \mathrm{CaO} \cdot \mathrm{Al}_{2} \mathrm{O}_{3} \cdot \mathrm{Fe}_{2} \mathrm{O}_{3}=\mathrm{C}_{4} \mathrm{AF}\right)$

These chemical compounds of Portland cement are discussed in the following (Mehta, 1986; Mindess and Young, 1981; Bayast et al., 1990 and Huang, 1990).

1. Tri-calcium silicate, $\mathrm{C}_{3} \underline{\underline{S}}$ : This product is responsible for the rapid hardening of concrete. With increasing percentage of $\mathrm{C}_{3} \mathrm{~S}$ in cement, the resulting concrete early strength(less than a week old) increases.

2. Dicalcium silicate, $\mathrm{C}_{2} \underline{\mathrm{S}}: \mathrm{C}_{2} \mathrm{~S}$ has a significant contribution to the late age strength of concrete. 
3. Tricalcium aluminate, $\mathrm{C}_{3} \underline{A}$ : This product hardens relatively slowly and is characterized by its relatively low contribution to early age strength.

4. Tricalcium aluminoferite, $\mathrm{C}_{4} \underline{\mathrm{AF}}$ : $\mathrm{C}_{4} \mathrm{AF}$ acts as a flux during cement production when limestone and clay are subjected to high baking temperature (clinkering). The flux action of $\mathrm{C}_{4} \mathrm{AF}$ reduces the clinkering temperature which can be beneficial to energy saving.

5. Based on the relative proportions of the components of Portland cement, it can be classified in five types. Each type, depending on its quality, is designated for its specific field applications. The following Table presents the most important types of Portland cement along with the relative proportions of their components (Mehta, 1986; Mindess and Young, 1981; Bayast et al., 1990 and Huang, 1990).

Table 3.1 Composition of Different Types of Portland cement

\begin{tabular}{|l|l|l|l|l|l|}
\hline \multirow{2}{*}{$\begin{array}{l}\text { Type of } \\
\text { Portland } \\
\text { cement }\end{array}$} & \multicolumn{4}{|l|}{ Compounds percentage } & \multirow{2}{*}{ Function } \\
\cline { 2 - 5 } & $\mathrm{C}_{3} \mathrm{~S}$ & $\mathrm{C}_{2} \mathrm{~S}$ & $\mathrm{C}_{3} \mathrm{~A}$ & $\mathrm{C}_{4} \mathrm{AF}$ & \\
\hline Type I & 55 & 19 & 10 & 7 & Ordinary \\
\hline Type II & 51 & 24 & 6 & 11 & Moderate sulphate resisting \\
\hline Type III & 63 & 19 & 10 & 7 & High early strength \\
\hline Type IV & 28 & 49 & 4 & 12 & Low heat of hydration \\
\hline Type V & 38 & 43 & 4 & 9 & Sulphate resisting \\
\hline
\end{tabular}


Portland cement Type II with specific gravity 3.15 and blain fineness of 377 $\mathrm{m}^{2} / \mathrm{kg}$ was used. It is used for general purposes, more especially when moderate sulphate resistance or moderate heat of hydration is desired. It was manufactured by Titan Florida that meets the requirements of ASTM C 150 standard. The chemical and physical properties are listed in Table 3.2 (APPENDICES).

\subsection{Aggregate}

In order to obtain an economic mix design, the coarse aggregate content should be the maximum possible. However, in order to increase the passing ability and reduce interparticle collision, the volume of coarse aggregate should be decreased, and the paste volume should be increased. To achieve an optimized SCC mixture, coarse aggregate is limited to $50 \%$ of the solid volume and fine aggregate is fixed at $40 \%$ of the mortar content (Okamura, 1997).

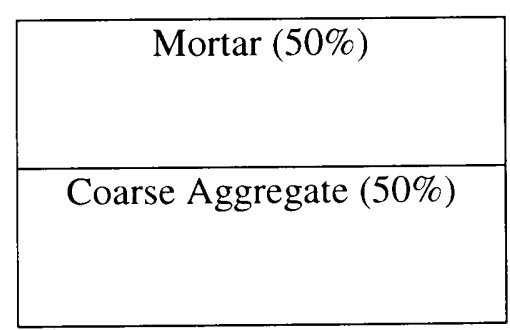

(a) Solid Volume

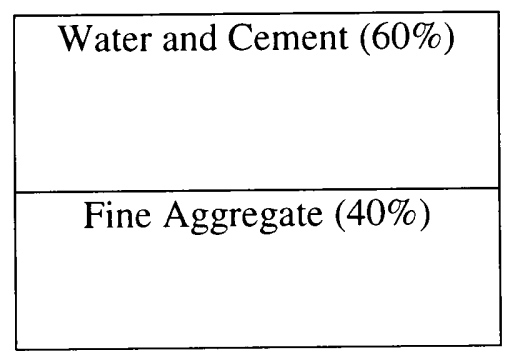

(b) Mortar Volume

Fig 3.1 Recommended Values for Coarse Aggregate Volume and Fine Aggregate Volume (Okamura, 1997). 
The aggregate particles larger than $4.75 \mathrm{~mm}(0.2 \mathrm{in})$ are termed as coarse aggregate, whereas the particles smaller than $4.75 \mathrm{~mm}$ but larger than $0.075 \mathrm{~mm}$ (0.003 in) are called fine aggregates. The finer aggregates are responsible for the enhancement of workability and uniformity of the mixture. The maximum size and grading of the aggregates depends on the particular application. However, the maximum size of coarse aggregate is usually limited to $20 \mathrm{~mm}$. (Mehta, 1986; Mindess and Young, 1981; Bayast et al., 1990 and Huang, 1990).

The high volume of paste in SCC mixes helps to reduce the internal friction between the sand particles but a good grain size distribution is still very important. Many SCC mix design methods use blended sands to match an optimized aggregate grading curve and this can also help to reduce the paste content. Regarding the characteristics of different types of aggregate, crushed aggregate tend to improve the strength because of the interlocking of the angular particles, whereas rounded aggregates improve the flow because of lower internal friction. The particle size distribution and the shape of coarse aggregate directly influence the flow and passing ability of SCC and its paste demand. The more spherical the aggregate particles the less they are likely to cause blocking and the greater the flow because of reduced internal friction. However, as per Japanese approach and Orjan Petersson (Swedish Cement and Concrete Research Institute-Date 97-10-27/ line 8) suggests with the proof of experiment and result, the higher compressive strength obtained for mixes is explained by a better quality of the natural rounded $4 / 10$ aggregate compared to the semi crushed 4/10 (EFNARC, 2002; European Guidelines, 2005).

Coarse aggregate used was ASTM\#57 FDOT limestone with max nominal size of $19 \mathrm{~mm}$. It is abundantly available and comparatively cheap material in Florida. The aggregate have a SSD (saturated surface dry) mean specific gravity 2.483 and 
water absorption 4.8 percent. Fine aggregate used was commercial sand with SSD mean specific gravity 2.564 and water absorption 2.45 . Test method for sieve analysis of fine and coarse aggregates meets the standard specification of ASTM C 136. The grain size distributions of both aggregates were listed in Table 3.3 and 3.4.

Aggregate Grading: The grading and grading limits are usually expressed as the percentage of material passing each sieve. There are several reasons for specifying grading limits and nominal maximum aggregate size, they affect relative aggregate proportions as well as cement and water requirements, workability, pumpability, economy, porosity, shrinkage and durability of concrete. Variations in grading can seriously affect the uniformity of concrete from batch to batch. Very fine sands are often uneconomical; very coarse sands and coarse aggregate can produce harsh, unworkable mixtures. In general, aggregates that do not have a large deficiency or excess of any size and give a smooth grading curve will produce the most satisfactory results. However, a perfect gradation does not exist in the field -but we can try to approach it. If problems develop due to a poor gradation, alternative aggregates, or special screening of existing aggregates, should be considered. For example, sometimes midsized aggregate, around the $9.5 \mathrm{~mm}$ size, is lacking in an aggregate supply, resulting in a concrete with high shrinkage properties, high water demand, poor workability, poor pumpability, and low strength. The combined gradation can be used to better control workability, pumpability, shrinkage and other properties of concrete (Steven et al., 2003). 


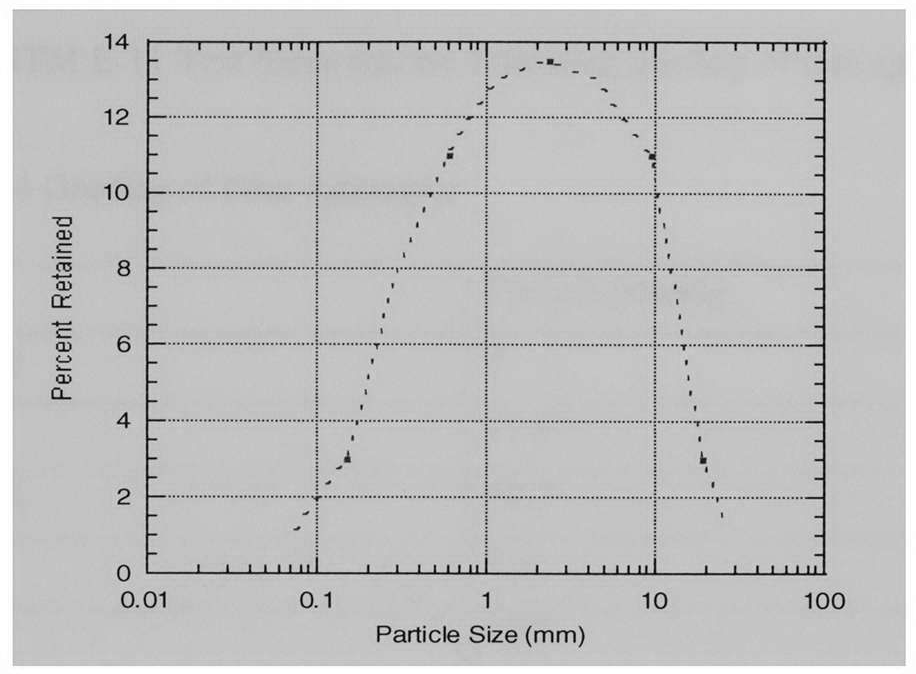

Figure 3.2 Symmetrical Curves for a Combined Gradation

Coarse Aggregate: The coarse aggregate used in this study is ASTM\#57, FDOT, limestone. The average value of water absorption is $4.85 \%$. The ASTM E-11 Test Sieve has the following grading result:

Table 3.3 Grading of Coarse Aggregate

\begin{tabular}{|l|l|}
\hline Sieve Opening & Percent passing \\
\hline 1 in. $(25.4 \mathrm{~mm})$ & 0 \\
\hline $3 / 4$ in. $(19 \mathrm{~mm})$ & 3.2 \\
\hline $1 / 2$ in. $(12.5 \mathrm{~mm})$ & 39.7 \\
\hline $3 / 8$ in. $(9.5 \mathrm{~mm})$ & 33.4 \\
\hline $3 / 16$ in. $(4.75 \mathrm{~mm})$ & 22.5 \\
\hline
\end{tabular}


Fine Aggregate: 'Commercial Concrete' sand was used as fine aggregate. It was obtained from Rinker Materials, South Miami Plant, FL. The water absorption was $2.5 \%$. The ASTM E-11 Test Sieve has the following grading of fine aggregate:

Table 3.4 Grading of Fine Aggregate

\begin{tabular}{|l|l|}
\hline Sieve & Percent passing \\
\hline$\# 4(4.750 \mathrm{~mm})$ & 0 \\
\hline$\# 8(2.36 \mathrm{~mm})$ & 11.4 \\
\hline$\# 16(1.80 \mathrm{~mm})$ & 30.7 \\
\hline$\# 30(600 \mu \mathrm{m})$ & 9.5 \\
\hline$\# 50(300 \mu \mathrm{m})$ & 15.2 \\
\hline$\# 100(150 \mu \mathrm{m})$ & 28.2 \\
\hline
\end{tabular}

\subsection{Pozzolanic Materials}

Pozzolans are basically composed of siliceous $\left(\mathrm{SiO}_{2}\right)$ or siliceous and aluminous $\left(\mathrm{SiO}_{2}\right.$ and $\left.\mathrm{Al}_{2} \mathrm{O}_{3}\right)$ materials which combine with lime $\left[\mathrm{Ca}(\mathrm{OH})_{2}\right]$ in the presence of moisture (Lemond, ACI SP 79). Fly ash, silica fume, limestone powder and blast furnace slag are the basic pozzolanic materials. Fly ash or limestone powder is used in SCC to replace or reduce the content of cement. These fill the capillary pores in concrete making it denser, thus, increasing the durability of concrete. In addition, some of the pozzolans like fly ash and blast furnace slag can also increase the flowability of concrete which results in the reduction of the amount of superplasticizers (Xie et al., 2002; Bouzoubaa and Lachemi, 2001; and Ho et al., 2003). The particle size of pozzolanic materials is finer than cement; hence it helps to reduce the porosity improving strength and durability of SCC. 


\subsection{Fly ash}

Fly ash is an inorganic by-product obtained from the combustion of pulverized coal and is carried from the combustion chamber of a furnace by exhaust gases. It is classified as pozzolan. Pozzolans are siliceous $\left(\mathrm{SiO}_{2}\right)$ and aluminous $\left(\mathrm{Al}_{2} \mathrm{O}_{3}\right)$ materials which combine with lime $\left[\mathrm{Ca}(\mathrm{OH})_{2}\right]$ in the presence of moisture. For use in Portland cement concrete, fly ash is divided into two classes, class $\mathrm{C}$ and class $\mathrm{F}$. Class $\mathrm{C}$ ash is obtained from the use of sub bituminous and lignite coal in power plants. It is characterized by its relatively high $\mathrm{CaO}$ content and $\tan$ color. Class $\mathrm{F}$ fly ash is generated from burning bituminous and anthracite coals in the electric power plants. It is gray in color and contains relatively high carbon and low lime contents. Class $\mathrm{F}$ fly ash was used for the experimentation which matches the requirements of ASTM C 618.

Fly ash is used as a partial replacement of cement in concrete. Ratio of fly ash to binder (cement plus fly ash) ranges from 20 to $60 \%$. However, 20 to $30 \%$ is usually considered optimum for strength. For class F fly ash, this ratio is considered optimum for workability also. Typical chemical composition of fly ash class F and Portland cement are described in Table 3.5 (Lemond; Bayasi and Soroushian, 1988-1989; Popovics, 1982; Sturrup, 1983; Ravina, 1984; Portland Cement Association, 1979).

Properties of Fly Ash: Fly ash particles are spherical and vary in size from 1 to 100 microns with a typical average size of 9 to 15 microns. The density of fly ash ranges from 2.2 to $2.8 \mathrm{~g} / \mathrm{cm}^{3}$.

The pozzolan consists of heterogeneous combination of crystalline and amorphous oxides, unhydrated lime and carbon. For use in Portland cement concrete, 
fly ash is divided into two classes, C and F. Class C ash is generated from the use of sub-bituminous and lignite coal in power plants. It is characterized by its relatively high $\mathrm{CaO}$ content and Tan color. On the other hand, burning bituminous and anthracite coals in power plants produces a grey class $\mathrm{F}$ ash with relatively high carbon and low lime contents.

Table 3.5 Typical Chemical Compositions of Fly Ash and Portland Cements

\begin{tabular}{|l|l|l|l|}
\hline \multirow{2}{*}{ Compound } & \multicolumn{2}{|l|}{ Quantity (\%) } & \multirow{2}{*}{ Portland Cement } \\
\cline { 2 - 3 } & Fly Ash & Class C & \\
\cline { 2 - 3 } & Class F & $38-45$ & $20-25$ \\
\hline $\mathrm{SiO}_{2}$ & $50-55$ & $15-18$ & $2-5$ \\
\hline $\mathrm{Al}_{2} \mathrm{O}_{3}$ & $20-27$ & $5-10$ & $1-5$ \\
\hline $\mathrm{Fe}_{2} \mathrm{O}_{3}$ & $5-10$ & $15-25$ & $60-65$ \\
\hline $\mathrm{CaO}$ (lime) & $5-10$ & $2-6$ & $1-4$ \\
\hline $\mathrm{MgO}$ & $0-5-2$ & $2-6$ & $2-5$ \\
\hline $\mathrm{SO}_{3}$ & $0-2$ & & \\
\hline
\end{tabular}

For use in concrete, the optimum percentage of $\mathrm{SiO} 2$ and $\mathrm{CaO}$ are $45-65 \%$ and $10-20 \%$, respectively. Uniformity is especially important because fly ash is a waste material from coal burning where electricity is the principal product of the operation. The finer particles of fly ash, especially those less than 10 microns, are more beneficial for microstructure. The finer particles also contain less carbon which is harmful to concrete in any amount (Lemond, SP 79; Bayasi and Soroushian, 19881989; Popovics, 1983; Sturrup et al., 1983; Ravina 1984; PCA, 1979).

Fly ash is used as a partial replacement of cement in concrete. Ratio of fly ash to binder (cement + fly ash) ranges from 20 to $60 \%$. Generally, 20 to $30 \%$ is 
considered optimum for strength and microstructure. For class $\mathrm{F}$ fly ash this ratio is usually optimum for workability. However, with case $\mathrm{C}$ ash, improvements in workability continue consistently with increasing the ratio of fly ash to binder (Lemond SP 79; Bayasi and Soroushian, 1988-1989; Popovics, 1983; Sturrup et al., 1983; Ravina 1984; PCA, 1979).

Advantages of Fly Ash in Concrete: The addition of fly ash increases workability, flowability, mobility and uniformity because the spherically shaped fly ash particles act as ball bearings between the surfaces of neighboring cement particles. Compared to larger particles, fly ash particles less than 10 microns are generally more effective as ball bearings. Since class $\mathrm{C}$ fly ash contains larger quantities of particles smaller than 10 microns compared to class $\mathrm{F}$ ash, class $\mathrm{C}$ fly ash in particular is very effective in improving concrete workability. The improvements in flowability and mobility resulting from fly ash addition also improve pumpability of concrete. Furthermore, the additional binding material and improved workability of fly ash concrete permit mix designs with relatively low water to binder ratios which yield concrete mixtures with more compressive strength.

Fly ash provides concrete with more $\mathrm{SiO}_{2}$ which improves the stability and uniformity of the mix. The increase of binder volume by the application of fly ash retards setting time resulting delay of the finishing process because it has lower reactivity than cement. Finishing of concrete surfaces usually causes an accumulation of fines which may block bleed water movement to the surface and cause plastic shrinkage cracking (Lemond, SP 79; Bayasi and Soroushian, 1988-1989; Popovics, 1983; Sturrup et al., 1983; Ravina 1984; PCA, 1979). 


\subsection{Silica Fume}

It is the finely divided residue resulting from the production of silicon or silicon containing alloys that are carried from the furnace by exhaust gases. Silica fume is composed of round spherical shape particles with diameters going from about $0.1 \mu \mathrm{m}$ and up to 1 or $2 \mu \mathrm{m}$. The mean diameter of silica fume is 100 times smaller than the mean diameter of cement (Aitcin, P.C., 2001).

Many researchers are using this silica fume in concrete as a partial replacement of cement not only for improving the quality of concrete but also for consuming this industrial waste material which is harmful to human health (ACI Committee 234). The use of less than $10 \%$ of silica fume in concrete has a fludifying effect on very low $w / \mathrm{cm}$ mixtures. The use of silica fume can sharply reduce viscosity given the morphology of silica fume particles (ball-bearing effect). Silica fume particles displace some of the water present among the flocculated cement grains, thus increasing the amount of water available to fluidify concrete (Aitcin, P.C., 2001).

It is used in concrete mainly for ferrosilicon replacement of cement improving the quality of concrete. The silica fume used in the experiment was a product of 'GRACE Construction 'under the trade name of 'Force 10,000D' densified microsilica.

The concentration of amorphous $\mathrm{SiO}_{2}$ is very high in silica fume. Silica fume is characterized by its extremely fine spherical particles of about 0.1 micron. The higher the silicon dioxide content in silica fumes, the more reactive it will be in concrete. Since the color of silica fume is dark, concrete containing silica fume is grey dark in color compared to normal concrete. By increasing the amount of silica fume, water demand increases to a very large extent. The reason is that the small particles of 
silica fume have large surface areas which absorb large amounts of water. Mixes containing above $10 \%$ silica fume (by mass) replacement of cement are sticky, cohesive and hard to handle. (Bayast et al., 1990; Huang, 1990; ACI Committee 234, Journal, 2000). It meets the requirements of ASTM C 1240 standards. The general physical and chemical properties of silica fume are given in Table 3.6.

Properties of Fresh Silica Fume Concrete: Because of its fineness, the silica fume particles can fill the voids between the larger cement particles resulting dense microstructures and good bond between the hydrated cement paste and aggregates. With this enhanced microstructure of the interstitial transition zone, silica fume increases the compressive strength of concrete, especially between 7 and 28 days. Moreover, as silica fume reduces the porosity of cement paste at its interface with aggregate, the concrete permeability is greatly reduced (Aitcin, P.C., 2001).

Silica fume damages the workability of fresh concrete. The reason is that the small particles of silica fume have large surface areas which absorb large amounts of water. This problem is solved by using water reducing agents or superplasticizers rather than using high water-cement ratio because the latter will have negative effects on concrete. By increasing the amount of silica fume, water demand increases to a very large extent. Mixes containing above $10 \%$ silica fume replacement of cement (on a mass basis) are sticky, cohesive and hard to handle (Bayast et al., 1990; Huang, 1990; ACI Committee 234 Journal, 2000).

Silica fume reduces concrete bleeding by its high affinity for water. As a result, plastic shrinkage cracks may occur when water evaporation rate from fresh concrete surface exceeds the rate at which water rises to the surface by capillary 
pressure. Thus, curing becomes significantly important especially at early ages (Bayast et al., 1990; ACI Committee 234 Journal, 2000)

Table 3.6 Physical and Chemical Properties of Silica Fume (Huang, 1990)

[A]: Physical Properties:

Particle Size:

0.1 to $0.2 \mu \mathrm{m}[4 \times 10-5$ to $8 \times 10-5$ in. $]$

Bulk Density:

200 to $300 \mathrm{~kg} / \mathrm{m}^{3}$ [14 to $19 \mathrm{lb} / \mathrm{ft}^{3}$ ]

Specific Gravity:

2.2 to 2.3

Color:

Light to dark gray

[B]: Chemical Properties:

\begin{tabular}{|l|l|}
\hline Chemical Constituent & Percent of Total Weight \\
\hline $\mathrm{S}_{\mathrm{i}} \mathrm{O}_{2}$ & $90-98$ \\
\hline $\mathrm{Al}_{2} \mathrm{O}_{3}$ & $0.5-3.0$ \\
\hline $\mathrm{Fe}_{2} \mathrm{O}_{3}$ & $0.15-0.8$ \\
\hline $\mathrm{M}_{\mathrm{g}} \mathrm{O}$ & $0.2-1.5$ \\
\hline $\mathrm{C}_{\mathrm{a}} \mathrm{O}$ & $0.1-0.5$ \\
\hline $\mathrm{Na}_{2} \mathrm{O}$ & $0.2-0.7$ \\
\hline $\mathrm{K}_{2} \mathrm{O}$ & $0.4-1.0$ \\
\hline $\mathrm{C}$ & $0.5-1.4$ \\
\hline
\end{tabular}

\subsection{Superplasticizer}

Superplasticizing admixtures are often added to cement paste to gain greater fluidity at lower water-cement ratios. The most important property of superplasticizer is its ability to disperse cement particles. In addition to enhancing the flow properties of cement pastes, superplasticizers retard the hydration reaction (Mindess and Young, 1981). 
SP is developed to enable the reliable production of SCC, primarily in precast/prestress environments. It produces a concrete with excellent segregation resistance, filling ability and passing ability. It meets the requirements of ASTM C 494 Type $\mathrm{F}$ high range water reducing admixture. Additionally, SCC made with ADVA Cast 555 SP exhibits low-water sensitivity normally encountered in concrete production.

SP used in the experiment was Polycarboxylate based under the trade name of ADVA Cast 555. The most important admixtures are the superplasticizers (high range water reducers), used with water reduction greater than $20 \%$. Other types may be incorporated as necessary, such as Viscosity Modifying Admixtures (VMA) gives more possibilities of controlling segregation providing very good homogeneity (typically 2-10 oz/cft); air entraining admixtures (AEA) to improve freeze-thaw resistance, retarders for control of setting, etc. ( Beitzel; Zhu et al., 2000). 


\section{CHAPTER 4}

\section{EXPERIMENTAL PROGRAM}

\subsection{Introduction}

Independent variables were chosen in such a way that the sum of binders i.e. Portland cement, fly ash and silica fume is 100 percent. The ratio of fine and coarse aggregates as well as the water binder ratio were established as same as that of precast SCC plant, Coreslab, Miami. Water binder ratio was chosen as 0.39 (lowest one). The amount of superplasticizer was selected as minimum as possible $14 \mathrm{oz} / \mathrm{cft}$ of concrete (1 $\mathrm{kg} / \mathrm{m}^{3}$ ) by doing several trials with different mixes to determine the flowability of SCC.

The experimental program was started first by performing spread test of the fresh concrete. The test included a base plate and slump cone (called spread test) that conforms to ASTM C-1611 standard test. The target slum flow was established between 24 in to 28 in $(600 \mathrm{~mm}$ to $700 \mathrm{~mm})$.

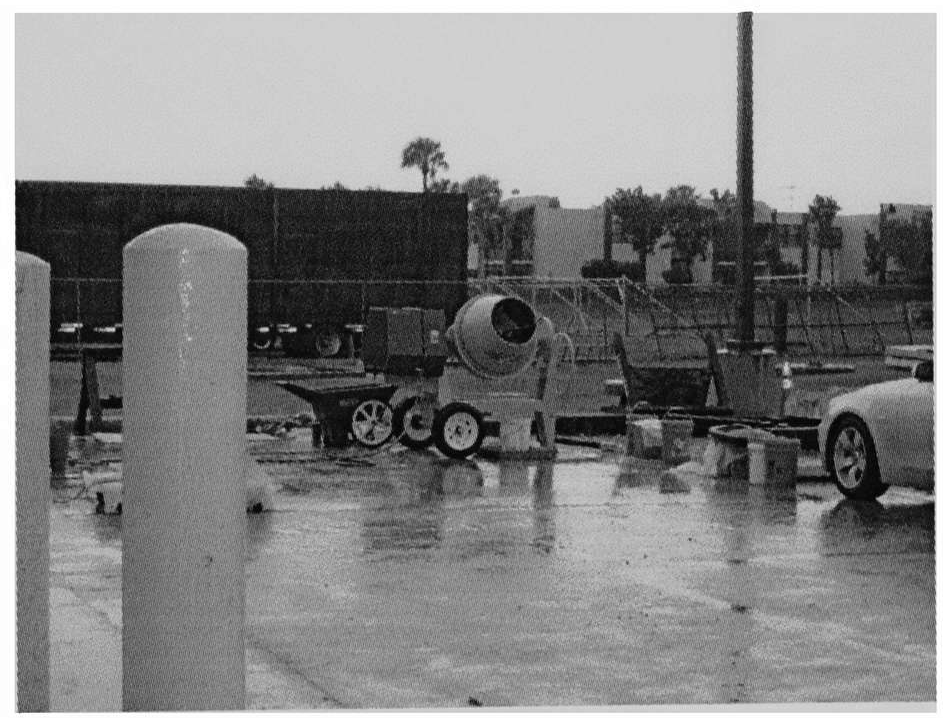

Figure 4.1 Concrete Mixer 


\subsection{Mix Design}

SCC mixes must meet three key properties: (1) ability to flow into and completely fill intricate and complex forms under its own weights, (2) ability to pass through and bond to congested reinforcement under its own weight, and (3) high resistance to segregation.

At present time, there is no research approach available that can be used to design SCC with optimum pozzolanic materials. There are no specific mix designs that indicate the best performance in its mechanical properties. Without optimizing the new fillers (i.e. pozzolanic materials) with the locally available aggregates, most economical SCC can't be produced. Therefore, mix designs were developed using six different combinations of fly ash and silica fume to enhance the mechanical properties of concrete and to determine if they were indeed viable with the better strength and durability of concrete. For reference, mix design of SCC with cement, aggregate and water was taken from the Miami based SCC precast plant.

Table 4.1 Mix Design of SCC

\begin{tabular}{|l|l|l|}
\hline Ingredient & Mix $\left(\mathrm{lb} / \mathrm{yd}^{3}\right)$ & Mix $\left(\mathrm{kg} / \mathrm{m}^{3}\right)$ \\
\hline Cement & 775 & 450 \\
\hline Rock & 1358 & 806 \\
\hline Sand & 1440 & 855 \\
\hline Water & 307 & 182 \\
\hline
\end{tabular}


Table 4.2 Trial Mix of Fly Ash, Silica Fume and Ordinary Portland cement

\begin{tabular}{|l|l|l|l|l|l|l|}
\hline & SCC 1 & SCC 2 & SCC 3 & SCC 4 & SCC 5 & SCC 6 \\
\hline OPC (\%) & 100 & 90 & 80 & 70 & 87 & 97 \\
\hline FA (\%) & 0 & 10 & 20 & 30 & 10 & 0 \\
\hline SF (\%) & 0 & 0 & 0 & 0 & 3 & 3 \\
\hline Total Filler (\%) & 100 & 100 & 100 & 100 & 100 & 100 \\
\hline
\end{tabular}

\subsection{Mixing Procedure}

All the mixtures were prepared in a 3 cubic feet capacity mixer. During the mixing time, the mixer should be covered to avoid moisture loss from the fresh concrete. The prepared samples are also protected against wind and sun until brought to a room temperature.

\subsubsection{Mixing (ASTM C-192)}

The mixing method as per ASTM C-192 utilized was as follows:

- The concrete mixture was dampened lightly with water.

- The coarse aggregate and one-third of the water was introduced in the mixer and rotated for about half a minute.

- The sand was then added followed by cement and pozzolanic materials and the concrete mixer was rotated for about four minutes.

- The remaining water was then added gradually. 
- The superplasticizer was then slowly introduced until a consistent mix could be observed.

- The mixing proceeded for about seven minutes from the introduction of coarse aggregate.

- The mixture was then stopped and allowed to keep in rest for about three minutes so as to allow a complete reaction of the mix with pozzolanic materials and superplasticizer.

- Total elapsed time for the mixing sequence was approximately ten minutes.

\subsubsection{Spread Test (ASTM C-143)}

The spread test consists of a base plate and slump cone that conforms to ASTM C-143 standard. Unlike the standard slump test, the fresh concrete is measured after the removal of the cone to characterize the flowability of the concrete. The diameter of the slump flow is the recorded average of orthogonal axis through the center of the slump flow. This measurement should be greater than 22 in. $(560 \mathrm{~mm})$ for the concrete to process good self-consolidation. The recommended slump flow of SCC ranges between 500 and $700 \mathrm{~mm}$ diameter i.e. 20 and 28 in. (Nagataki and Fujiwara, 1995). The target slump flow for the SCC was between 24 and $28 \mathrm{in.} \mathrm{(600} \mathrm{and} 700 \mathrm{~mm})$. 
Table 4.3 Results of the Slump Flow (Spread) Test

\begin{tabular}{|l|l|l|}
\hline Mix Number & $\begin{array}{l}\text { Slump } \\
\text { in.(mm) }\end{array}$ & $\begin{array}{l}\text { Slump Flow } \\
\text { Av. Spread value, in.(mm) }\end{array}$ \\
\hline SCC 1 & - & $25.5(648)$ \\
\hline SCC 2 & - & $27.0(686)$ \\
\hline SCC 3 & - & $26.0(660)$ \\
\hline SCC 4 & - & $26.5(673)$ \\
\hline SCC 5 & - & $25.0(635)$ \\
\hline SCC 6 & - & $25.5(648)$ \\
\hline
\end{tabular}

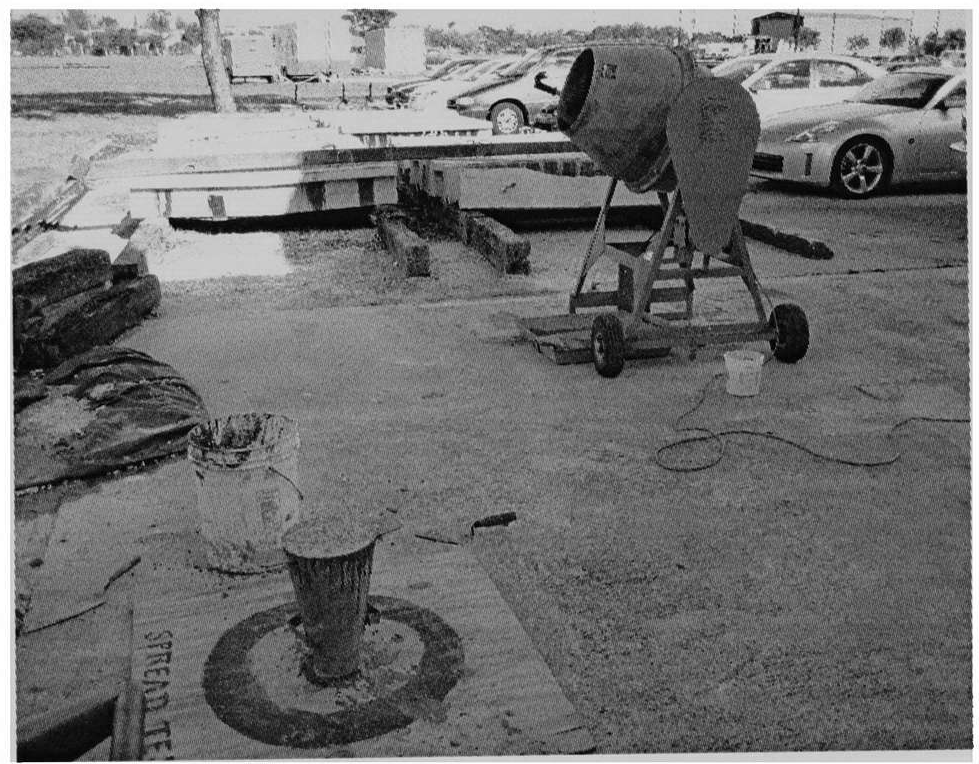

Figure 4.2 Typical Slump Flow for Spread Test 


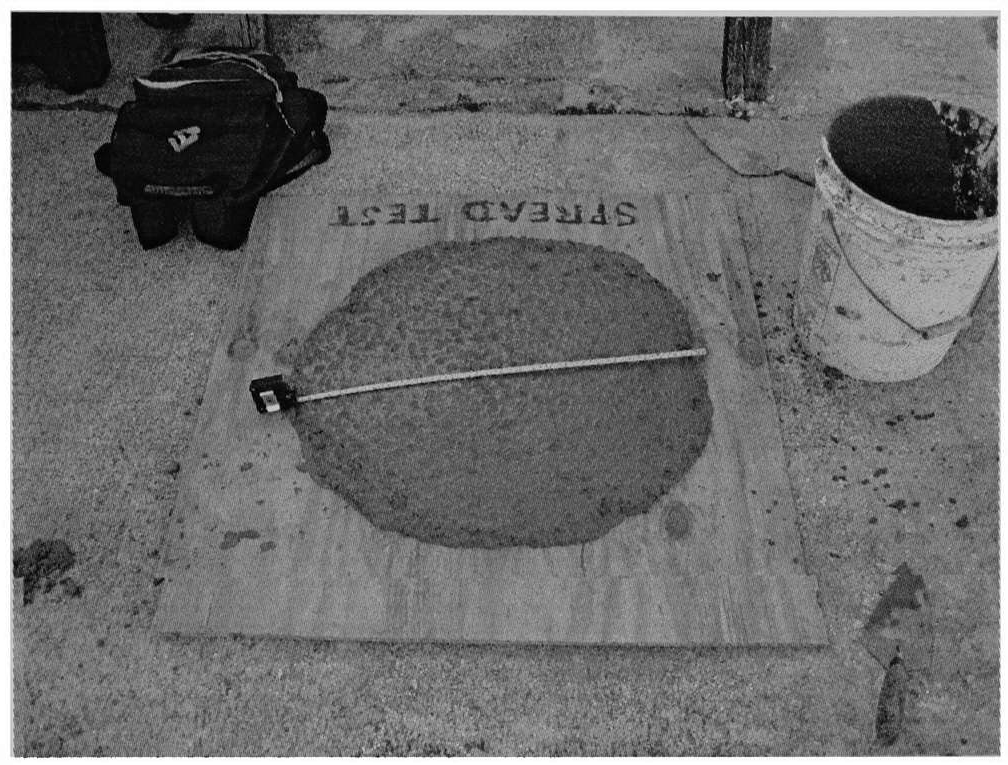

Figure 4.3 Spread Test According to ASTM C-1611

\subsubsection{Curing Methods}

After 18 to 24 hours of time, the freshly mixed and prepared concrete samples were de-molded and kept in a water tank of laboratory normal temperature as shown Figure 4.4. Two types of curing were performed. The cylindrical SCC samples 4 in $\times 8$ in $(100 \mathrm{~mm} \times 200 \mathrm{~mm})$ and $6 \mathrm{in} \times 12$ in $(150 \mathrm{~mm} \times 300 \mathrm{~mm})$ were kept in water for 7 days and 28 days to determine the compressive strength, splitting tensile strength and modulus of elasticity. The others were SCC prisms of size 4 in $\times 4$ in $\times 11.2$ in $(100 \mathrm{~mm} \times 100 \mathrm{~mm} \times 285$ $\mathrm{mm}$ ) cured under water for seven days and then left in air forever. These samples were prepared for the drying shrinkage test. To provide normal and uniform humidity and temperature, the samples were cured inside the laboratory. 


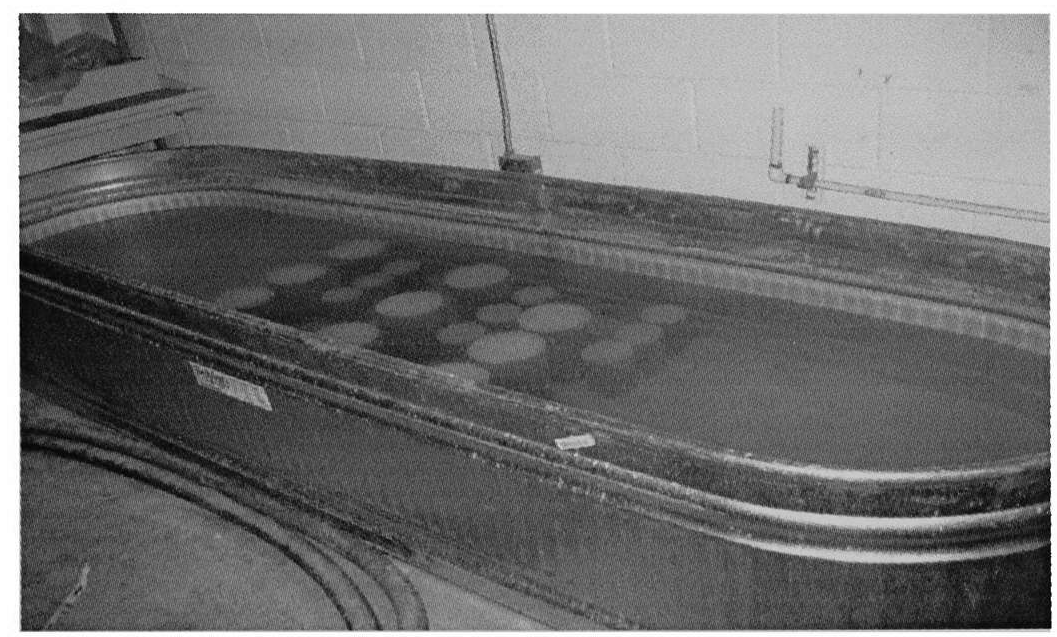

Figure 4.4 SCC Samples Curing in Water

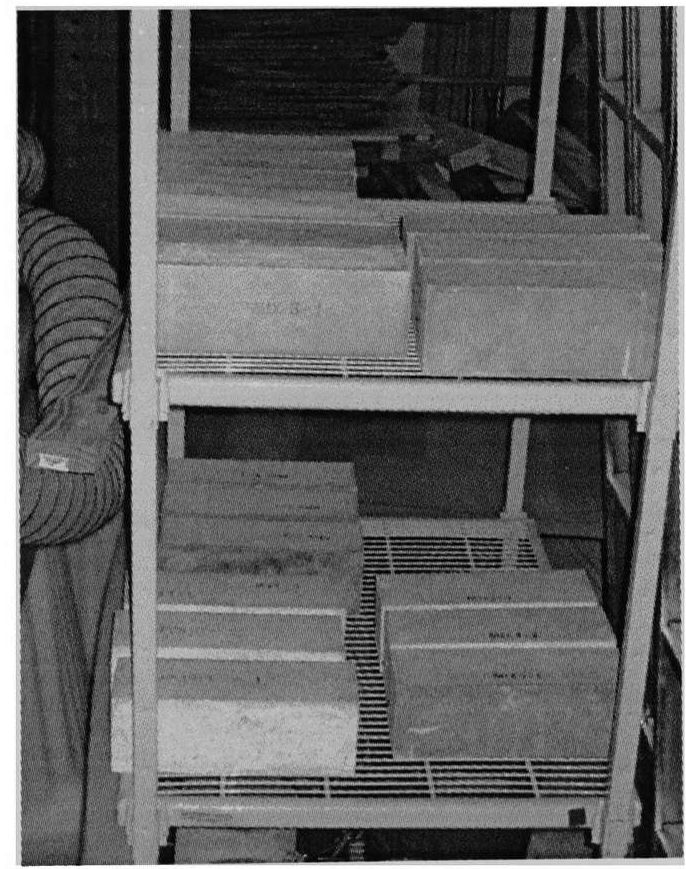

Figure 4.5 Samples for Drying Shrinkage Test 


\subsection{Compressive Strength Test}

Hardened concrete was measured in terms of its performance by means of compressive strength at ages of 7 and 28 days. The 28 day design compressive strength was established as $8000 \mathrm{psi}$ (55 MPa). The average compressive strengths were obtained from three 4 in $\times 8$ in $(100 \mathrm{~mm} \times 200 \mathrm{~mm})$ cylinders for each batch at each age. The tests were performed in accordance with the ASTM C39 standards.

Self-compacting concrete with a similar water cement or cement binder ratio will usually have a slightly higher strength compared with traditional vibrated concrete, due to the lack of vibration giving an improved interface between the aggregate and hardened paste. The strength development will be similar so maturity testing will be an effective way to control the strength development whether accelerated heating is used or not (European Guidelines for SCC, 2005).

After 28 days compressive strength of SCC and normal vibrated concrete of similar composition does not differ significantly in the majority of the published test results. Some of the published test results show that an increase of the cement content and a reduction of filler content at the same time increase the initial concrete strength and the ultimate concrete strength. Especially if limestone powder is used higher compressive strength are noticeable at the beginning of the hardening process (Holschemacher and Klug, 2002). 


\subsection{Splitting Tensile Test}

The tests were performed by loading the standard 6 in $\times 12$ in $(150 \mathrm{~mm} \times 300 \mathrm{~mm})$ cylinder by a line load perpendicular to its longitudinal axis with the cylinder placed horizontally on the testing machine platen in accordance with ASTM C 496 standards for all mixes. The tensile splitting strength can be defined as:

$\mathrm{f}^{\prime}{ }_{\mathrm{t}}=2 \mathrm{P} / \pi \mathrm{DL}$

Where, $\mathrm{P}=$ total value of the line load registered by the testing machine

$\mathrm{D}=$ diameter of the concrete cylinder

$\mathrm{L}=$ cylinder height

The results of all these tests give the designer a measure of the expected strength of the designed concrete in the built structure.

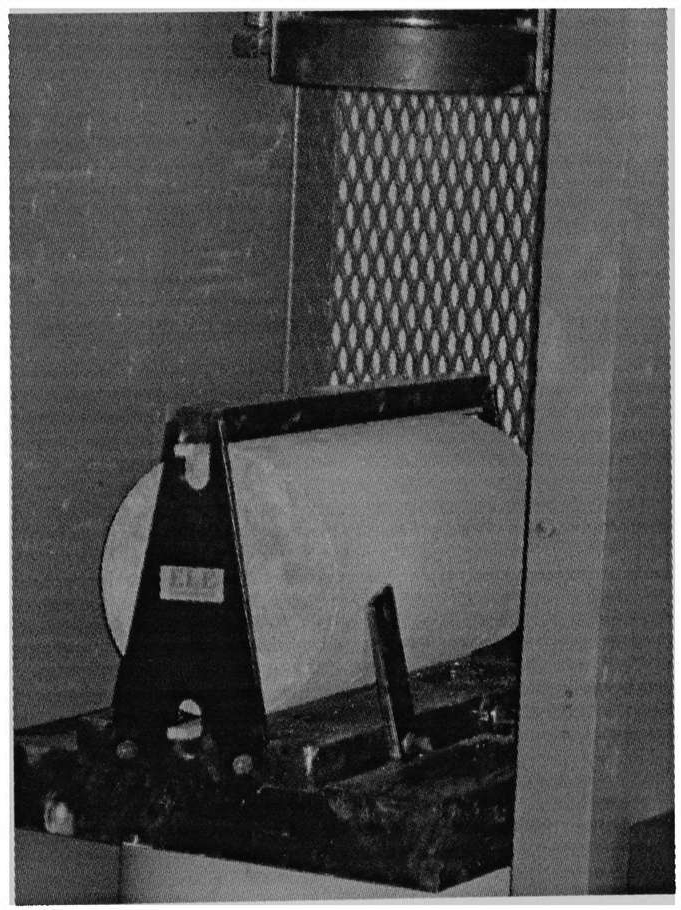

Figure 4.6 Splitting Tensile Test Set Up 


\subsection{Modulus of Elasticity Test}

The elastic modulus tests were evaluated in accordance with the ASTM C469 standard. The modulus of elasticity is used in the elastic calculation of deflection, often the controlling parameter in slab design, and of pre or post tensioned elements. However, increasing the paste volume could decrease the modulus of elasticity. Because SCC often has higher paste content than traditional vibrated concrete, some differences can be expected and the modulus of elasticity may be somewhat lower but this should be adequately covered by the safe assumptions on which the formulae provided in standard code are based.

If SCC does have a slightly lower elastic modulus than traditional vibrated concrete, this will affect the relationship between the compressive strength and the camber due to prestressing or post-tensioning. For this reason, careful control should be exercised over the strength at the time when the prestressing and post-tensioning strands or wires are released (The European Guidelines for SCC, 2005).

Since the stress- strain curve is curvilinear at a very early stage of its loading history. Young's modulus of elasticity can be applied only to the tangent of the curve at the origin. The slope of the straight line that connects the origin to a given stress (about $0.4 \mathrm{f}_{\mathrm{c}}$ ) determines the secant modulus of elasticity of concrete. This value, termed in design calculation the modulus of elasticity, satisfies the practical assumption that strains occurring during loading can be considered basically elastic (recoverable on unloading) and that any subsequent strain due to the load is regarded as creep. 


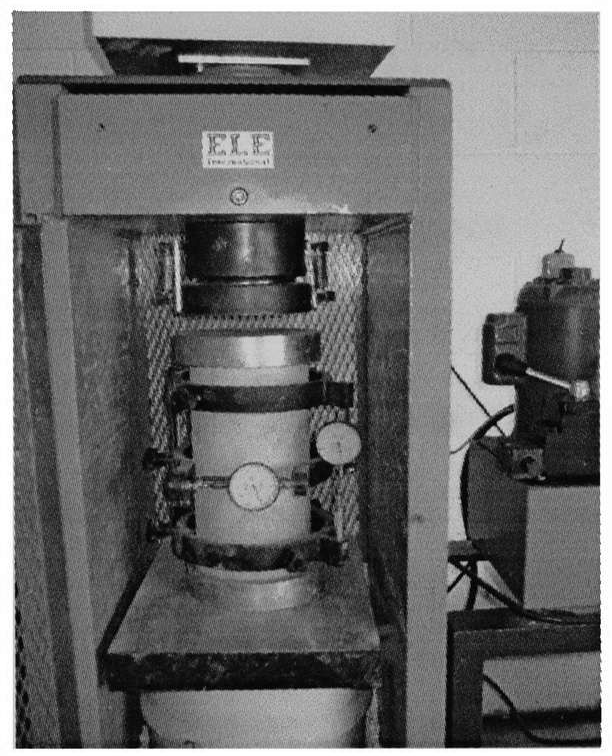

Figure 4.7 Strain Gauge for Modulus of Elasticity Test Set Up

The ACI code gives the following expressions for calculating the secant modulus of elasticity of concrete $\left(E_{c}\right)$ for $\mathrm{f}_{c}$ upto $6000 \mathrm{psi}$ ( $40 \mathrm{MPa}$ )

$\mathrm{E}_{\mathrm{c}}(\mathrm{psi}) \quad=33 \mathrm{w}_{\mathrm{c}}{ }^{1.5} \sqrt{\mathrm{f}}_{\mathrm{c}}$ for $90 \mathrm{lb} / \mathrm{ft}^{3}\left(1440 \mathrm{~kg} / \mathrm{m}^{3}\right)<\mathrm{w}_{\mathrm{c}}<155 \mathrm{lb} / \mathrm{ft}^{3}\left(2480 \mathrm{~kg} / \mathrm{m}^{3}\right)$

$\mathrm{E}_{\mathrm{c}}(\mathrm{MPa})=0.0143 \mathrm{w}_{\mathrm{c}} 1.5 \sqrt{ } \mathrm{f}^{\prime}{ }_{\mathrm{c}}$

Where, $w_{c}$ is the density of concrete in pounds per cubic foot $\left(1 \mathrm{lb} / \mathrm{ft}^{3}=16.02\right.$ $\mathrm{kg} / \mathrm{m}^{3}$ ) and $\mathrm{f}_{\mathrm{c}}$ is the compressive cylinder strength in psi. For normal weight concrete, $E_{c}=57000 \sqrt{ } f_{c}$ psi or $E_{c}=4730 \sqrt{ } f_{c} N / m^{2}$

For concrete compressive strength $\mathrm{f}^{\prime}{ }^{\mathrm{c}}=6000$ to $12000 \mathrm{psi}(40$ to $80 \mathrm{MPa})$

$\mathrm{E}_{\mathrm{c}}(\mathrm{psi})=\left(40,000 \sqrt{ } \mathrm{f}_{\mathrm{c}}{ }_{\mathrm{c}}+1.0 \times 10^{6}\right)\left(\mathrm{w}_{\mathrm{c}} / 145\right)^{1.5}$

$\mathrm{E}_{\mathrm{c}}(\mathrm{MPa})=\left(3.32 \sqrt{ } \mathrm{f}_{\mathrm{c}}{ }_{\mathrm{c}}+6895\right)\left(\mathrm{w}_{\mathrm{c}} / 2320\right)^{1.5} \quad(\mathrm{Nawy}, 2005)$

An attempt has been made to find a finer distinction between the compressive strength and modulus of elasticity in SCC. Several of the test results of Suksawang et.al, 2005 are graphically represented. In Figure 4.8, 4.10 and 4.12 compressive strength of 
SCC is uniformly increasing, whereas modulus of elasticity is dropped suddenly near the seventh day test. Although Figure 4.8 shows similar nature of compressive strength and modulus elasticity in SCC, Figure 4.9, 4.11, 4.12 and 4.13 state that after about two months of maturity in concrete, the uniform nature of compressive strength and modulus of elasticity is suddenly changed. From this phenomenon, we can clearly say that the increase in compressive strength in concrete not necessarily means the increase in modulus of elasticity.

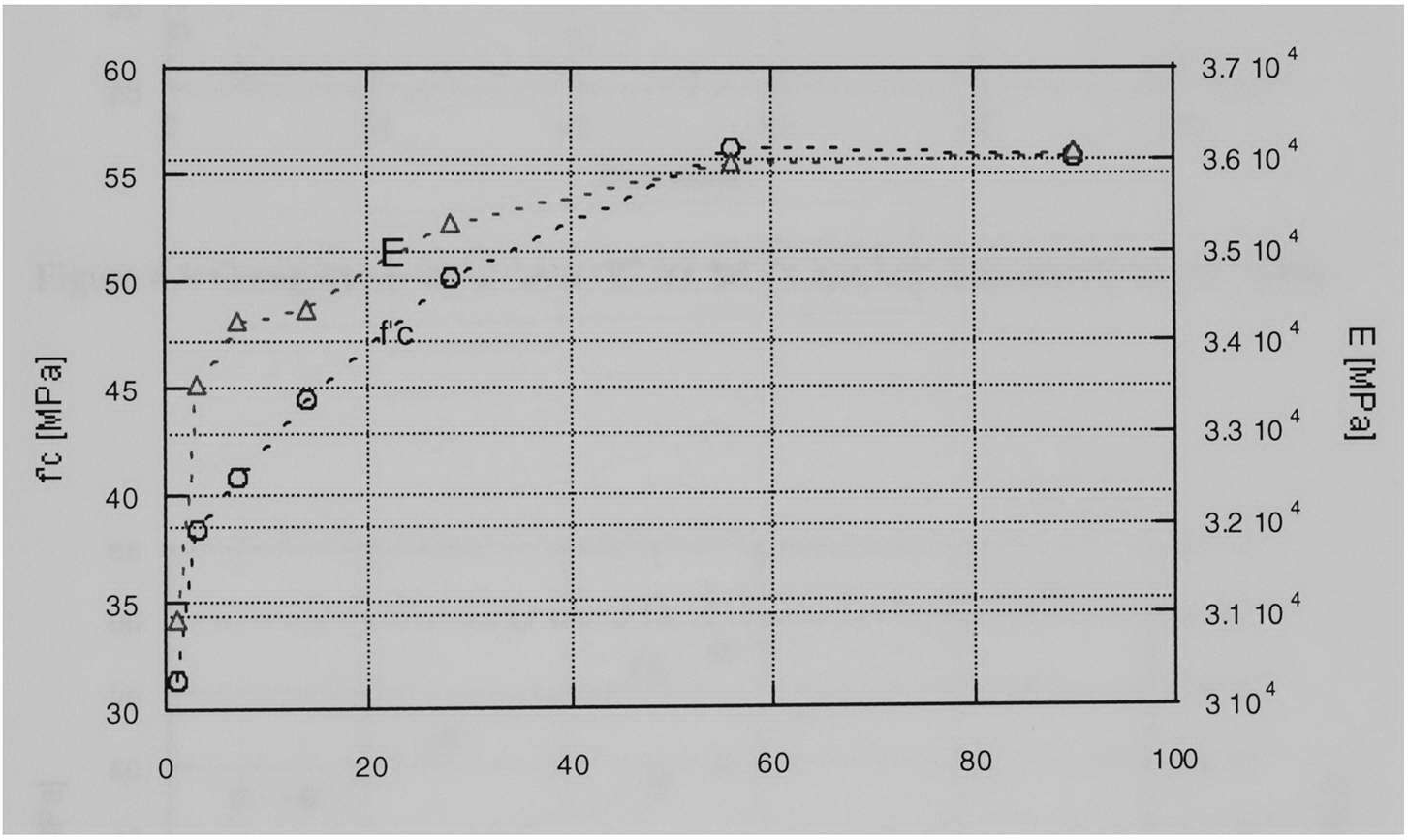

Figure 4.8 Comparison of $\mathrm{f}_{\mathrm{c}}$ and $\mathrm{E}$ for $\mathrm{NC}$ mix (N. Suksawang et. al., 2006) 


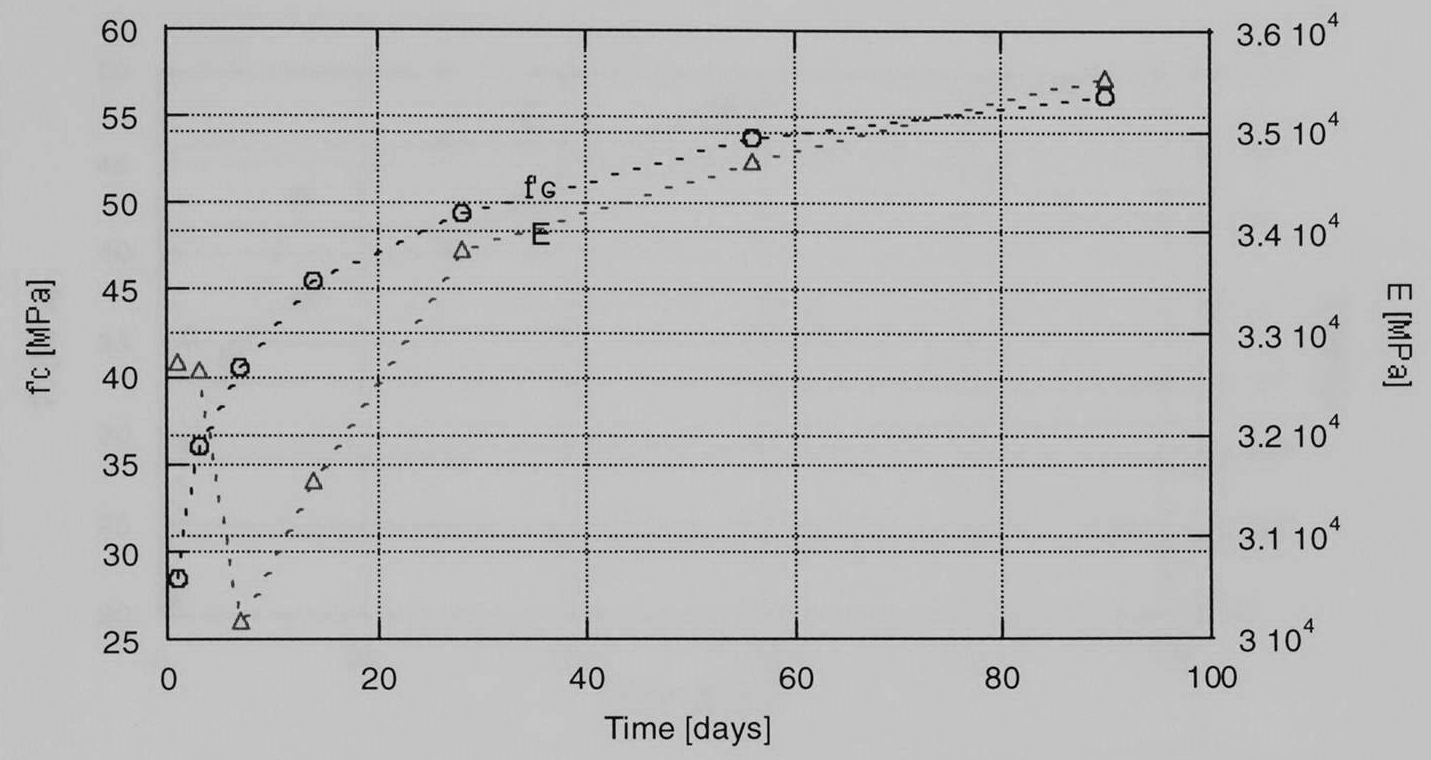

Figure 4.9 Comparison of ' $\mathrm{f}_{\mathrm{c}}$ ' and ' $\mathrm{E}$ ' for SCC1 mix (N. Suksawang et. al., 2006)

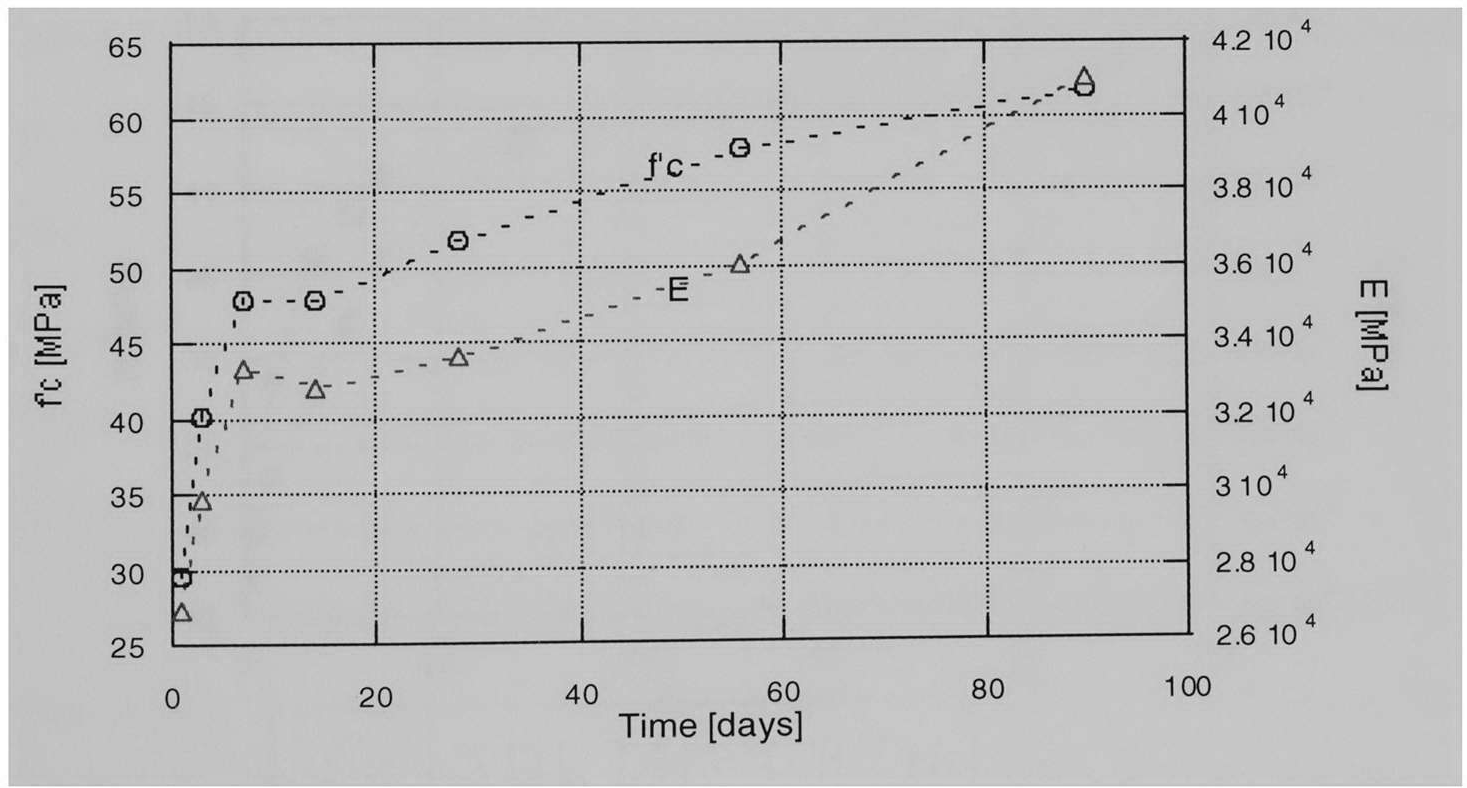

Figure 4.10 Graph for SCC 2 mix (N. Suksawang et. al., 2006) 


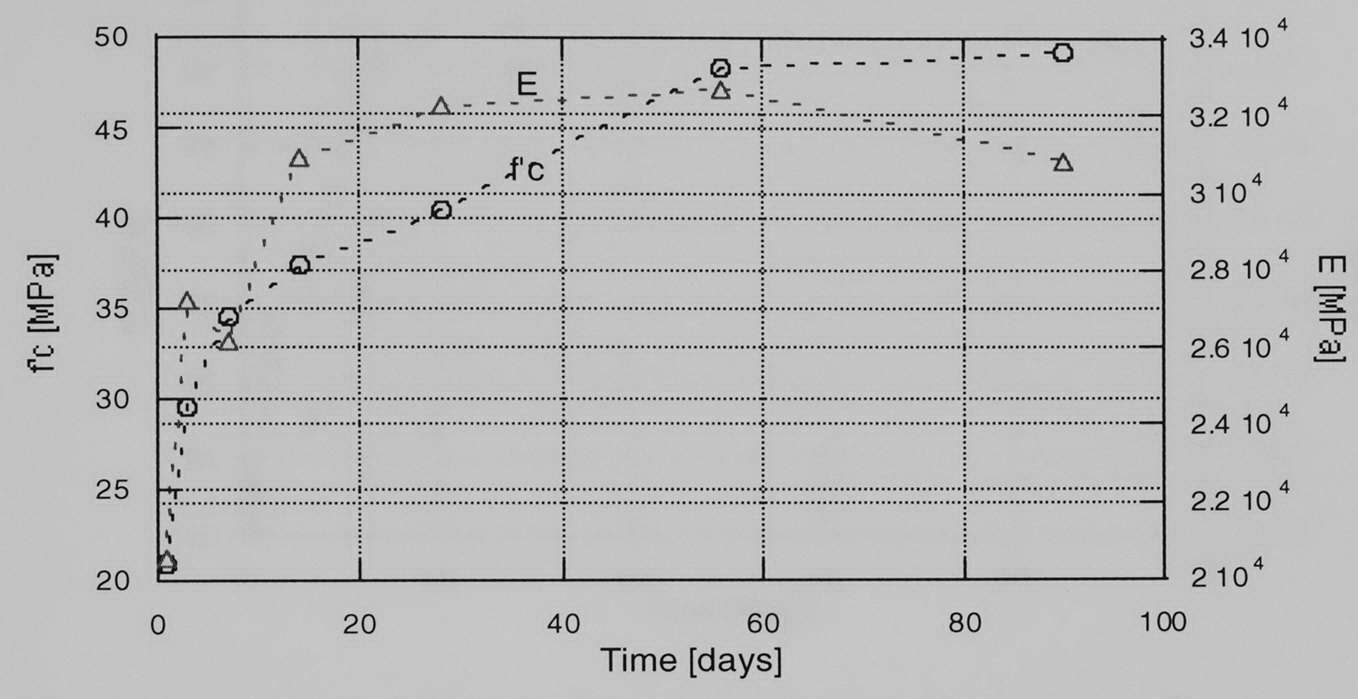

Figure 4.11 Comparison of ' $f_{c}$ ' and ' $E$ ' for SCC 3 mix (N. Suksawang et. al., 2006)

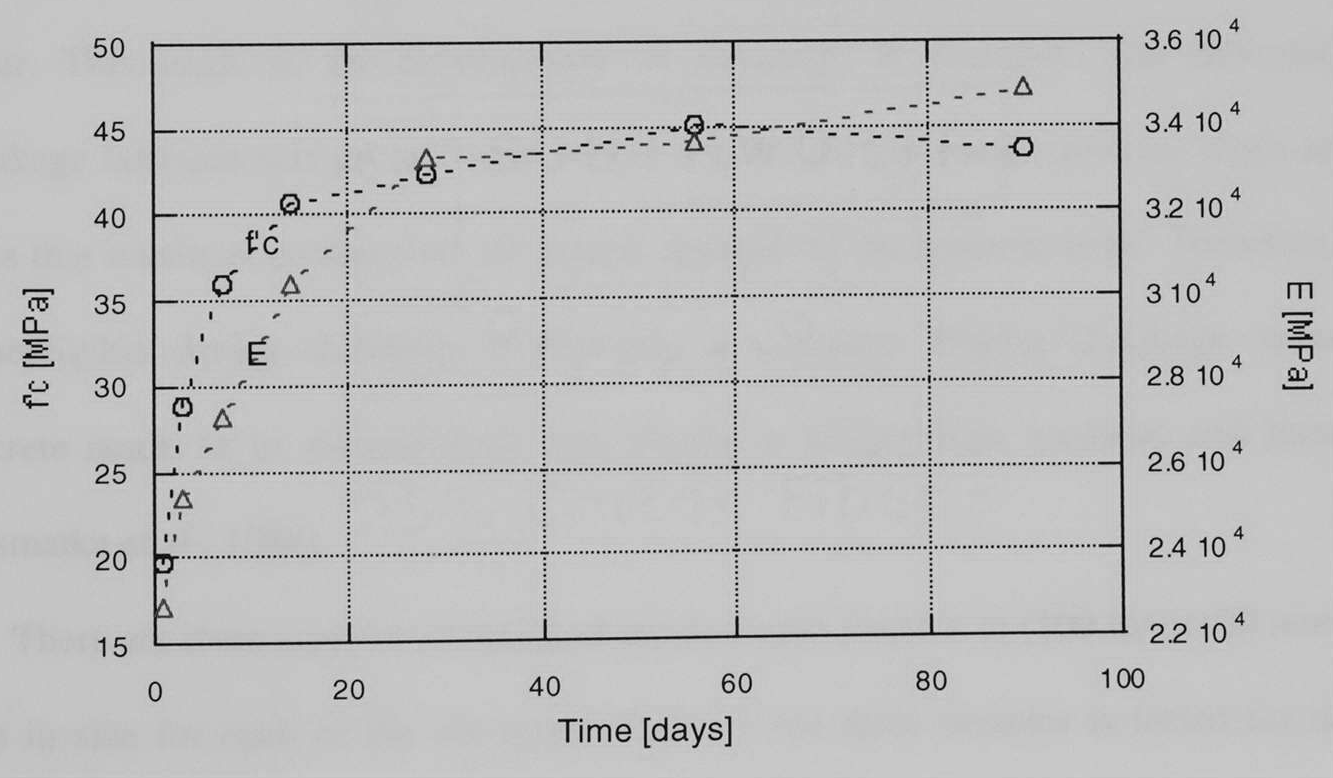

Figure 4.12 Comparison of ' $\mathrm{f}_{\mathrm{c}}$ ' and 'E' for SCC4 mix (N. Suksawang et. al., 2006) 


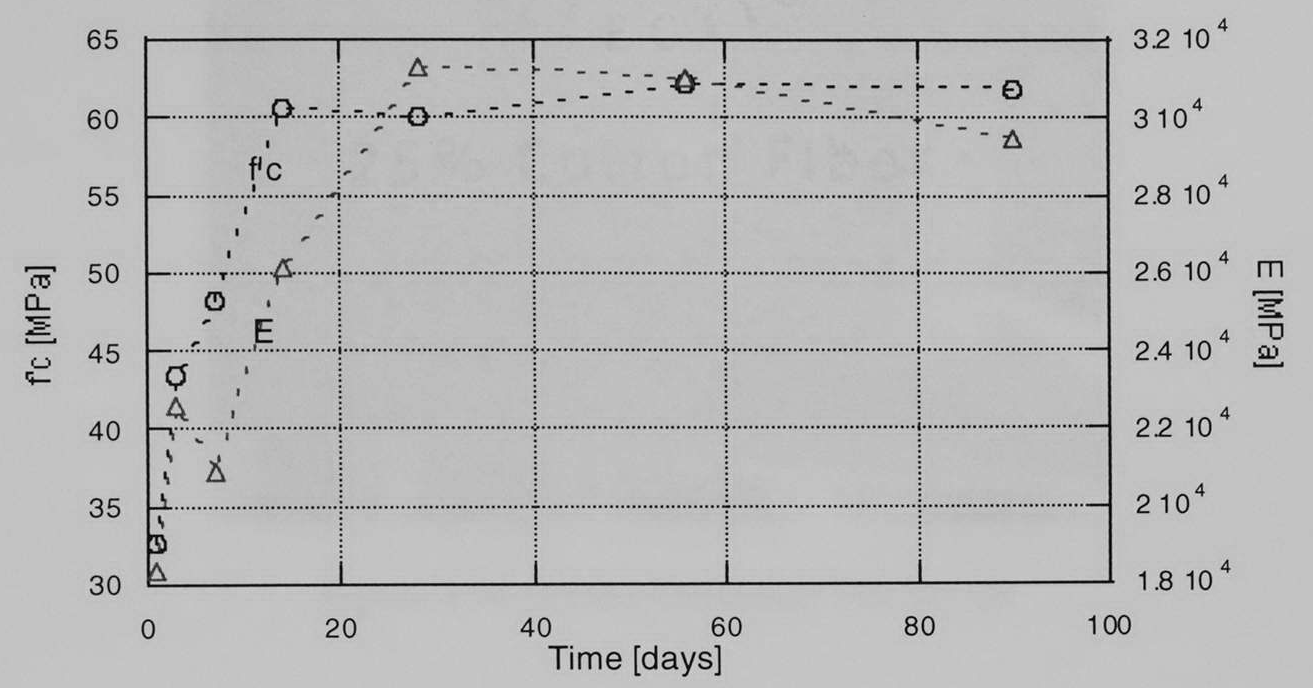

Figure 4.13 Graph for SCC 5 mix (N. Suksawang et. al., 2006

\subsection{Drying Shrinkage Test}

The surface of concrete loses moisture faster than that of the concrete near the center. This leads to the development of shrinkage in concrete. The difference of shrinkage between surface and near center in concrete can cause cracking when tensile stress that results is greater than the tensile strength of the concrete itself. Therefore, less or negligible drying shrinkage is expected in concrete. Drying shrinkage occurs as concrete reacts to its surroundings, specifically to temperature, moisture and humidity (Kosmatka et al., 1988).

There are three samples of standard prism 4 in $\times 4$ in $\times 11.2$ in $(100 \mathrm{~mm} \times 100 \mathrm{~mm} \times 285$ $\mathrm{mm}$ ) in size for each of the six mixes. Each of the three samples is tested for drying shrinkage for 7, 10, 14, 21 and 28 days and an average value is taken for each batch. 


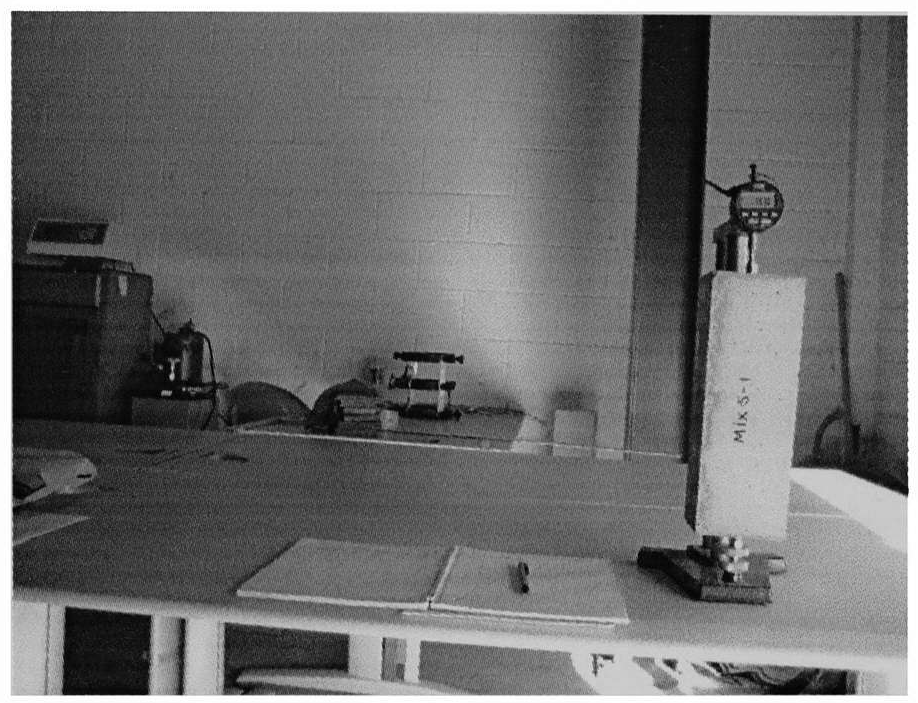

Figure 4.14 Drying Shrinkage Test Set up

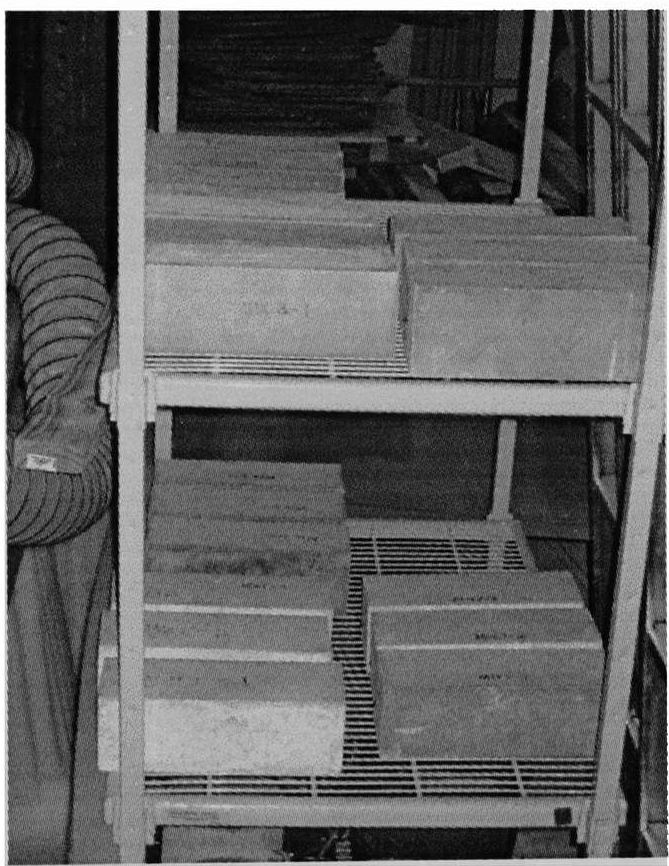

Figure 4.15 Samples for Drying Shrinkage Test

The samples were allowed to dry in a normal laboratory temperature and humidity. For uniform drying purpose, a special open air type of shelve was used as shown in Figure 4.15 . 


\section{CHAPTER 5}

\section{TEST RESULTS}

\subsection{Compressive Strength}

The compressive strength of hardened concrete was obtained in accordance with the ASTM C39 standards. The tests were performed at 7 and 28 days. The results are summarized in Table 5.1 (APPENDICES).

The test results show that the mix SCC 1 produced the highest 28 days compressive strength 8,547 psi (59 MPa) among the selected six mix models. However, mix SCC 6 has highest 7 days compressive strength $7,395 \mathrm{psi}(51 \mathrm{MPa})$. It indicates that the use of pozzolanic materials in SCC not necessarily increase the compressive strength in concrete; but a small amount ( 3 percent) of silica fume in ordinary cement has a best performance in attaining initial strength. For reference, the combination of pozzolanic materials i.e. new fillers has been provided in Table 4.2, page 29 .

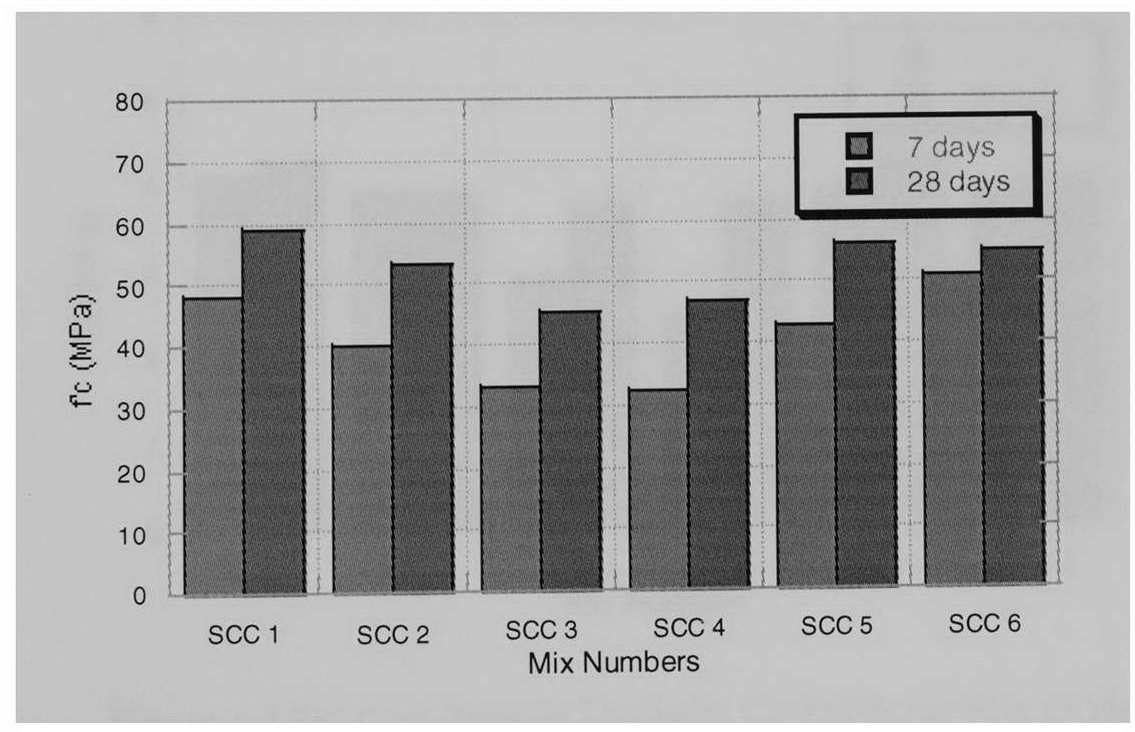

Figure 5.1 Compressive Strengths for Different Mix Models 


\subsection{Splitting Tensile Strength}

It was performed in accordance with ASTM C 496 standards for all mixes. The cylinders for experimentation were 6 in $\times 8$ in $(150 \mathrm{~mm} \times 300 \mathrm{~mm})$.Tests were conducted at 7 and 28 days with two cylinders for each test. The results are included in Table 5.2 (APPENDICES).

The best 28 day splitting tensile strength was obtained with the SCC 1 and SCC 5 mix producing same values as 620 to $630 \mathrm{psi}(4.3 \mathrm{MPa})$. It shows that only $100 \%$ OPC or $97 \%$ OPC with $3 \%$ SF are the best combinations of the mix. Also, these two mixes have almost the same splitting tensile strength with the 7 days and 28 days test results (with only about $5 \%$ difference). However, all the 28 days test results are slightly lower or higher than $4 \mathrm{MPa}$.

Diagram 5.3 and 5.4 shows the variation of strengths with the two testing sample. The variation has been shown in both strength and percentage difference of the strengths.

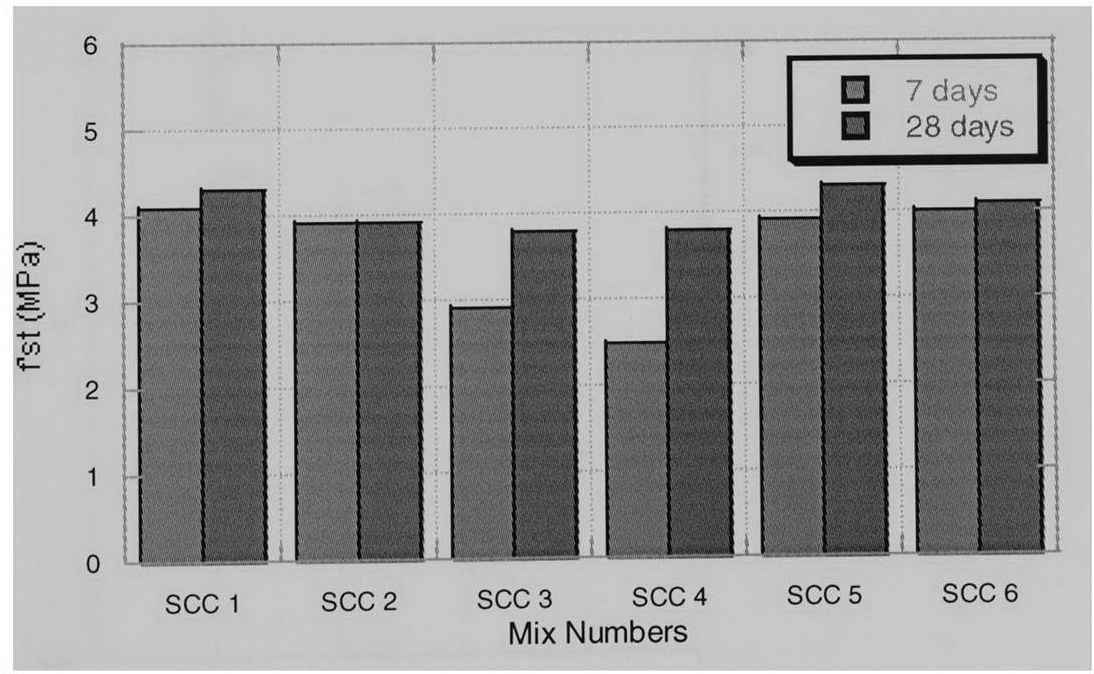

Figure 5.2 Splitting Tensile Strengths for Different Mix models 


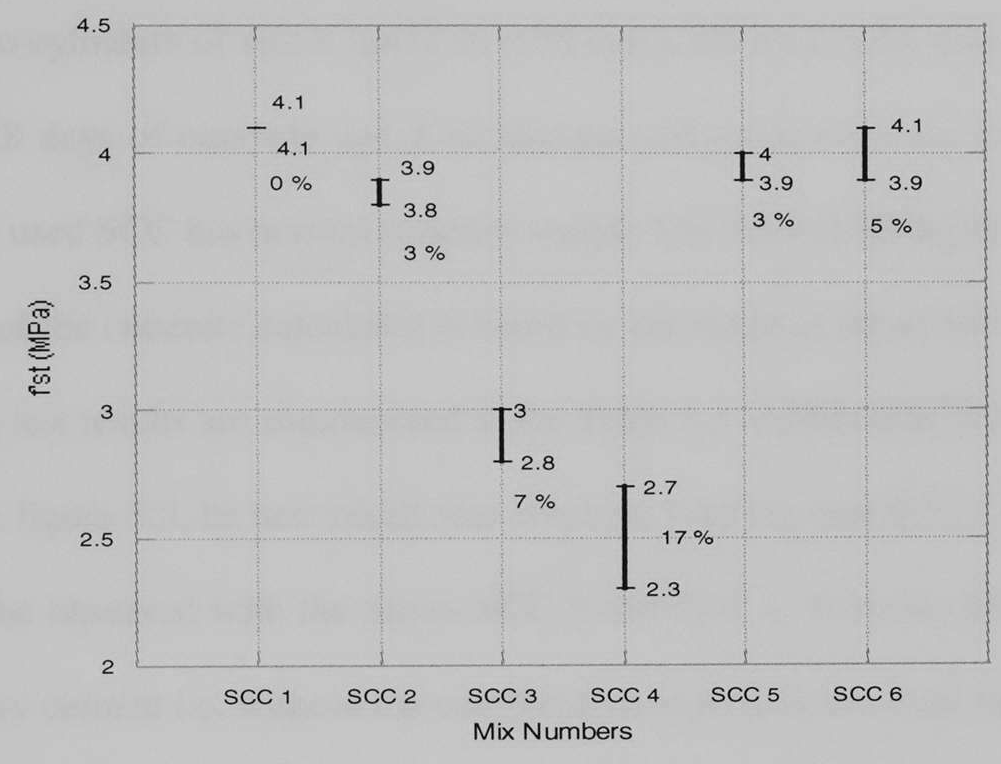

Figure 5.3 Seven day Tensile Test Results with Two Samples

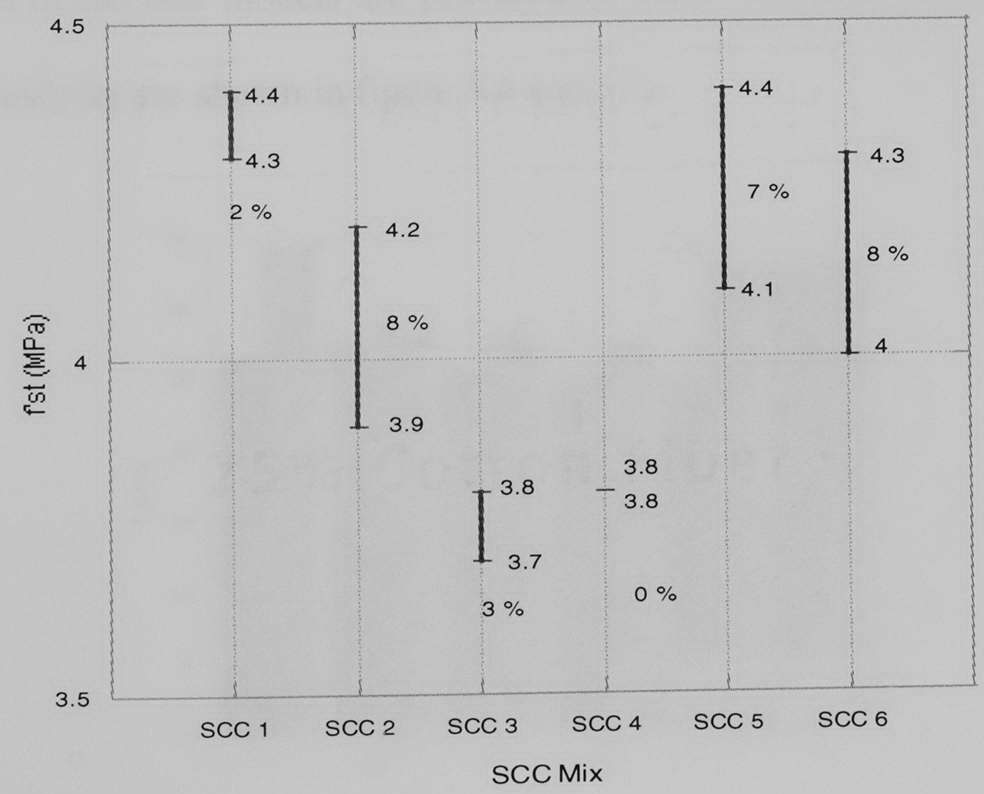

Figure 5.4 Twenty Eight day Tensile Test Results with Two Samples 


\subsection{Modulus of Elasticity}

The elastic modulus tests were conducted in accordance with the ASTM C 469 standard. Two cylinders of size 6 in $\times 12$ in $(150 \mathrm{~mm} \times 300 \mathrm{~mm})$ were used for each test at 7 days and 28 days of concrete age. Calculations and predictions are performed on the basis that the used SCC has normal concrete weight $150 \mathrm{lb} / \mathrm{cft}\left(2400 \mathrm{~kg} / \mathrm{m}^{3}\right)$. The modulus of Elasticity of the concrete calculated is based on the strain at about $40 \%$ of the ultimate strength. The test results are summarized in the Table 5.3 (APPENDICES).

In the figure 5.5, he best result was obtained with the mix SCC 1. Second highest result could be observed with the mixes SCC 5 and SCC 6 . It means SCC 1 which was $100 \%$ ordinary cement i.e. without the combination of pozzolanic materials, produced the highest modulus of elasticity $34.2 \mathrm{GPa}$. However, SCC 5 with $10 \%$ fly ash and 3\% silica fume could also give higher values as 32.7 and $32.9 \mathrm{MPa}$. Besides, SCC 6 with 3\% silica fume alone had highest 7 days modulus of elasticity. For reference, the compositions of fillers for each of the mix models are provided in Table 4.2, page 29. The variations of modulus of Elasticity are shown in figure 5.6 and 5.7.

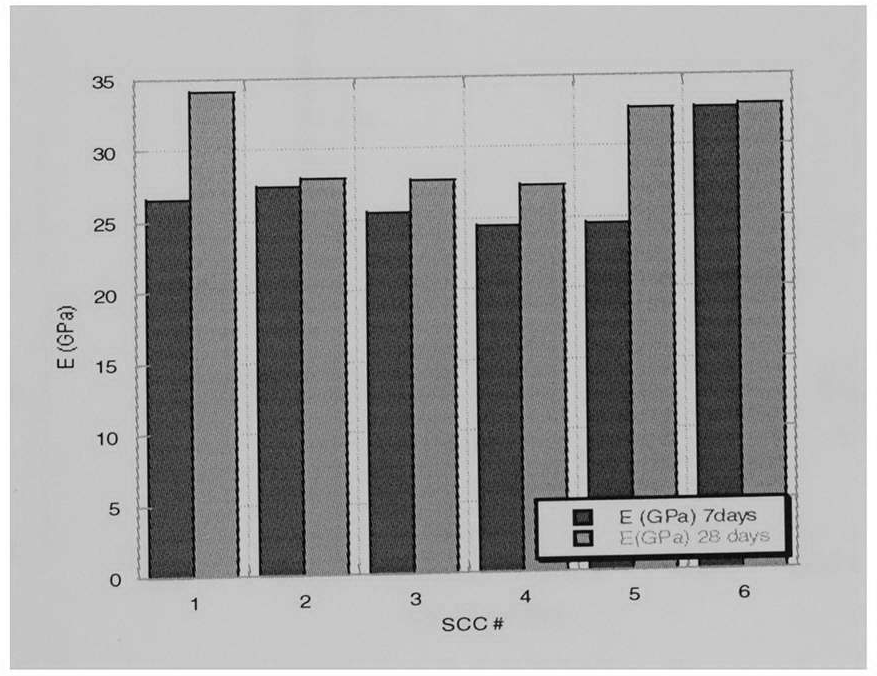

Figure 5.5 Modulus of Elasticity for Different Mix Models 


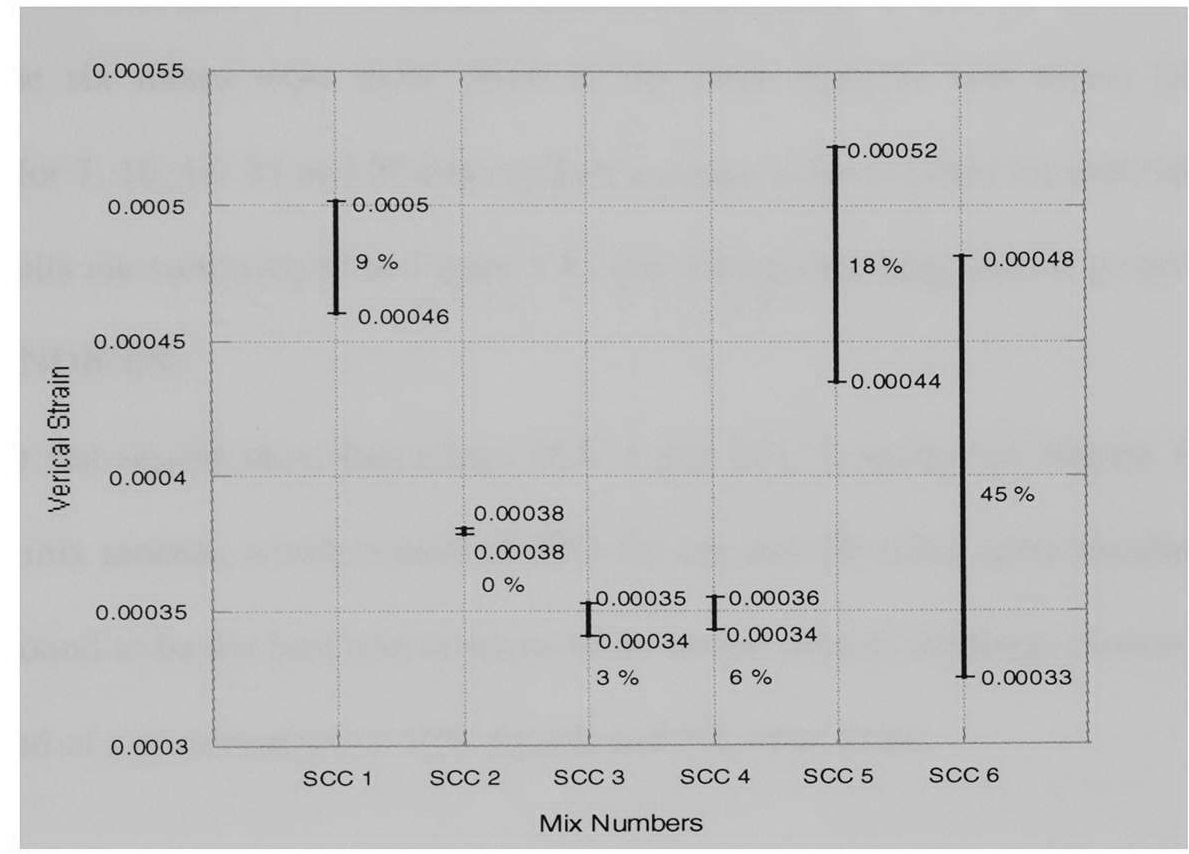

Figure 5.6 Seven days Test Results of Linear Strain for Modulus of Elasticity

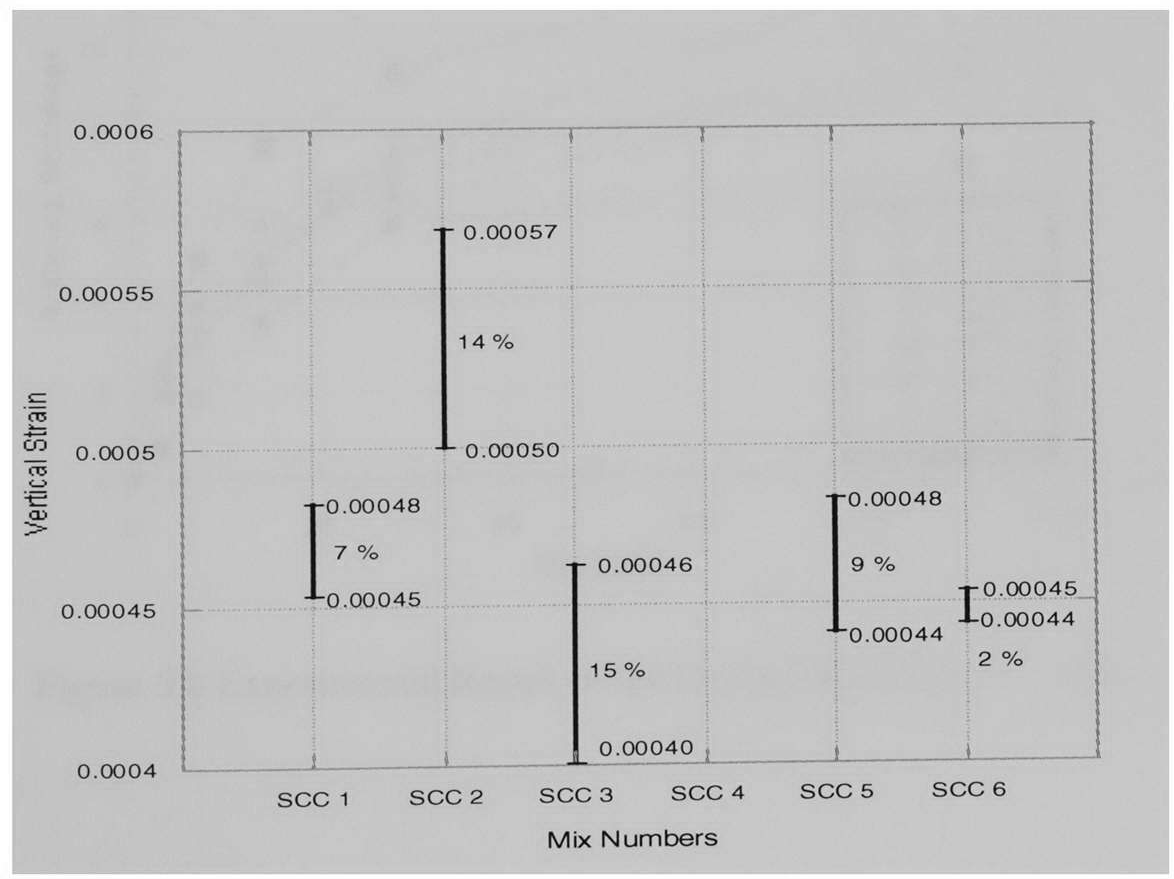

Figure 5.4 28 days Test Results of Linear Strain for Modulus of Elasticity 


\subsection{Drying Shrinkage}

Three samples of standard size 4 in $\times 4$ in $\times 11.2$ in $(100 \mathrm{~mm} \times 100 \mathrm{~mm} \times 285 \mathrm{~mm})$ for each of the six mixes were used. Each of the three samples was tested for drying shrinkage for $7,10,14,21$ and 28 days and an average value is taken for each batch. The testing results are summarized in Figure 5.4. The drying shrinkage data is given in Table 5.4 (APPENDICES).

The test results show that mixes SCC 4 and SCC 6 attains the highest shrinkage than other mix models, which consist of $30 \%$ fly ash and $3 \%$ silica fume simultaneously. SCC 5 is found to be the best mix in terms of its lowest drying shrinkage character which is composed of a combination of $10 \%$ fly ash and $3 \%$ silica fume.

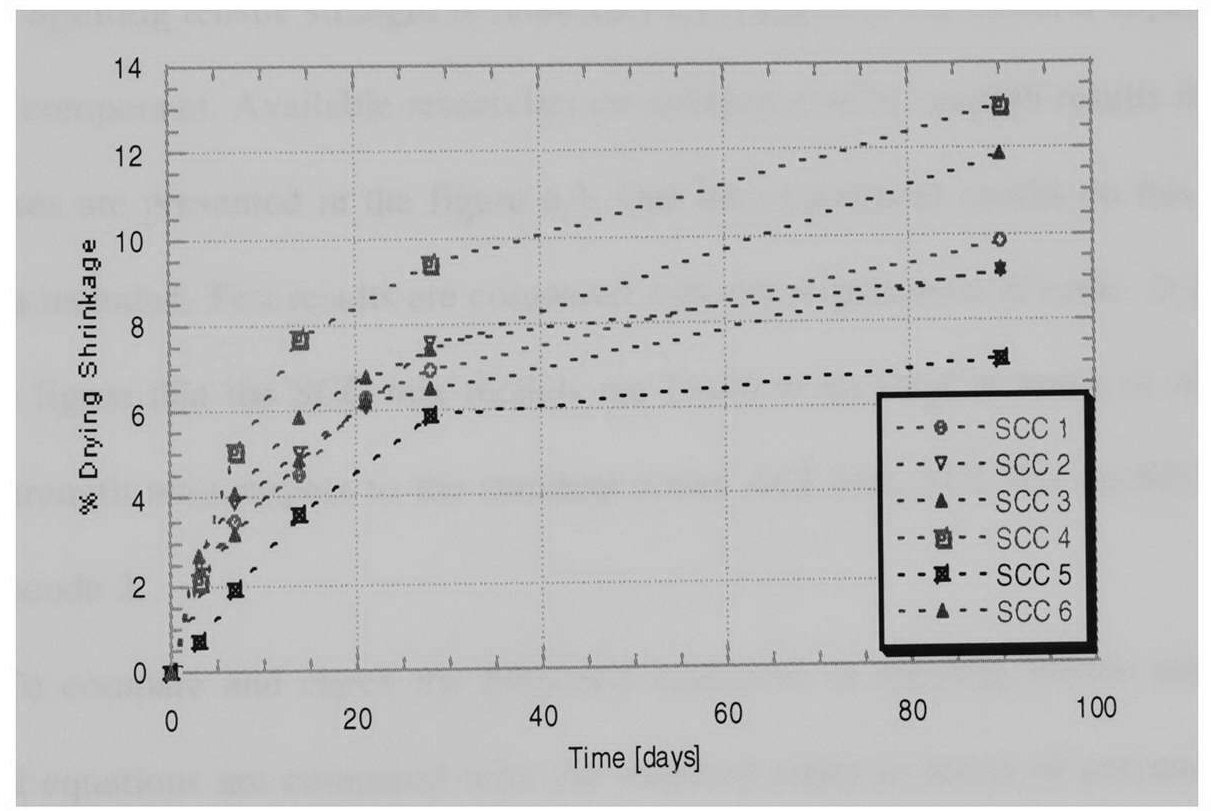

Figure 5.8 Experimental Result of the Drying Shrinkage vs. Time 


\section{CHAPTER 6}

\section{MODEL COMPARISONS}

A comprehensive study of ultimate loads from various mix designs was done for self-consolidating concrete. The summary of the experimental results are compared with the available research to investigate the suitability of materials, established statistical models and its mechanical properties.

\subsection{Splitting Tensile Strength}

Highest compressive strength not necessarily means the highest splitting tensile strength. Splitting tensile strength is important as it indicates the flexural capacity of the concrete component. Available researches on splitting tensile strength results for various SCC mixes are presented in the figure 6.1. Our lab experiment results on this test have also been included. Test results are compared with the requirement of code. It is obvious from the figure that the SCC mix models are found to be ideal in terms of its splitting tensile strength with respect to the standard codes ACI 318, ACI 363 AASHTO/LRFD and Eurocode 2.

To compare and check the proposed equations of splitting tensile strength, the proposed equations are compared with the standard codes in terms of percentage error. Percentage error is obtained by dividing the standard deviation (SD) by the mean value of the corresponding code. Where SD is mathematically expressed as: 
$\mathrm{SD}=\sqrt{\frac{\left(f s t-f_{s t} t_{\text {code }}\right)^{2}}{n-1}}$

Percentage error with respect to the given equation or code $=(\mathrm{SD} /$ mean $) \times 100$

Where $\mathrm{n}=$ degree of freedom

The increased number of data corresponds to higher degree of freedom, which tends to increase the accuracy of the result. We have a total of 102 data for splitting tensile strength. The aim of our study here is to propose a best equation in terms of least percentage error with respect to the given code or equation. Three codes as explained earlier and two linear best fit equations, regular and forced through were chosen for determining the best equation for the splitting tensile strength of SCC. Regular linear curve is based on slope and intercept of the equation, whereas the forced through zero curves passes through the origin without intercept value.

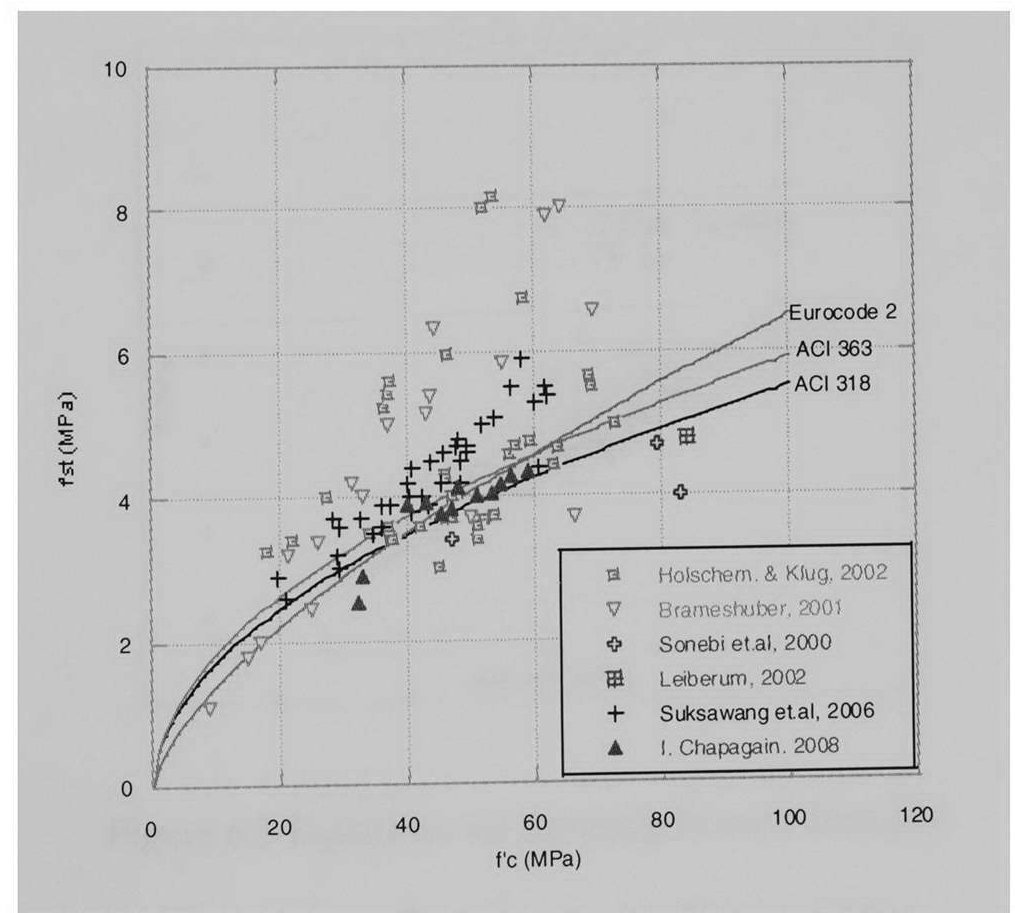

Figure 6.1 Comparison of Splitting Test Results with the Available Research and Codes 


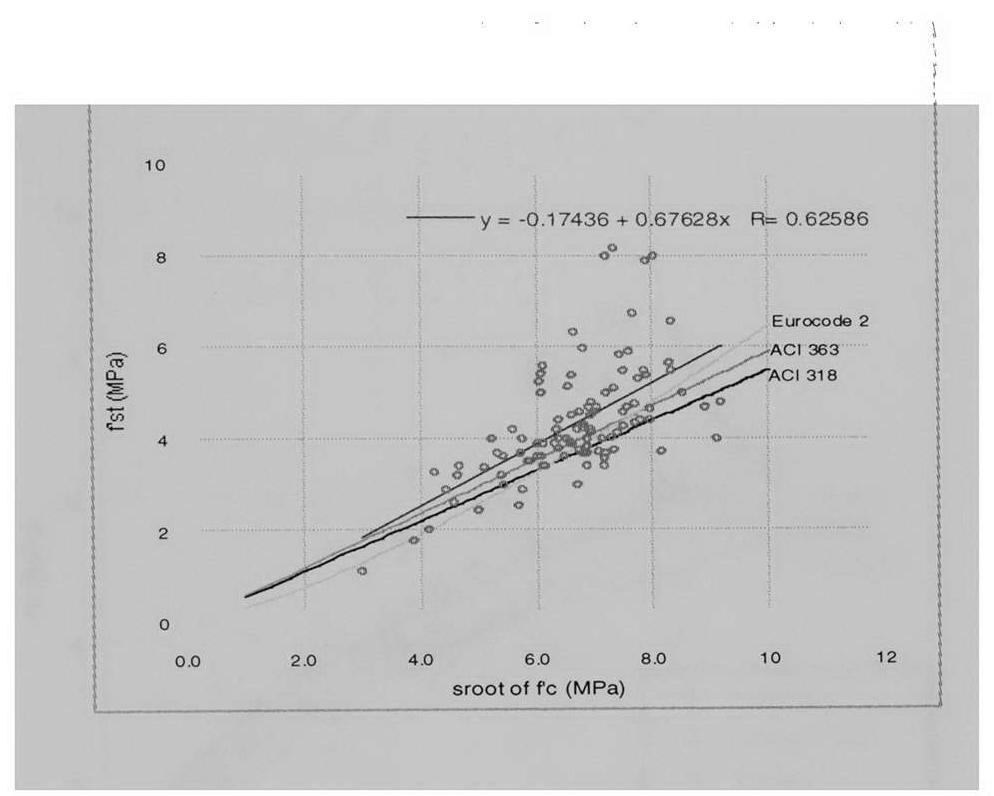

Figure 6.2 Equations for Splitting Tensile Strength (Using Linear Best Fit: Regular)

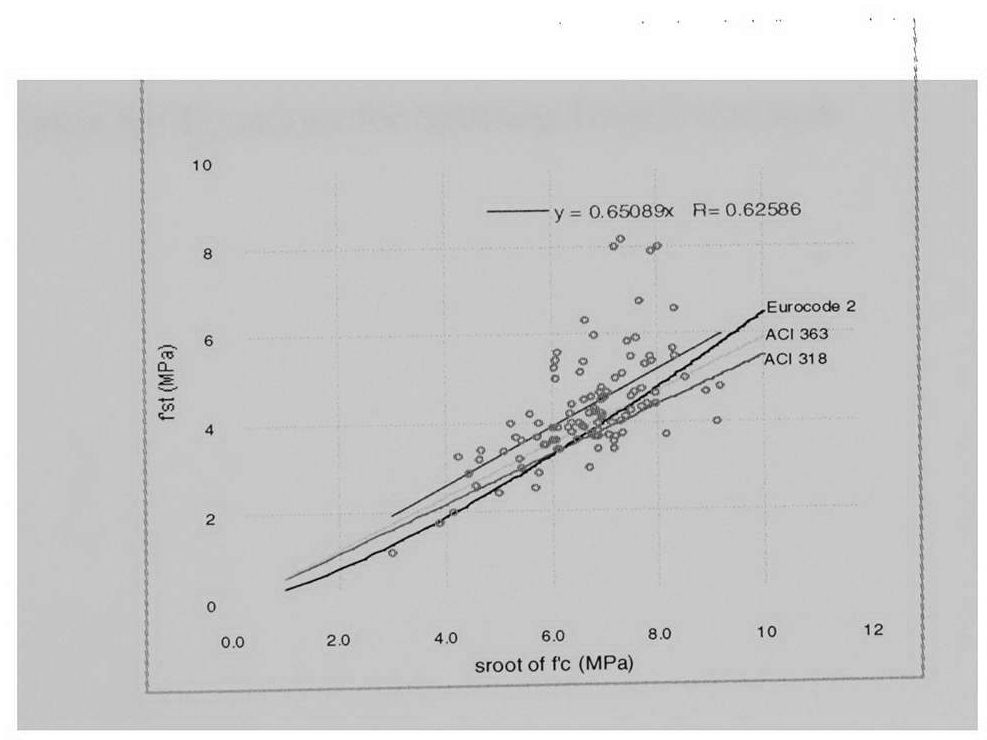

Figure 6.3 Equations for Splitting Tensile Strength

(Using Linear Best Fit: Forced Through Zero) 


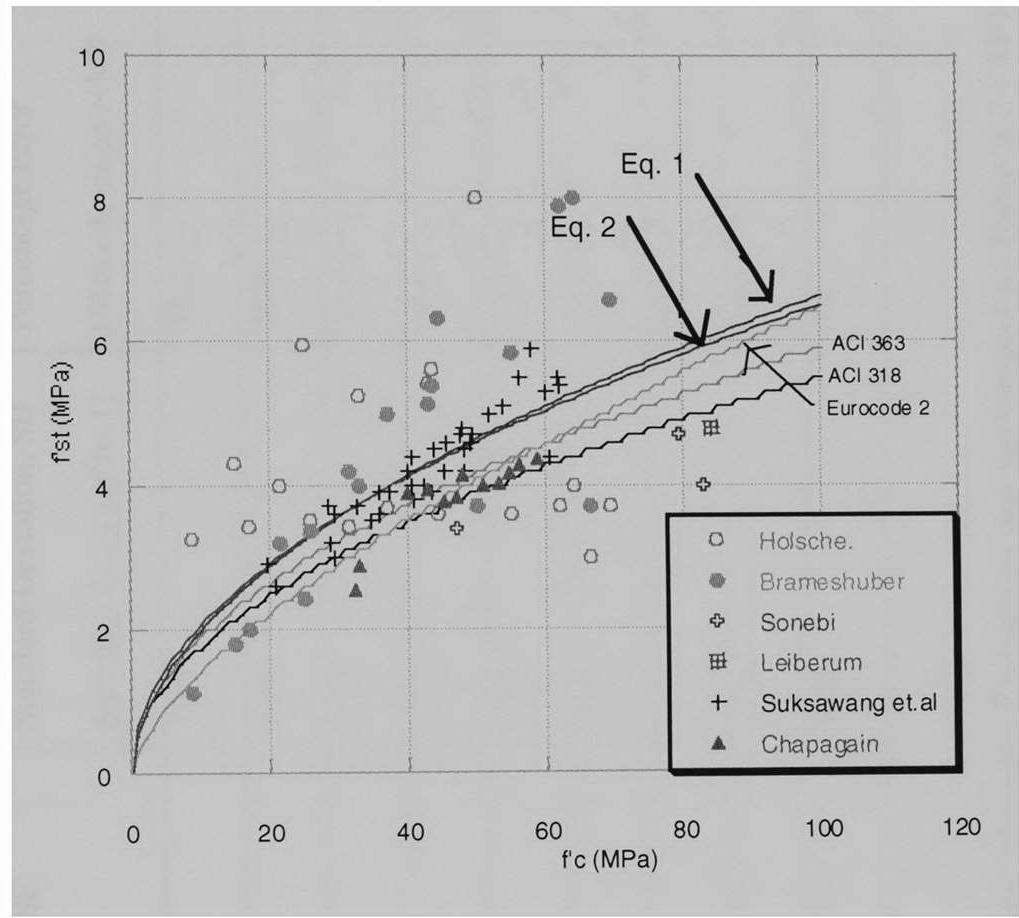

Figure 6.4 Equations for Splitting Tensile Strength 


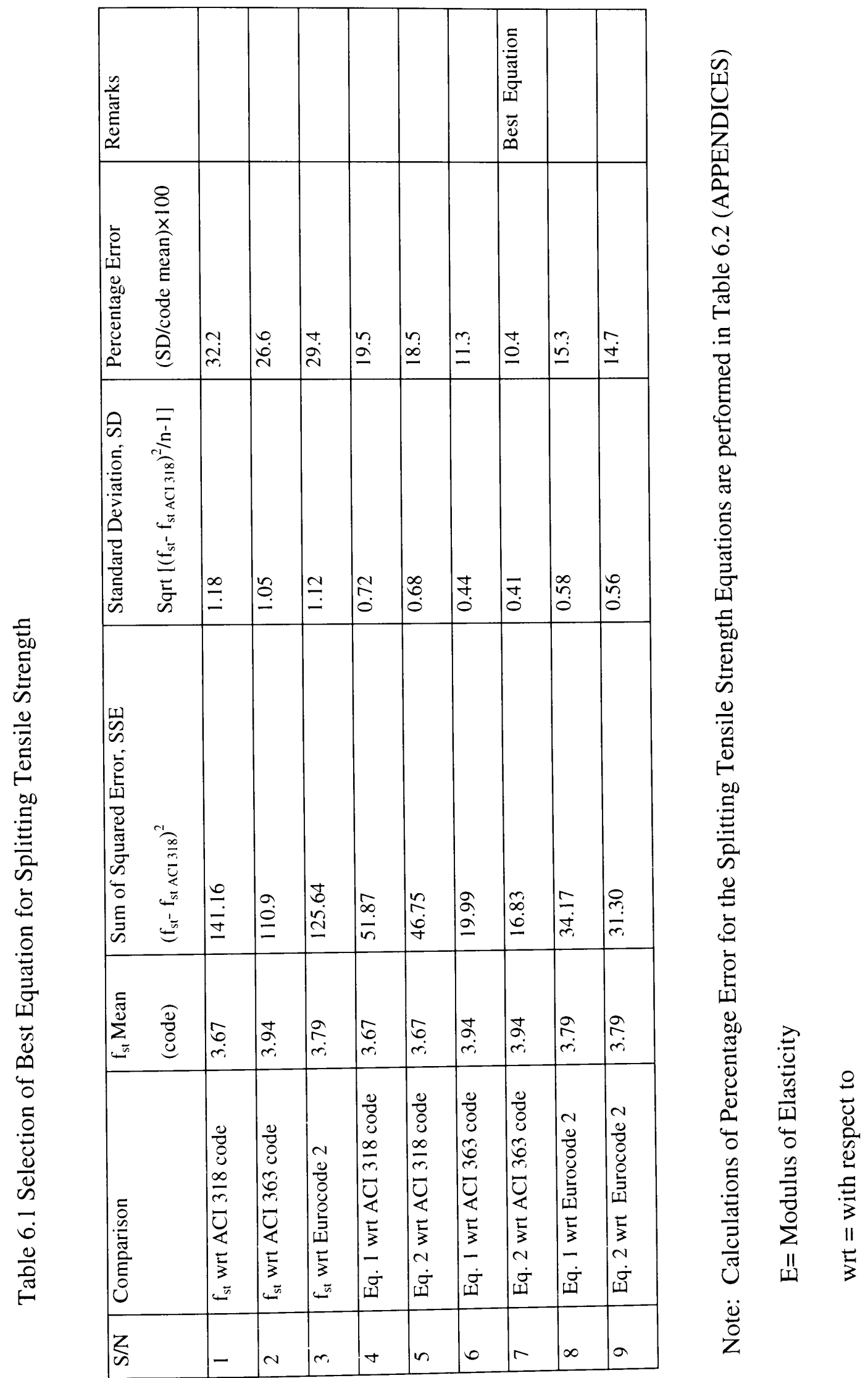




\subsection{Modulus of Elasticity}

Lesser the creep in concrete, the higher is the modulus of elasticity. Creep is undesirable as it tends to promote deflection in structural component. The research and data are limited and there is no specific mix proposed for the highest modulus of elasticity. Although the majority of the researchers suggest that modulus of elasticity is considerably increased with the addition of coarse aggregate in the mix, the fundamental concept of SCC is to limit coarse aggregate to get better consistency and flowability. Therefore, alternate mixes should be investigated independently to draw more conclusive statistical value of modulus of elasticity in SCC.

We have 129 data record for modulus of elasticity. The aim of the research is not only to compare the data and codes, but also to find the best curve for modulus of elasticity of SCC. To determine the best proposed equation for modulus of elasticity (E), the selected codes and the linear equations are compared with the available data in terms of its percentage error. Percentage error is obtained by dividing the standard deviation (SD) by the mean value of the equation of code. Where SD is mathematically expressed as:

$\mathrm{SD}=\sqrt{\frac{\left(E-E_{\text {coded }}\right)^{2}}{n-1}}$

Percentage error with respect to the given equation $=(\mathrm{SD} /$ mean $) \times 100$

Where $\mathrm{n}=$ degree of freedom

The higher number of data corresponds to higher degree of freedom, which tends to increase the accuracy of the result. 


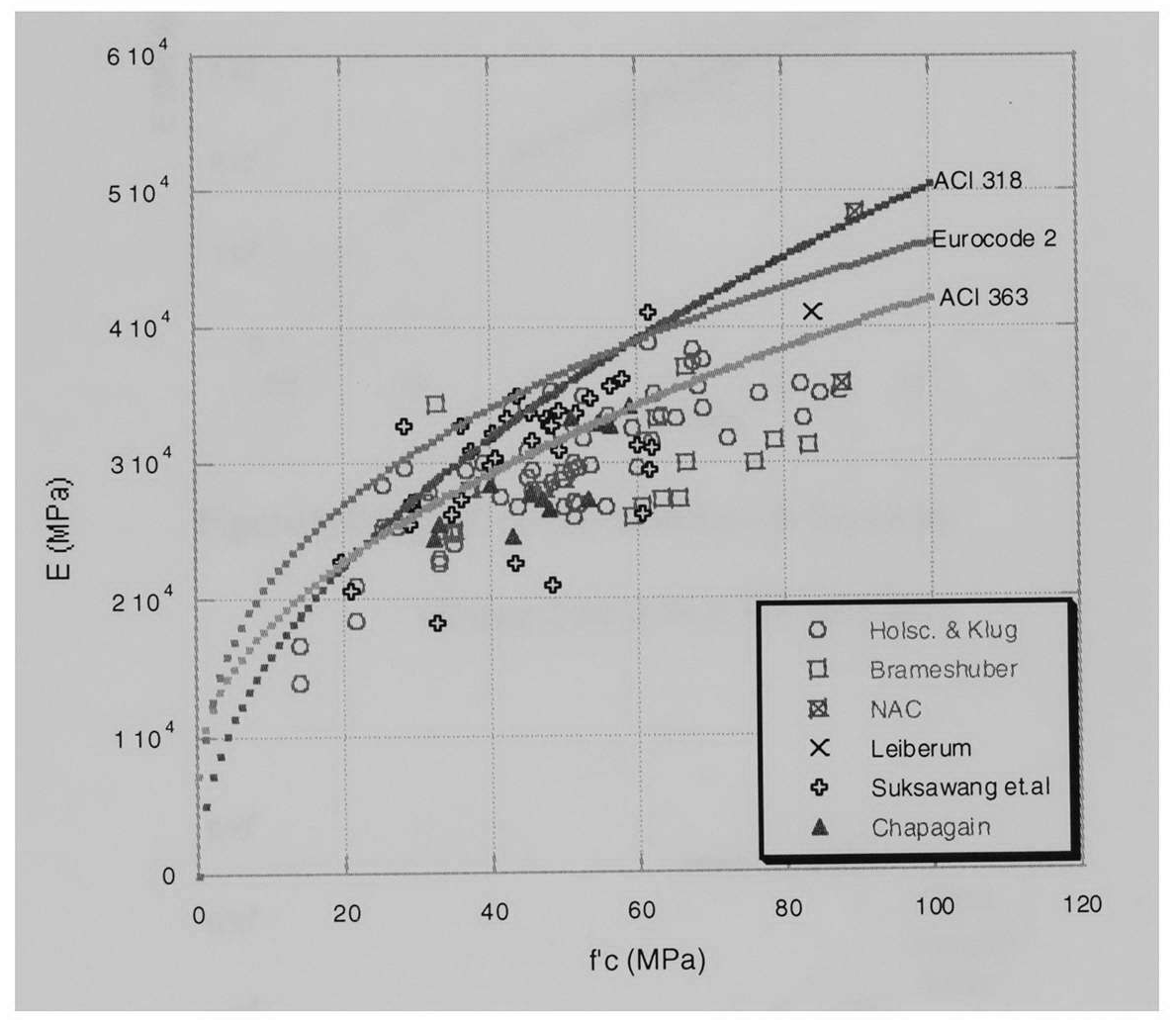

Figure 6.5 Comparison of Modulus of Elasticity Test Results with the Codes

Where, $\quad$ Holsc. \& Klug = K. Holschemacher \& Y. Klug, 1990

Brameshuber $=$ Brameshuber, 2001

NAC $=$ North American Conference on SCC, Nov 2002

Lieberum = Lieberum, 2002

Suksawang et.al. $=$ N. Suksawang et.al., 2006

Chapagan= Indra P. Chapagain, 2008 


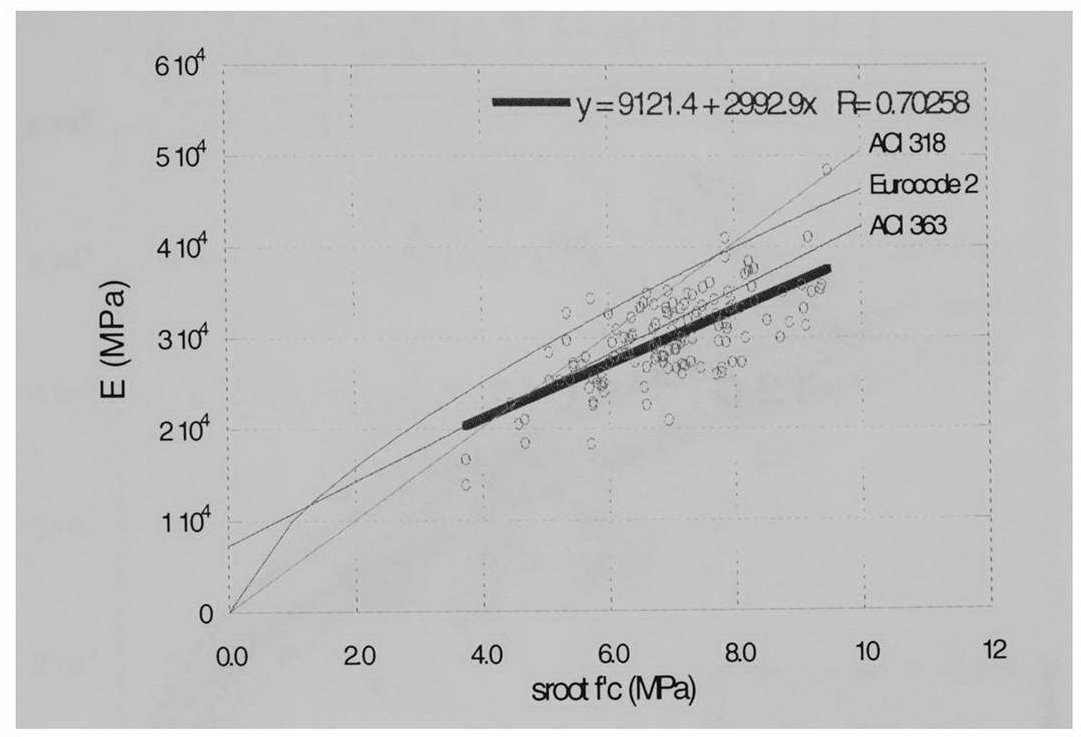

Figure 6.6 Equations for Modulus of Elasticity

(Using Linear Best Fit: Regular)

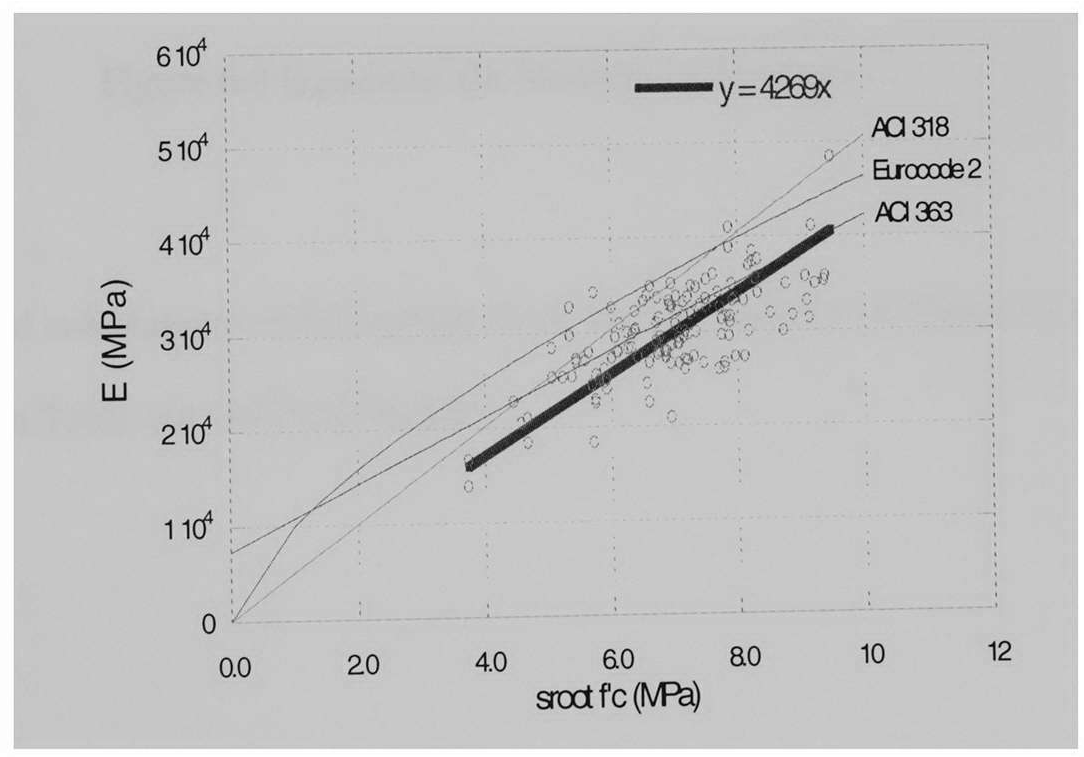

Figure 6.7 Equations for Modulus of Elasticity

(Using Linear Best Fit: Forced Through Zero) 


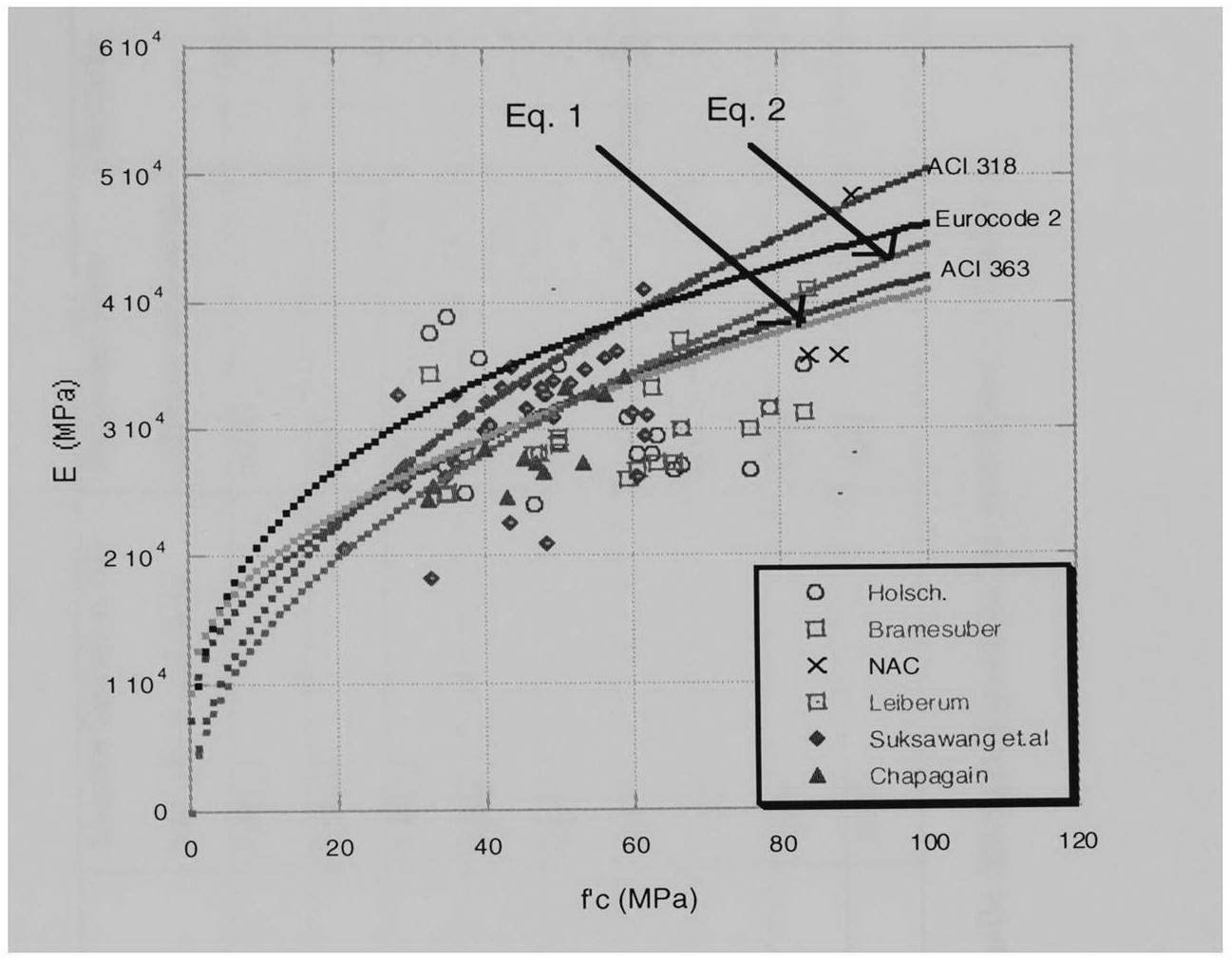

Figure 6.8 Equations for Modulus of Elasticity

Note: Partial calculations of Percentage Error for the Modulus of Elasticity are performed in Table 6.4 (APPENDICES) 


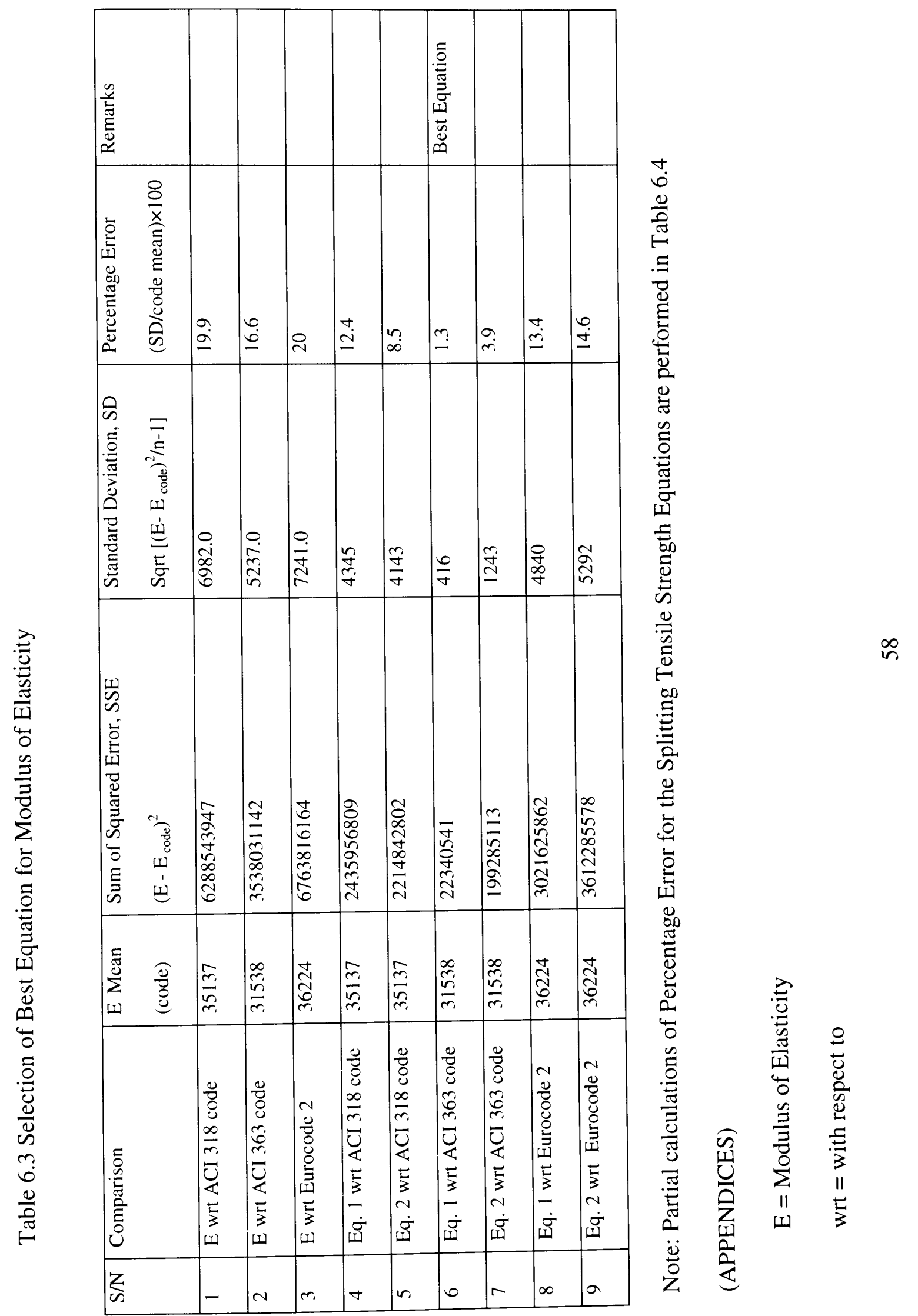




\section{CHAPTER 7}

\section{CONCLUSIONS}

The goals of the research were to access the material from a mechanical and durability (shrinkage) standpoint with the optimized mix design models and access the performance through a series of laboratory tests. The plastic and hardened concrete properties were thoroughly examined through spread test that conforms to ASTM C-1611 standard and material testing of concrete samples. Three SCC mix designs were strategically selected to bound the different proportioning methods: (1) a design based on controlled coarse to fine aggregate ratios, (2) a design based on the use of chemical admixtures and (3) a design based on the use of pozzolanic materials. A baseline comparison is made with the existing research of SCC.

The mix was prepared with the locally available aggregates and the cement was replaced by pozzolanic materials in different proportions. An experimental study was carried out to investigate the nature of compressive strength, tensile splitting strength, modulus of elasticity and drying shrinkage in concrete. The results demonstrate a better performance of concrete in its mechanical properties while proving to be economical as well. The obtained results were compared with the results of the existing research and ACI 318, ACI 363 and Eurocode 2.

After carefully performing the research and experimentation, the following conclusions were drawn: 
(1) The local aggregates (ASTM\# 57 FDOT and commercial sand) that were used in the tests were excellent to provide better compressive strength and modulus of elasticity with the SCC (Figure 6.4).

(2) Type of aggregate do not significantly affect on modulus of elasticity of selfconsolidating concrete. For example, in the research of Suksawang et.al the granites were used as aggregates, but in this study soft limestone (ASTM\#57 FDOT) were used and the difference of highest modulus of elasticity was only $3 \%$.

(3) An optimum amount of superplasticizer $14 \mathrm{oz} / \mathrm{cft}\left(14 \mathrm{~kg} / \mathrm{m}^{3}\right)$ was investigated with several trials for all the strategically selected mixes with a target slump flow of 22 to 28 in ( $560 \mathrm{~mm}$ to $700 \mathrm{~mm}$ ) according to ASTM C-143.

(4) A dosage of $14 \mathrm{oz} / \mathrm{cft}\left(14 \mathrm{~kg} / \mathrm{m}^{3}\right)$ of superplasticizer, $0.39 \mathrm{w} / \mathrm{b}$ ratio and $19 \mathrm{~mm}$ maximum size of aggregate produced satisfactory SCC with a good fluidity satisfying the requirement of targeted slump flow for all the selected mix models.

(5) The lowest and highest compressive strength results of the established mixes were 6,564 and 8,547 psi (45 MPa to $59 \mathrm{MPa}$ ) in comparison to the design strength of $8000 \mathrm{psi}(55 \mathrm{MPa})$. The results of the compressive and splitting tensile strengths of the SCC mix models were compared with the requirement of codes ACI 318, ACI 363 and Eurocode 2 (Figure 5.1).

(6) To reduce the drying shrinkage in concrete, a small percent (3\%) of silica fume with fly ash could be added (Figure 5.4).

(7) The addition of silica fume in SCC leads to the rapid initial strength gain in concrete (Figure 5.1). 
(8) There is a decrease of modulus of elasticity with the increase of fly ash up to $20 \%$, but $3 \%$ silica fume with fly ash considerably increased it. No significant difference was observed between SCC with different fly ash percentages above 20\% (Figure 5.3).

(9) The test result of modulus of elasticity of SCC was found to be satisfactory in comparison to the available research and corresponds to the codes ACI 318, ACI 363 and Eurocode 2 (Figure 6.4).

(10) The best proposed equation for splitting tensile strength of SCC was determined as the equation produced by the linear curve passing through the zero (Figure 6.2 and 6.30 . Similarly, for the modulus of elasticity, the best equation was obtained with the regular linier curve (Figure 6.6 and 6.7).

An attempt was made to develop some trial mixes that could be used as economical tools for the optimum design of pozzolanic materials based SCC mixtures. Concrete with the cohesion, stability and flowability alone with great filling capacity opens up many possibilities for many different applications. It is important to note that the proposed research was conducted on a particular mix design models. The conclusions drawn in the research are based on the mix studied.

Future research should include an investigation of the optimized mixture designs incorporating the pozzolanic materials. The optimized mixture design should enhance both durability and mechanical properties of SCC. It should specifically continue to focus on the comparison of the use of fly ash, silica fume and blast furnace slag. Water and chloride permeability test along with shrinkage test should also be included to cover up 
the durability test. The selected mixes should be tested in a laboratory setting to determine if they are indeed viable. 


\section{LIST OF REFERENCES}

ACI Committee 234 (1995), Guide for the Use of Silica Fume in Concrete, ACI Materials Journal, Vol. 7, pp.437-440.

Aitcin, P.C. (2001), "High Performance Concrete," (in French), $1^{\text {st }}$ Ed., Paris, France, Eyrolles; pp.683.

Asaga. K. and Roy (1980), D.M., Rheological Properties of Cement Mixes: IV. 'Effect of Superplasticizers on Viscocity and Yield Stress'. Cement and Concrete Research.

pp. 287-295.

ASTM C 39 (1997), "Standard test method for compressive strength measurement in concrete", Annual Book of ASTM Standards, vol. 04.05, American Society for Testing and Materials, Philadelphia.

ASTM C 426 (1993). "Standard Test Method for Drying Shrinkage of Concrete Block", Annual Book of ASTM Standards, vol. 4.01, American Society for Testing and Materials, Philadelphia.

ASTM C 469 (2002b). "Standard Test Method for Static Modulus of Elasticity and Poisson's ratio of Concrete in Compression.", ASTM, Philadelphia.

ASTM C 496 (1992). "Standard Test Method for Splitting Tensile Strength of Cylindrical Concrete Specimens", vol. 04.02. American Society for Testing and Materials, Philadelphia.

Bayasi, Z., and Soroushian, P. (January, 1988), 'High Fly Ash Concrete,' Fly Ash Applications to Concrete, Symposium, Michigan State University, pp. 1.7-15.7.

Bayasi, Z., and Soroushian, P. (1989), "Optimum Use of Pozzolanic Materials in steel Fiber Reinforced Concrete," Transportation Research Record 1226: International Symposium on Recent Developments in Concrete Fiber Composites, Washington D.C., pp.25-30.

Bayast, Z., Fuessle, R., Taylor, M., and Helenek, H. (Feb, 1990), "Silica Fume Effects on the Permeability and Microstructure of Concrete," Bradley University, pp. 54.

Beitzel Herald (2001), 'Influence of mixing procedure of the production of SCC', v.67 No.1, pp12-13.

Bouzoubaa, N., Lachemi M. (2001), Self-Compacting Concrete Incorporating High Volumes of Class F Fly Ash: Preliminary Results, Cement and Concrete Research, Vol. 31, No. 3, pp. 413-420. 
CARBO C., L.FERNANDEZ LUCO, S. MORENO, AND R. TORRENT (2003), 'SelfConsolidating Concrete: Design and Performance. North American Conference on the design and use of self-consolidating concrete.

Ozyildirim C. (2003), 'Evaluation of Self-Consolidating Concrete' pp. 15.

Daimon, M. and Roy D.M. (1978), Rheological Properties of Cement Mixes: I. Method, Preliminary Experiments, and Absorption Studies. Cement and Concrete Research, pp.753-764.

Daimon, M. and Roy, D. M. (1979). Rheological Properties of Cement Mixes: II. Zeta Potential and Preliminary Viscocity Studies. Cement and Concrete Research, pp.103110.

Dehn ${ }^{1}$ Frank, Klaus Holschemacher ${ }^{2}$, Dirk weiBe ${ }^{3}$ (2000), 'Time Development of Material Properties and Bond Behavior'.

Portland Cements Association (1979), Design and Control of Concrete Mixtures, pp. 139295.

Domone P.L. (2005), 'Self-compacting Concrete: An Analysis of 11 Years of Case Studies'.

EFNARC (February, 2002), "Specifications and Guidelines for Self-Compacting Concrete", UK (www.efnarc.org), pp. 1-32.

Gaimster, R., and Foord, C. (April, 2000), "Self-Compacting Concrete," Concrete, vol. 34 , pp 23-25.

Goodier C. (Winter 2002/2003), 'Design and use of SCC' vol 6 No. 4.

Gunnar Rise (2001), Concrete Precasting Plant and Technology: 'Self Compacting Concrete', vol.67 No.1, pp.83-85.

Hayakawa, M., Matsuaoka, Y., and Shindoh, T. (1993), Development and Application of Superworkable Concrete. RILEM International Workshop on Special Concretes: Workability and Mixing.

Ho, D.W.S., Sheinn A.M.M., Ng C.C. and C.T. Tam (2003), 'The Use of Quarry Dust for SCC Applications', Cement and Concrete Research, vol. 32, No. 4, pp. $505-511$.

Hogson D., Schindler A.K., Brown D.A., Mary group Gardiner, (2005), 'Selfconsolidating Concrete for use in Drilled Shaft Applications'.

Holschemacher K., Klug Y. (2002), 'A Database for the Evaluation of Hardened Properties of SCC.' Annual Civil Engineering Report No.7, pp. 123-134. 
Huang, J.W. (1990), "Engineering Properties of Silica Fume Concrete and Mortar," M.S. Thesis, Bradley University, Department of Civil Engineering and Construction, pp.108.

Khayat, K.H. (May-June,1999), "Workability, Testing and Performance of Self Consolidated Concrete", ACI Materials Journal, V.96 No.3, pp. 346-352.

Khayat, K.H., Assaad, J., Daczko J. (March- April 2004), "Comparison of Field-oriented Test Methods to Access Dynamic Stability of Self-Consolidating Concrete", ACI Materials Journal, V. 101, No. 2, pp. 168-176.

Kosmatka, S. H. and Panarese W.C. (1988). Design and Control of Concrete Mixtures, Skokie, IL: Portland cements Association.

Krieg, W. (October, 2003), "Self-Compacting Concrete: Definition, Development, and Applications", A Technical Paper Presented in the meeting of the ACI, Saudi Arabia Chapter, Eastern Province.

Lamond, J. (1983), "Twenty Five Years Experience Using Fly Ash in Concrete," ACI Publication SP 79: Fly Ash, Silica Fume, Slag and other Natural By-Products in Concrete, vol. 1, pp 47-69.

Mehta, P. (1986), "Concrete Structure, Properties and Materials," Prentice-Hall, Inc, pp. 1 to 169 .

Mindess, S. and Young, J.F. (1981), "Concrete," Prentice-Hall, Inc., Eaglewood Cliffs, NJ, pp. 671.

Mullarky, J.I. and Vanikar, S.; 'Opportunities and Challenges for SCC in Highway Structures', First North American Conference on the Design and Use of SelfConsolidating Concrete, pp 185-190.

Nagataki, S. and Fujiwara, H. (1995), 'Self-Compacting Property of Highly Flowable Concrete. ACI SP 154, Las Vegas, pp. 301-314.

Nawy Edward G., 'Reinforced Concrete, A Fundamental Approach', ACI 318-05 Code.

New Self-Compacting Concrete for Pre-cast Elements (2001), TR-6-03, vol. 67, No3, pp.100-108.

Okamura H. and Ouchi M. (January, 1989), Self-Compacting Concrete, Proceedings of the first International RILEM Symposium.

Ozawa K., Maekawa K., Kunishima M. and Okamura H. (1989); Development of High performance concrete based on the durability design of concrete structures, Proceeding of 
the second East-Asia and Pacific Conference on Structural Engineering and Construction, vol. 1, pp. 445-450.

Okamura H. (1997), "Self-Compacting High-performance Concrete," Concrete International, Vol. 19, No.7, pp.50-54.

Okamura, H. and Ouchi, M. (April 2003), "Self-compacting Concrete", Journal of Advanced Concrete Technology, vol. 1, No. 1, pp. 5-15.

Ouchi M., Nakamura S., Osterson T., Hallberg S., and Lwin M. (2003), 'Applications of Self-Compacting · Concrete in Japan, Europe and the United States..' ISHPC.

Ozyildirim C., Lane D.S. (June, 2003) Final Report on 'Evaluation of Self-Consolidating Concrete' pp.1-15.

Petersson O. (October, 1997), 'Final Report on Preliminary Mix Design', Swedish Cement and Concrete Research Institute, pp. 1-27.

Popovics, S. (January-February 1982), "Strength Relationships for Fly Ash Concrete," ACI Journal, Vol. 79, No.1, pp. 39-43.

Ravina, D. (April 1984), "Slump loss of Fly Ash Concrete," Concrete International, Detroit MI, Vol. 6, Vol. 4, pp. 35-39.

SHI CAIJUN, YANZHONG WU, YIXING SHAO, 'Comparison of two Design Approaches for SCC', Conference notes, First North American Conference on the Design and Use of Self-Consolidating Concrete, pp. 313.

Specification and Guidelines for SCC (Feb 2002), EFNARC.

Kosmatka, S.H. and Panarese, W.C. (2002), 'Design and Control of Concrete Mixtures'.

Sturrup, V.P., Hooton, R.D. and Clendenning, T.G. (1993), "Durability of Fly Ash Concrete," ACI Publication SP 79: Fly Ash, Silica Fume, Slag and Other Mineral ByProducts in Concrete, vol.1, pp. 71-86.

Subramanian, S. and Chattopadhyay, D. (Jan 2002), 'Experiments for Mix Proportioning of Self Compacting Concrete', Indian Concrete Journal vol. 76 No. 1, pp. 13-20.

Suksawan N., Nassif H.H. and Hussain S. N. (2006), "Evaluation of Mechanical Properties for Self-Consolidating, Normal, and High Performance Concrete."

The European Guidelines for Self-Compacting Concrete, 'Specification, Production and Use' (May, 2005). 
Uchikawa, H., Hanehara, S., and Sawaki, D. (January, 1997); 'The Role of Steric Repulsive Force in the Dispersion of Cement Particles in Fresh Paste Prepared with Organic Admixture. Cement and Concrete Research, vol. 27. No.1. pp. 37-50.

US Department of Transportation, Federal Highway Administration (July, 1986) 'Fly Ash Facts for Highway Engineers', pp. 47.

Xie, Y., Liu B., Yin J. and Zhou S. (2002), 'Optimum Mix Parameters of High-Strength Self-Compacting Concrete with Ultra pulverized Fly Ash. Cement and Concrete Research, vol. 32, No. 3, pp. 477-480.

Zhu W., Gibbs J. C. and Bartos P. J.M. (2000), 'Uniformity of in-situ Properties of SCC in Full Scale Structural Elements'. 


\section{APPENDICES}

Table 3.2 The Physical and Chemical properties of Portland cement

\begin{tabular}{|c|c|c|}
\hline \multicolumn{3}{|l|}{ CHEMICAL } \\
\hline Item & Spec. Limit & Test Result \\
\hline $\mathrm{SiO}_{2}(\%)$ & $20.0 \mathrm{~min}$ & 21.3 \\
\hline $\mathrm{Al}_{2} \mathrm{O}_{3}(\%)$ & $6.0 \max$ & 4.6 \\
\hline $\mathrm{Fe}_{2} \mathrm{O}_{3}(\%)$ & $6.0 \max$ & 3.4 \\
\hline $\mathrm{CaO}(\%)$ & NA & 63.2 \\
\hline $\mathrm{MgO}(\%)$ & $6.0 \max$ & 2.2 \\
\hline $\mathrm{SO}_{3}(\%)$ & $3.0 \max$ & 2.7 \\
\hline Loss on ignition (\%) & $3.0 \max$ & 1.2 \\
\hline $\mathrm{Na}_{2} \mathrm{O}(\%)$ & NA & 0.19 \\
\hline $\mathrm{K}_{2} \mathrm{O}(\%)$ & NA & 0.50 \\
\hline Insoluble Residue (\%) & $0.75 \max$ & 0.27 \\
\hline $\mathrm{C}_{3} \mathrm{~S}$ & NA & 52 \\
\hline $\mathrm{C}_{2} \mathrm{~S}$ & NA & 22 \\
\hline $\mathrm{C}_{3} \mathrm{~A}$ & $8 \max$ & 6 \\
\hline $\mathrm{C}_{4} \mathrm{AF}$ & NA & 10 \\
\hline $\mathrm{C}_{4} \mathrm{AF}+2\left(\mathrm{C}_{3} \mathrm{~A}\right)$ & NA & 22 \\
\hline
\end{tabular}




\begin{tabular}{|c|c|c|}
\hline \multicolumn{3}{|l|}{ PHYSICAL } \\
\hline Item & Spec. Limit & Test Result \\
\hline Air content of mortar (volume $\%$ ) & $12 \max$ & 8 \\
\hline Fineness $\left(\mathrm{m}^{2} / \mathrm{kg}\right)$ (Air permeability) & $280 \mathrm{~min}$ & 377 \\
\hline Autoclave expansion (\%) & $0.80 \max$ & 0.04 \\
\hline Compressive Strength (MPa) & $\min$ & \\
\hline 1 Day & NA & \\
\hline 3 Days & 7.0 & 23.4 \\
\hline 7 Days & 12.0 & 29.8 \\
\hline 28 Days & NA & \\
\hline Time of Setting (minutes) & & \\
\hline Initial (Vicat's apparatus) & $\begin{array}{l}\text { Not less than } 45 \text { and } \\
\text { not more than } 375\end{array}$ & 124 \\
\hline
\end{tabular}

$\mathrm{NA}=$ Not applicable. 
Table 4.3 General Physical and Chemical Properties of Silica Fume

\begin{tabular}{|l|l|l|}
\hline \multirow{2}{*}{ Compound } & \multicolumn{2}{|l|}{ Quantity (\%) } \\
\cline { 2 - 3 } & Fly Ash (Class F) & Portland Cement \\
\hline $\mathrm{SiO}_{2}$ & $50-55$ & $20-25$ \\
\hline $\mathrm{Al}_{2} \mathrm{O}_{3}$ & $20-27$ & $2-5$ \\
\hline $\mathrm{Fe}_{2} \mathrm{O} 3$ & $5-10$ & $1-5$ \\
\hline $\mathrm{CaO}$ & $5-10$ & $60-65$ \\
\hline $\mathrm{MgO}$ & $0.5-2$ & $1-4$ \\
\hline $\mathrm{SO}_{3}$ & $0-2$ & $2-5$ \\
\hline
\end{tabular}



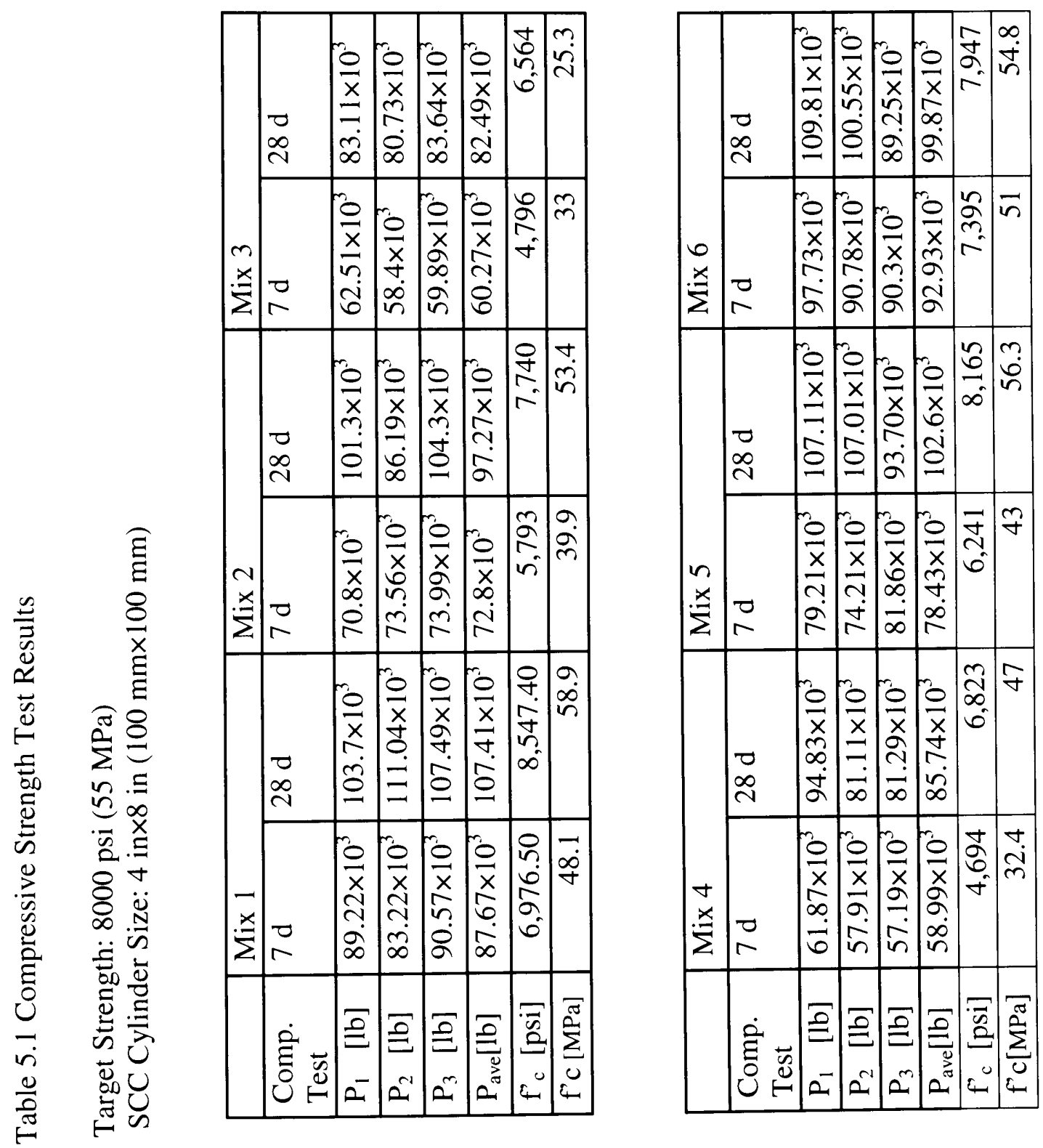

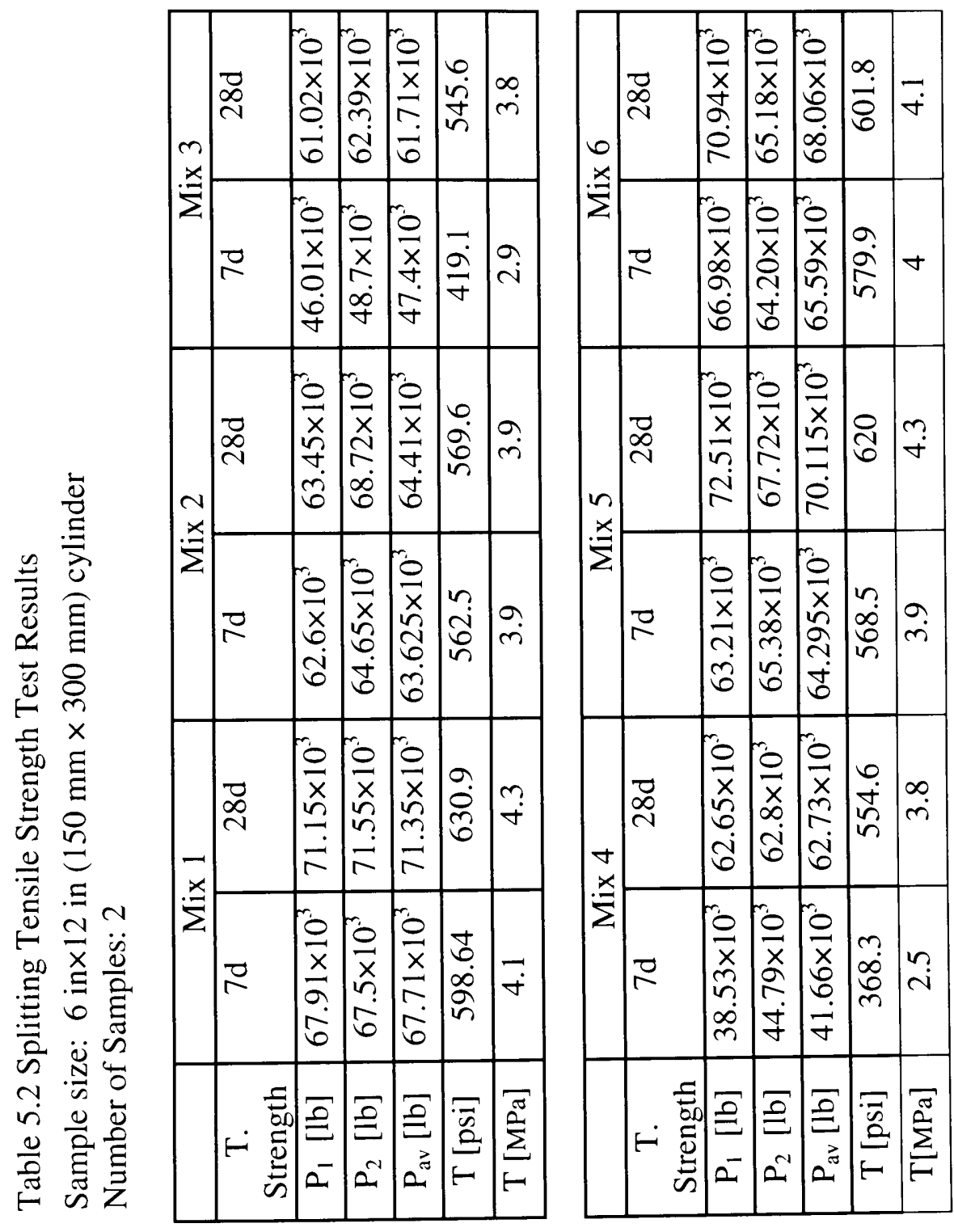


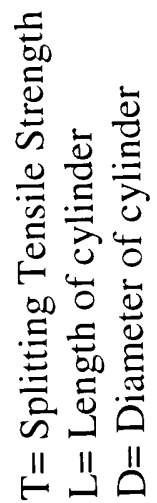



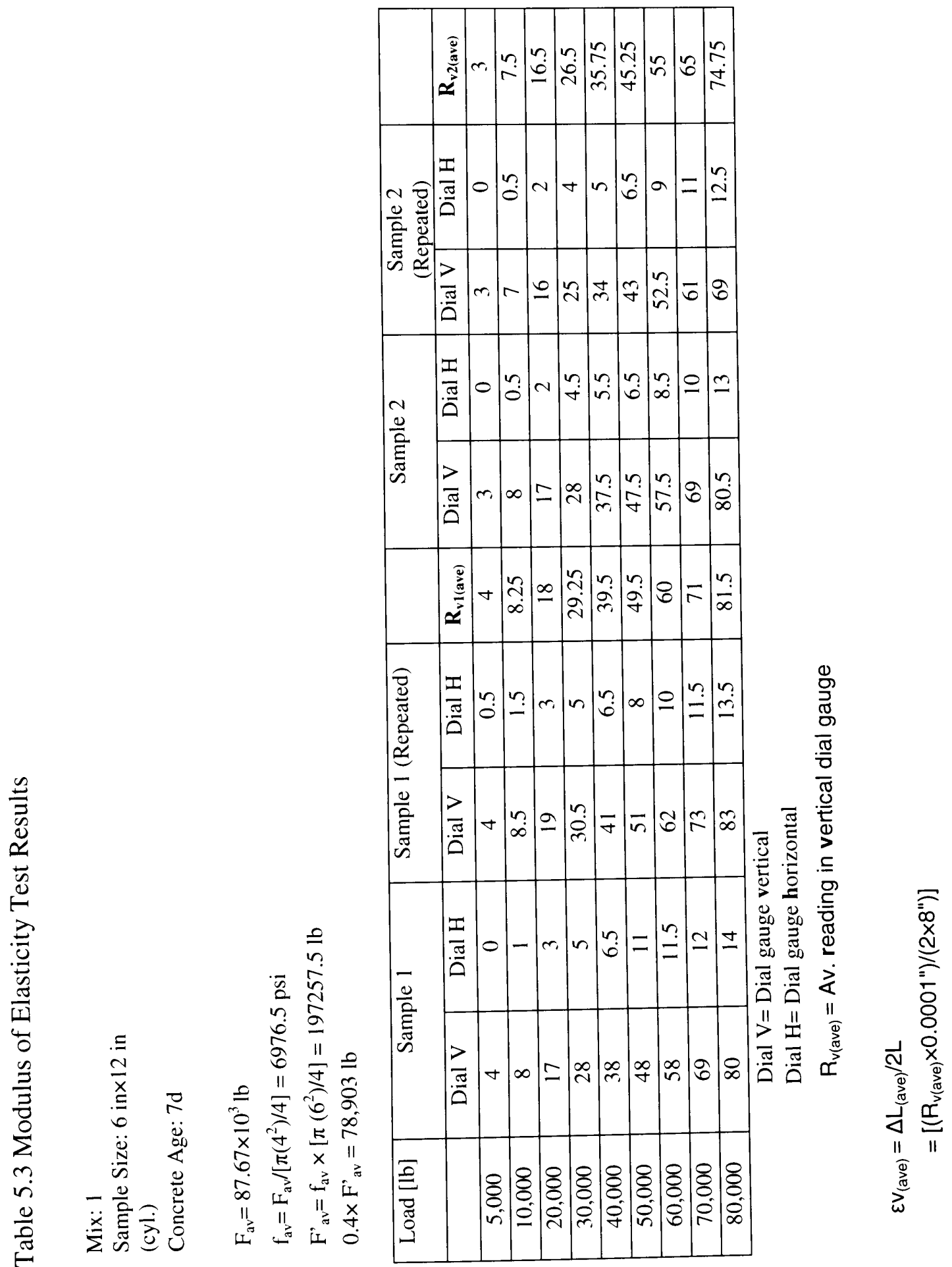

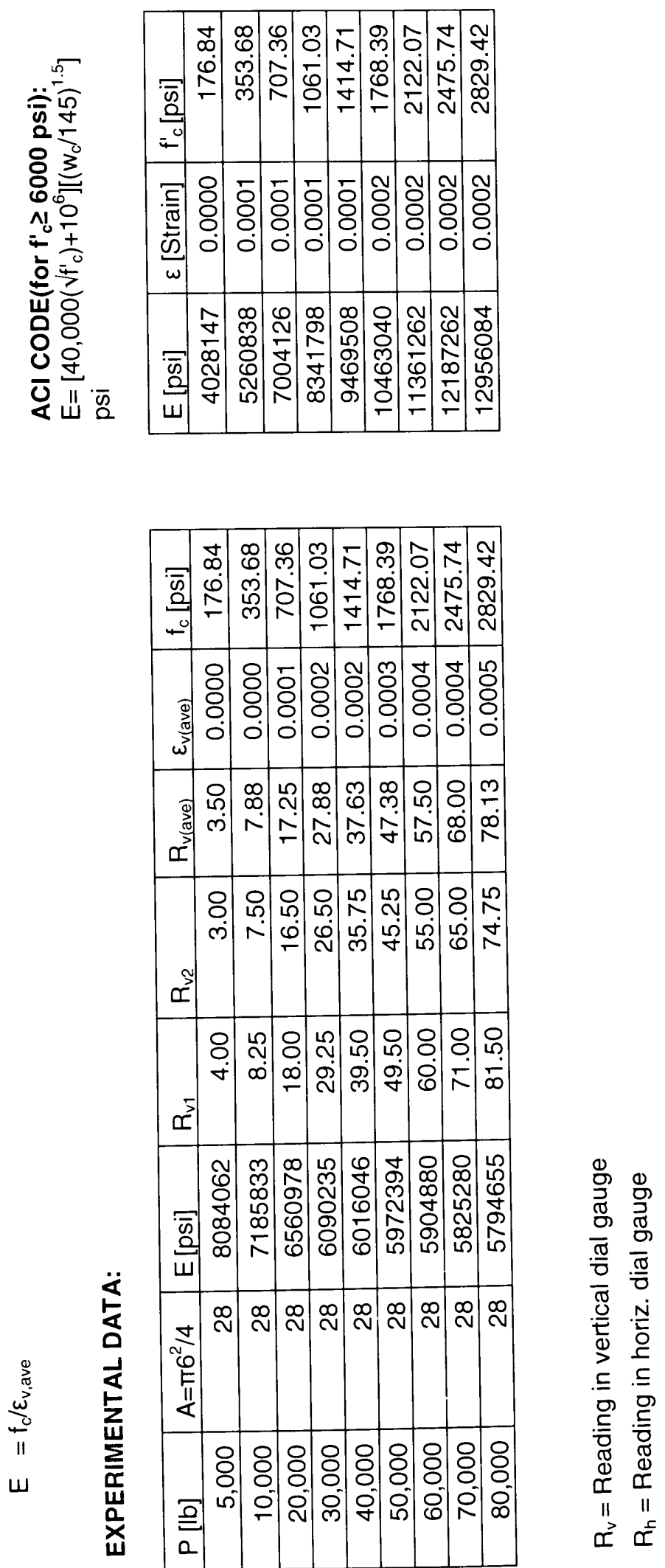


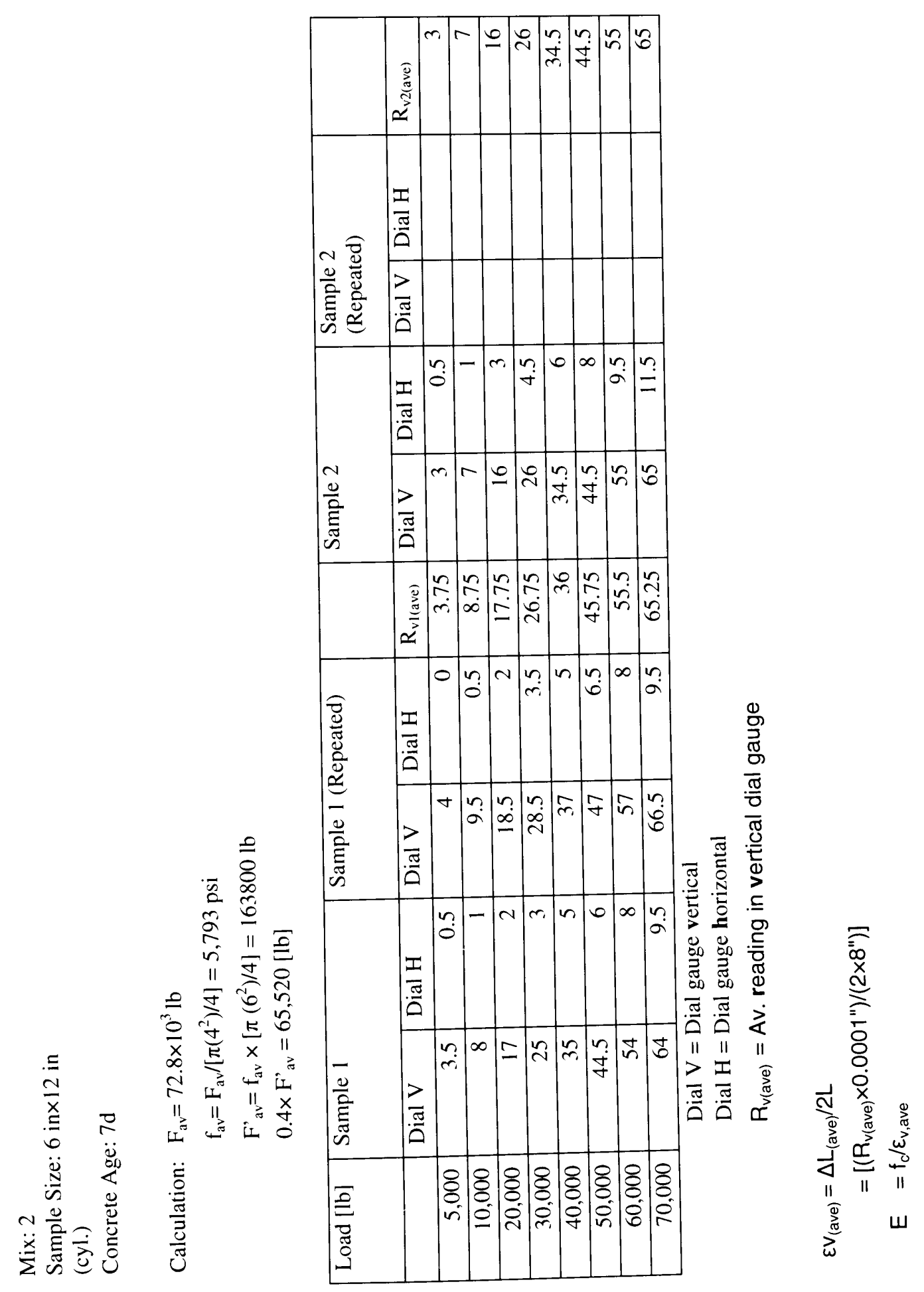



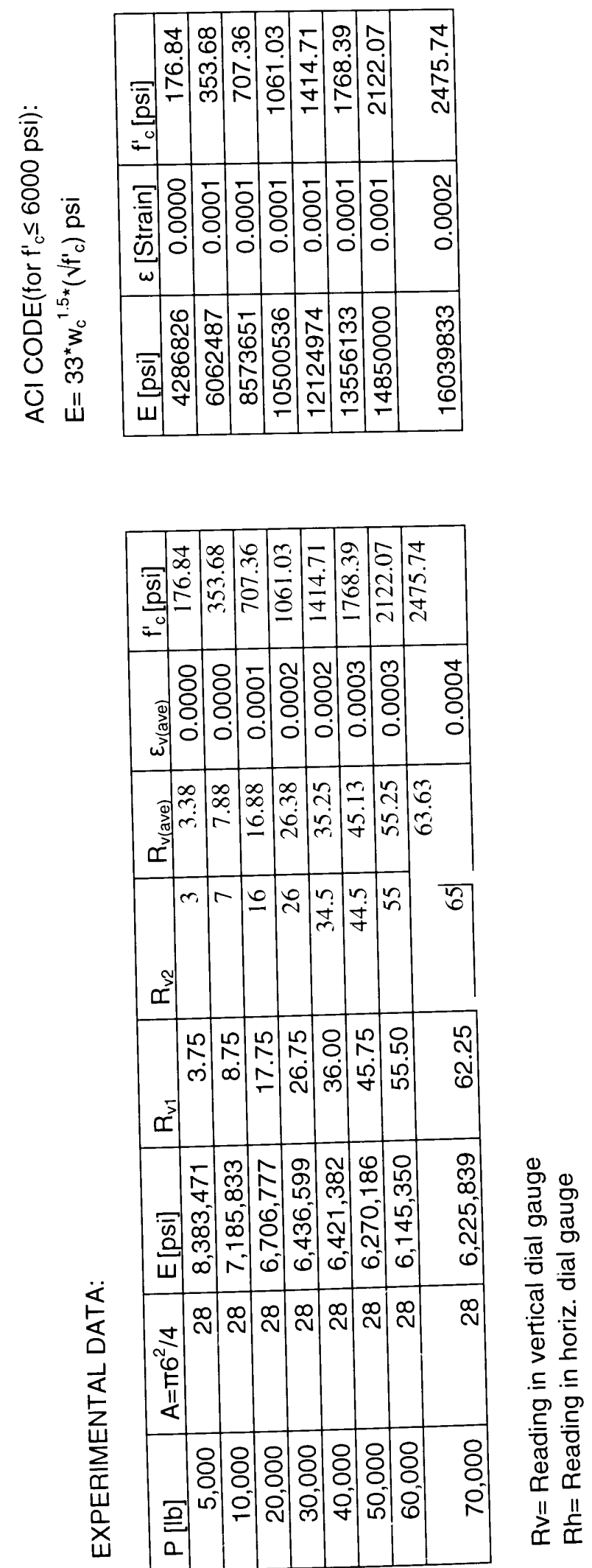


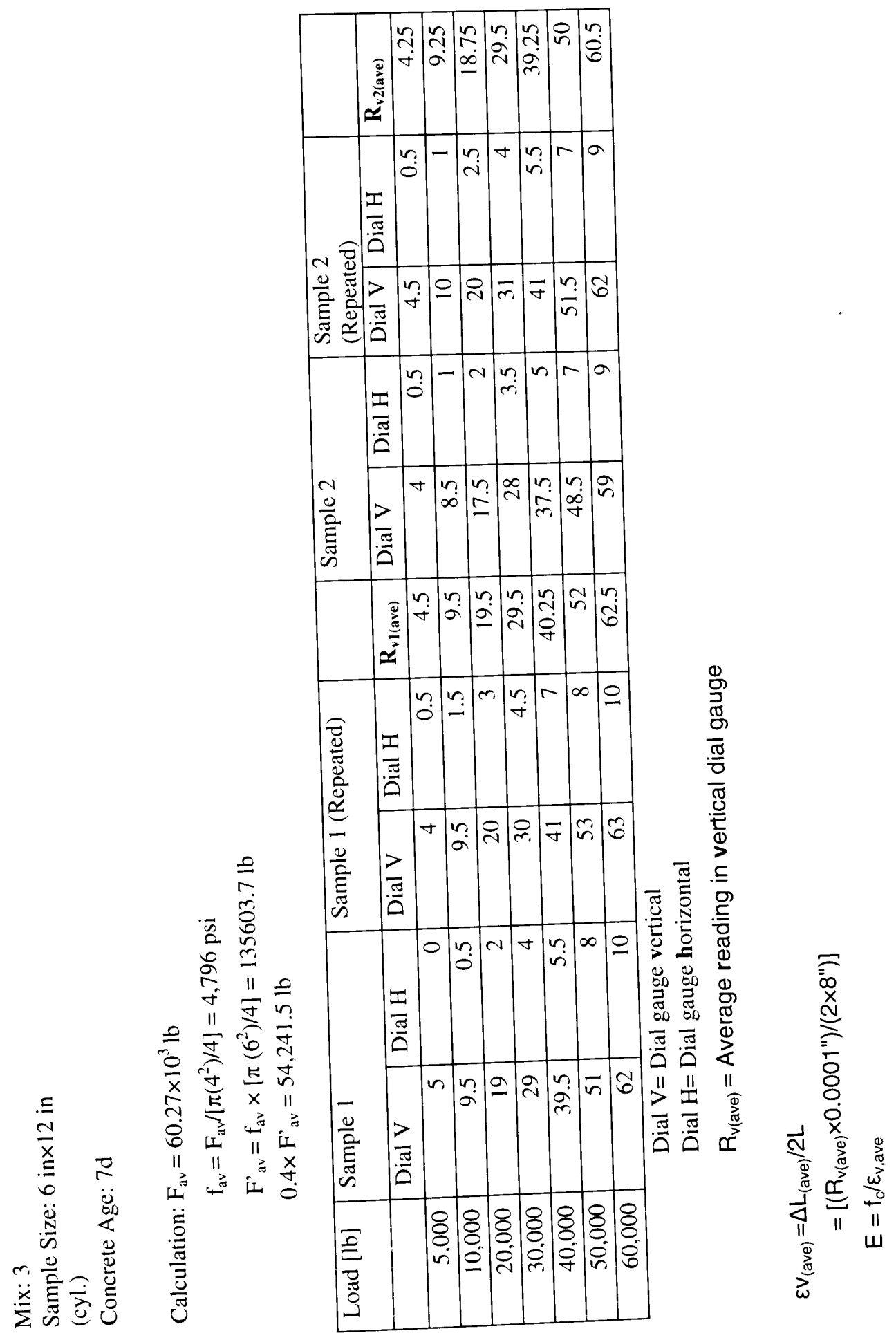



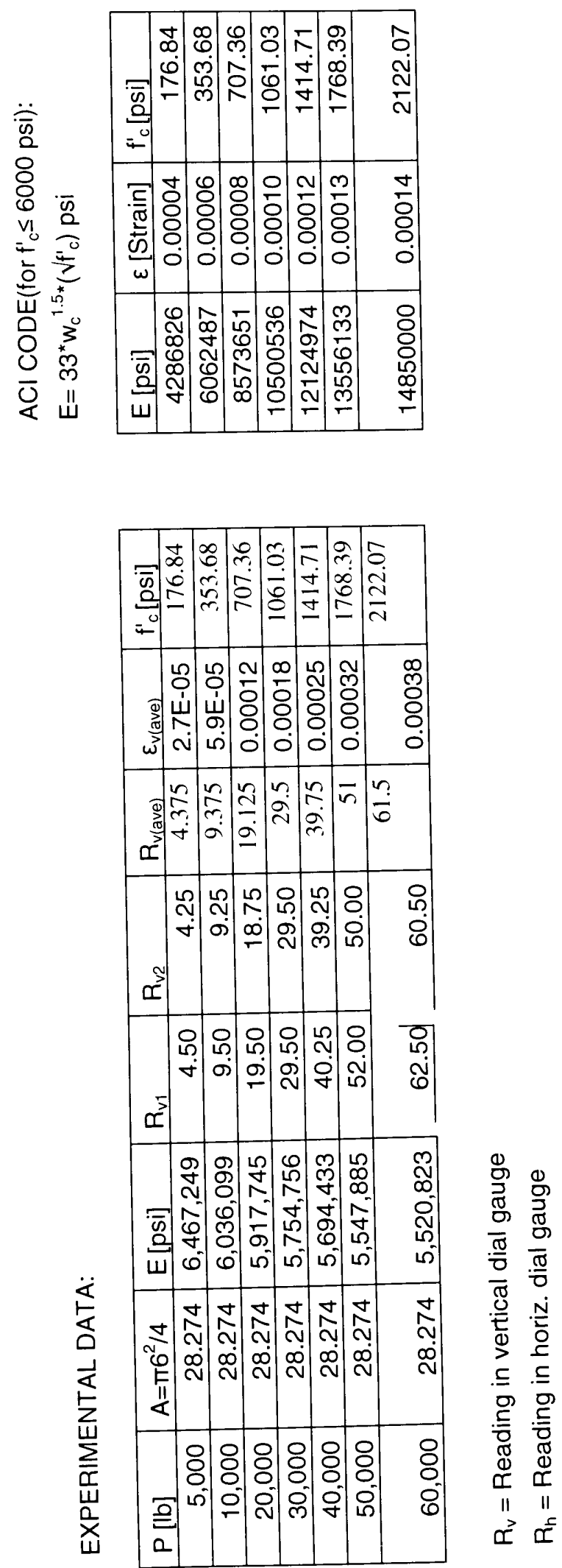


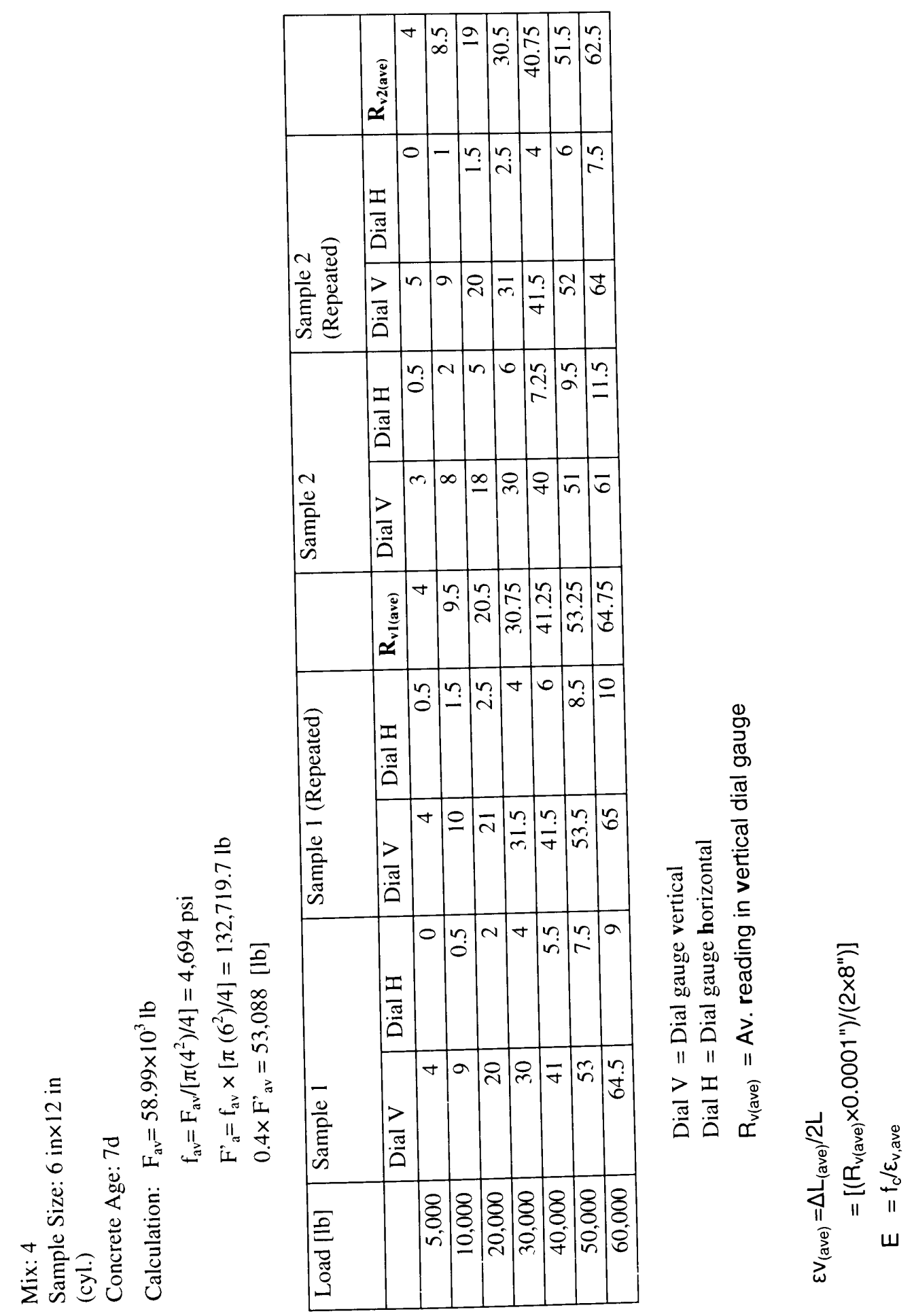



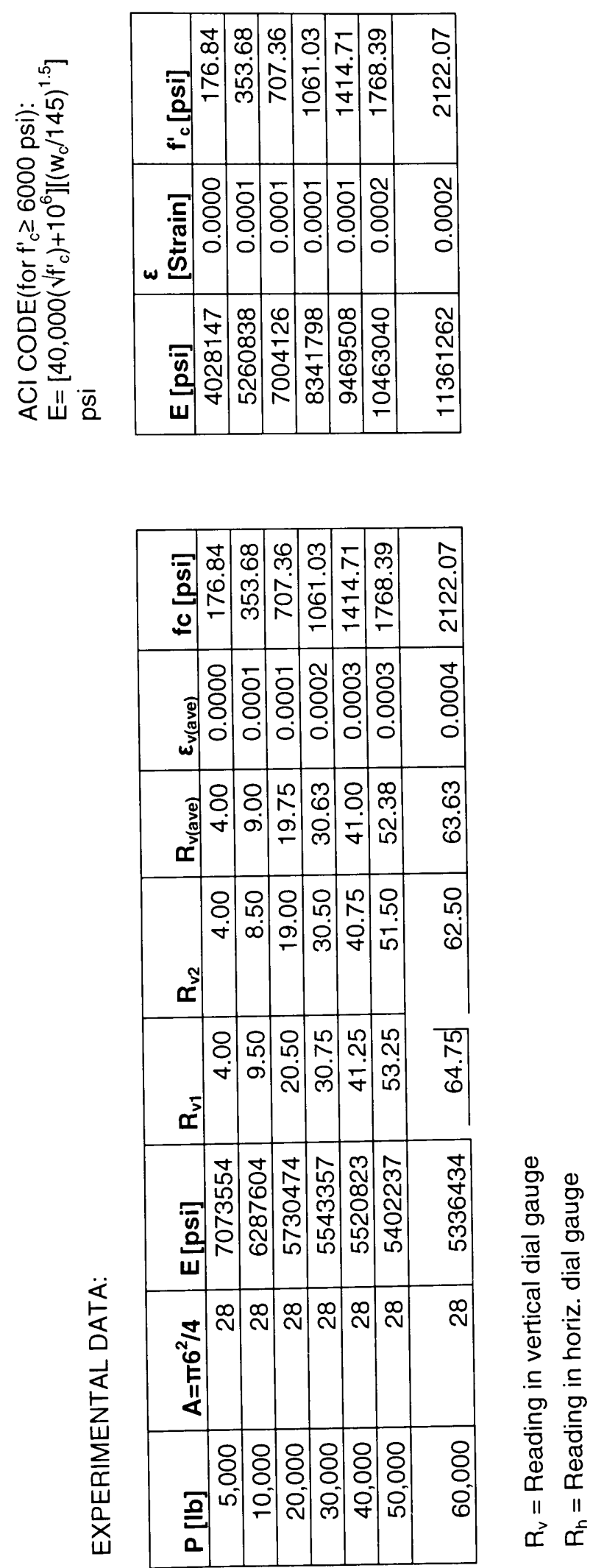


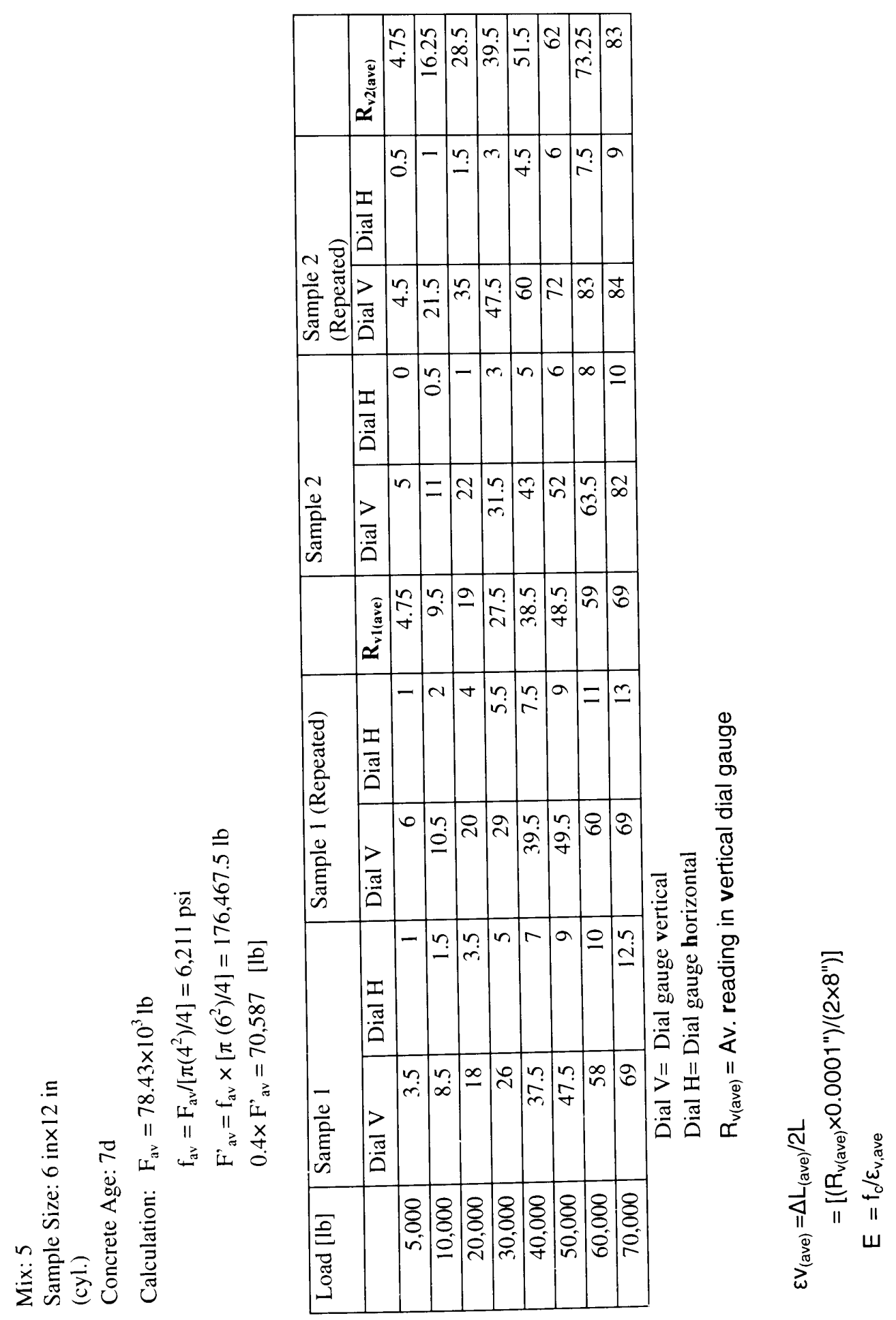



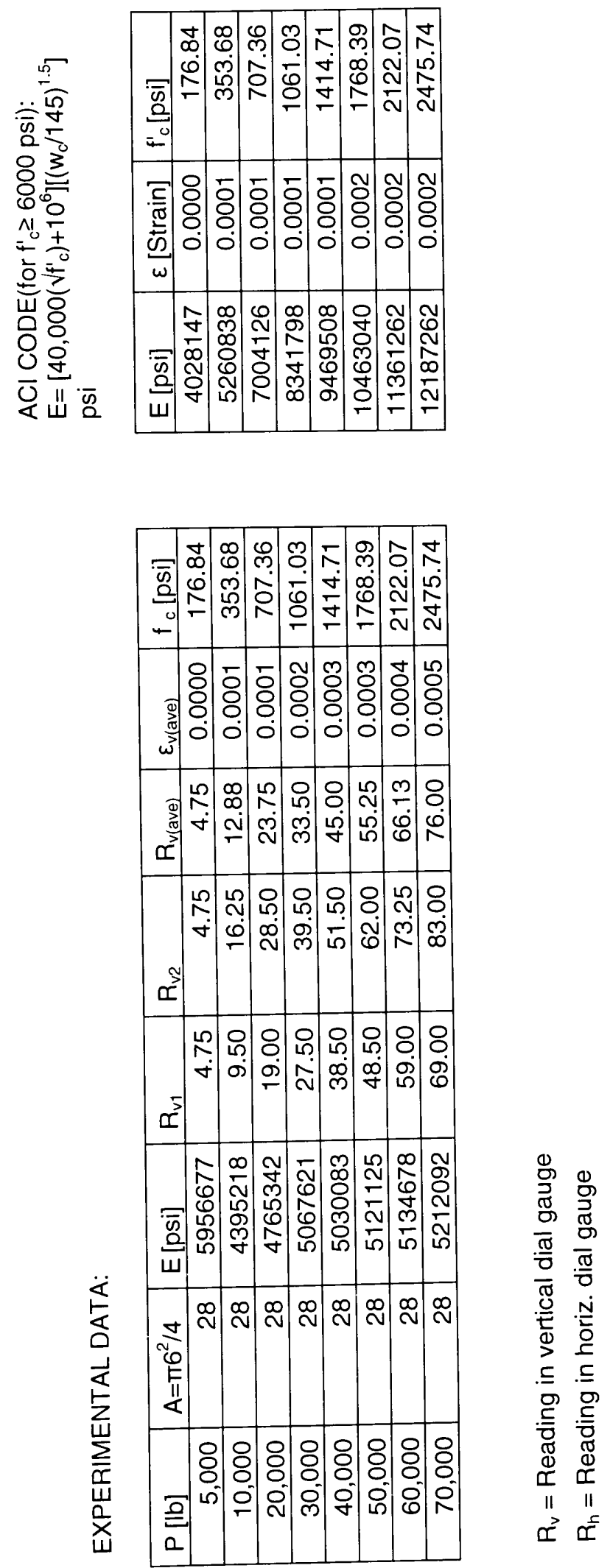


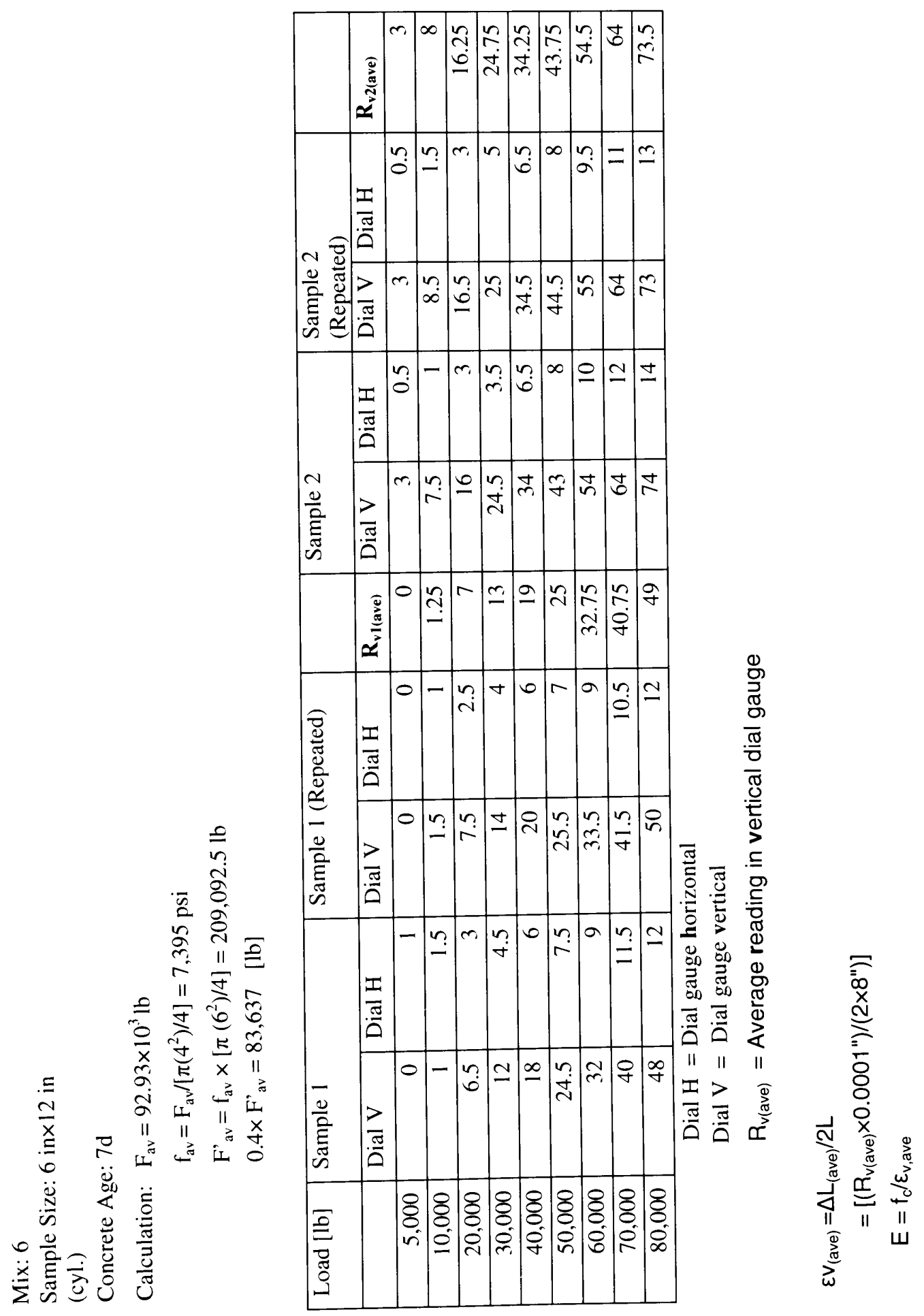



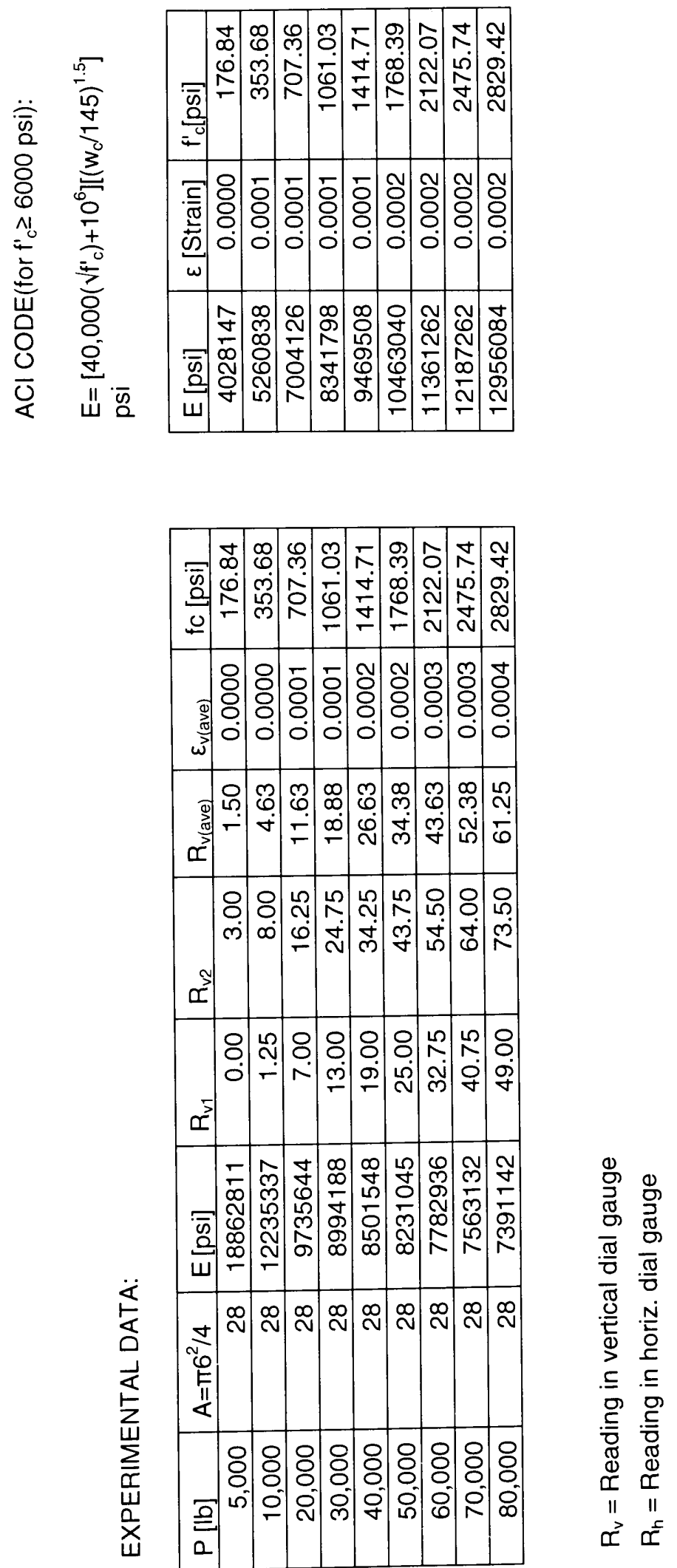


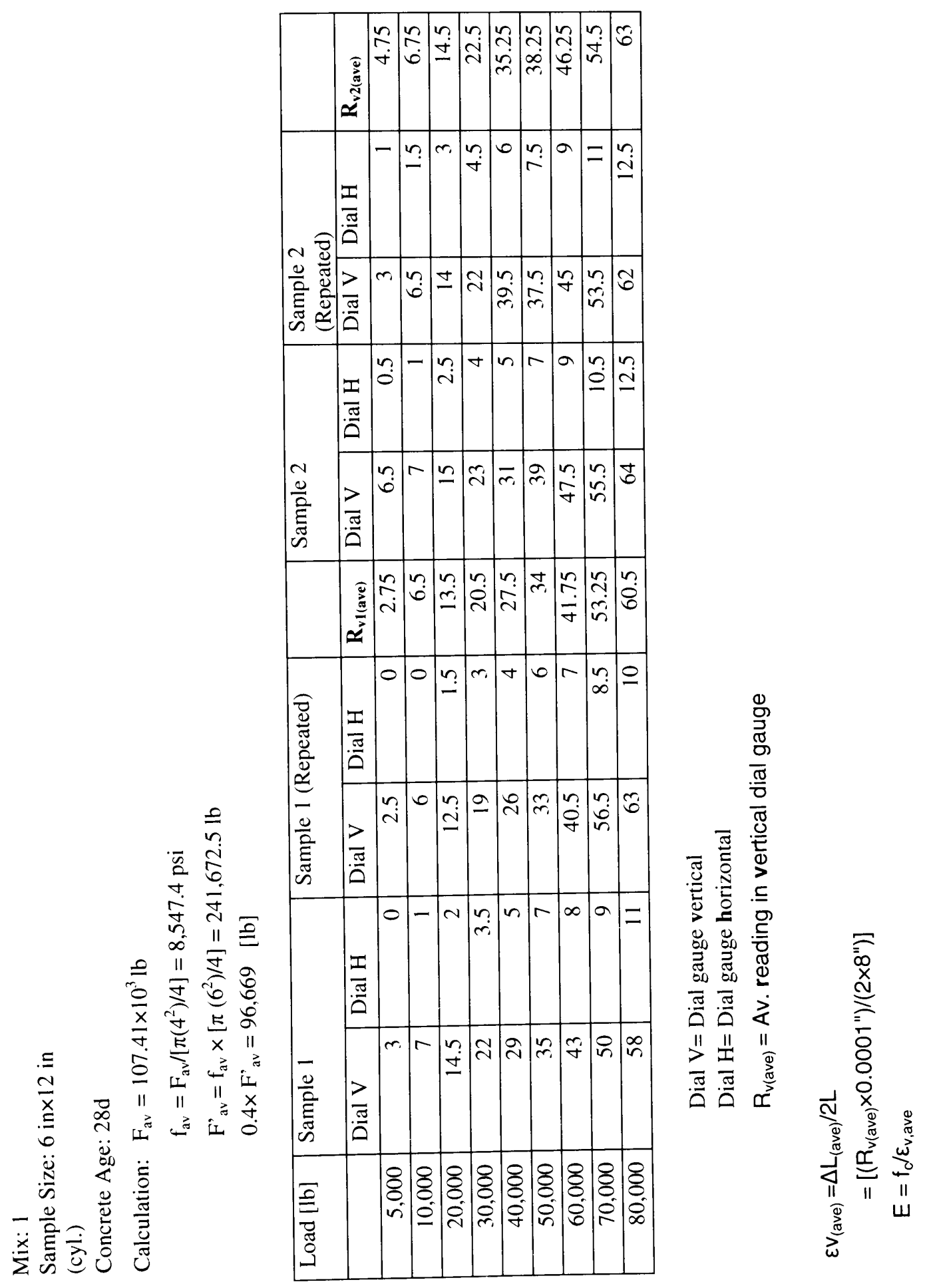



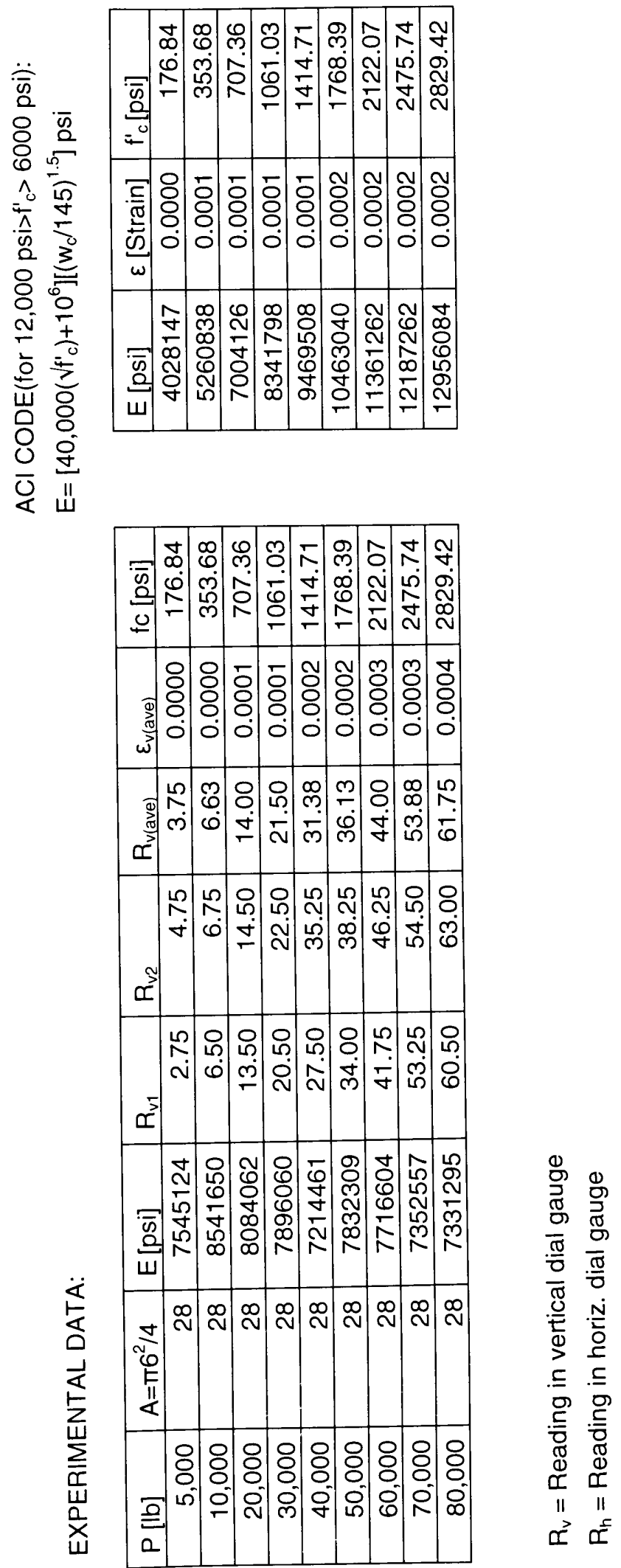


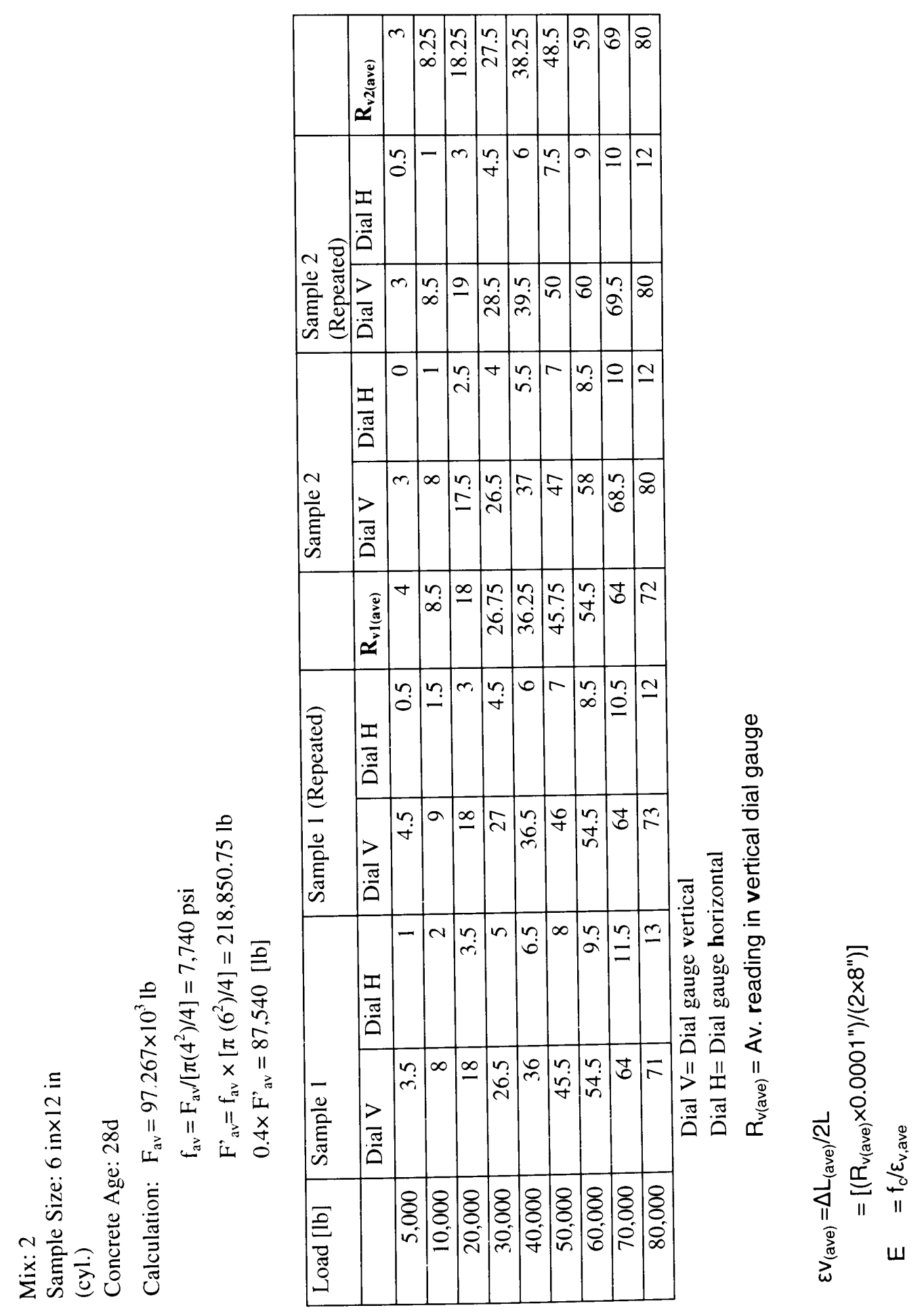



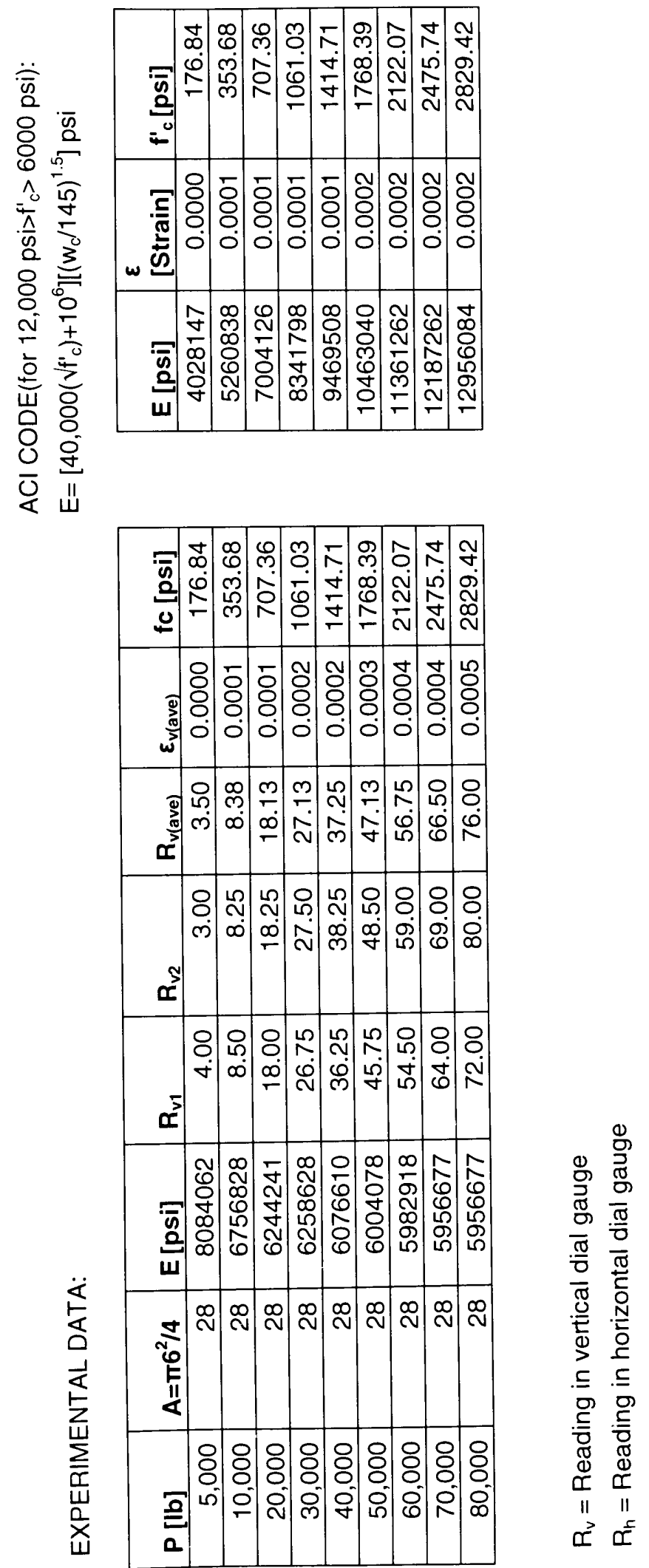


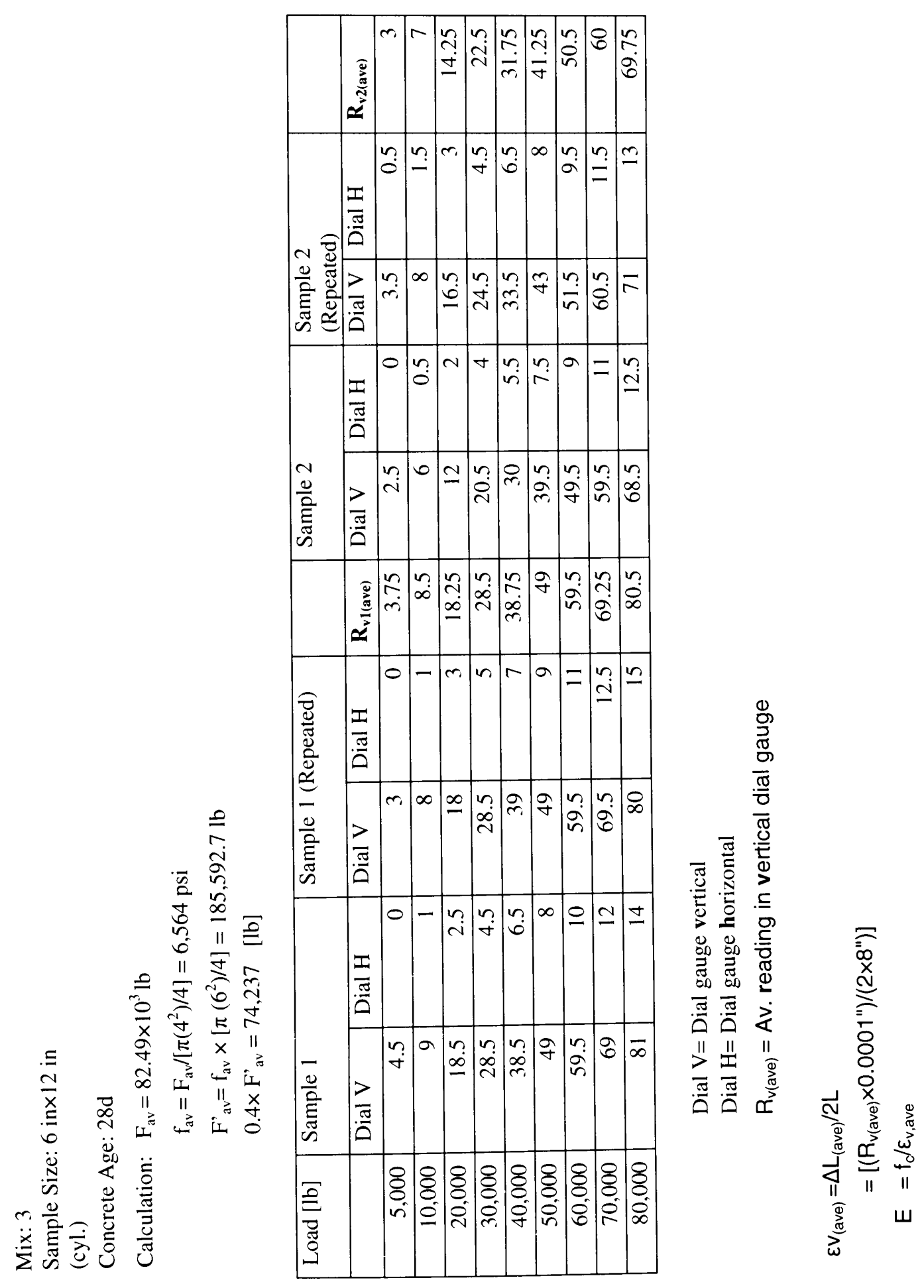



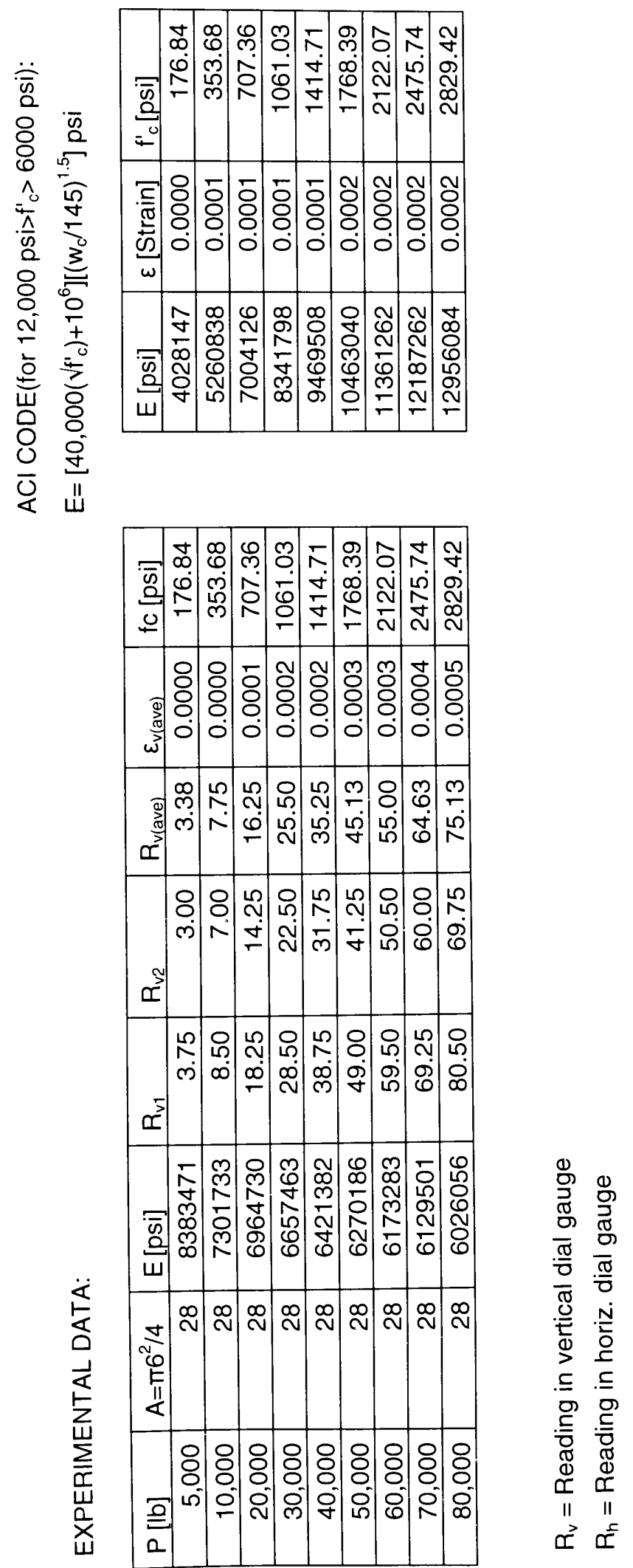


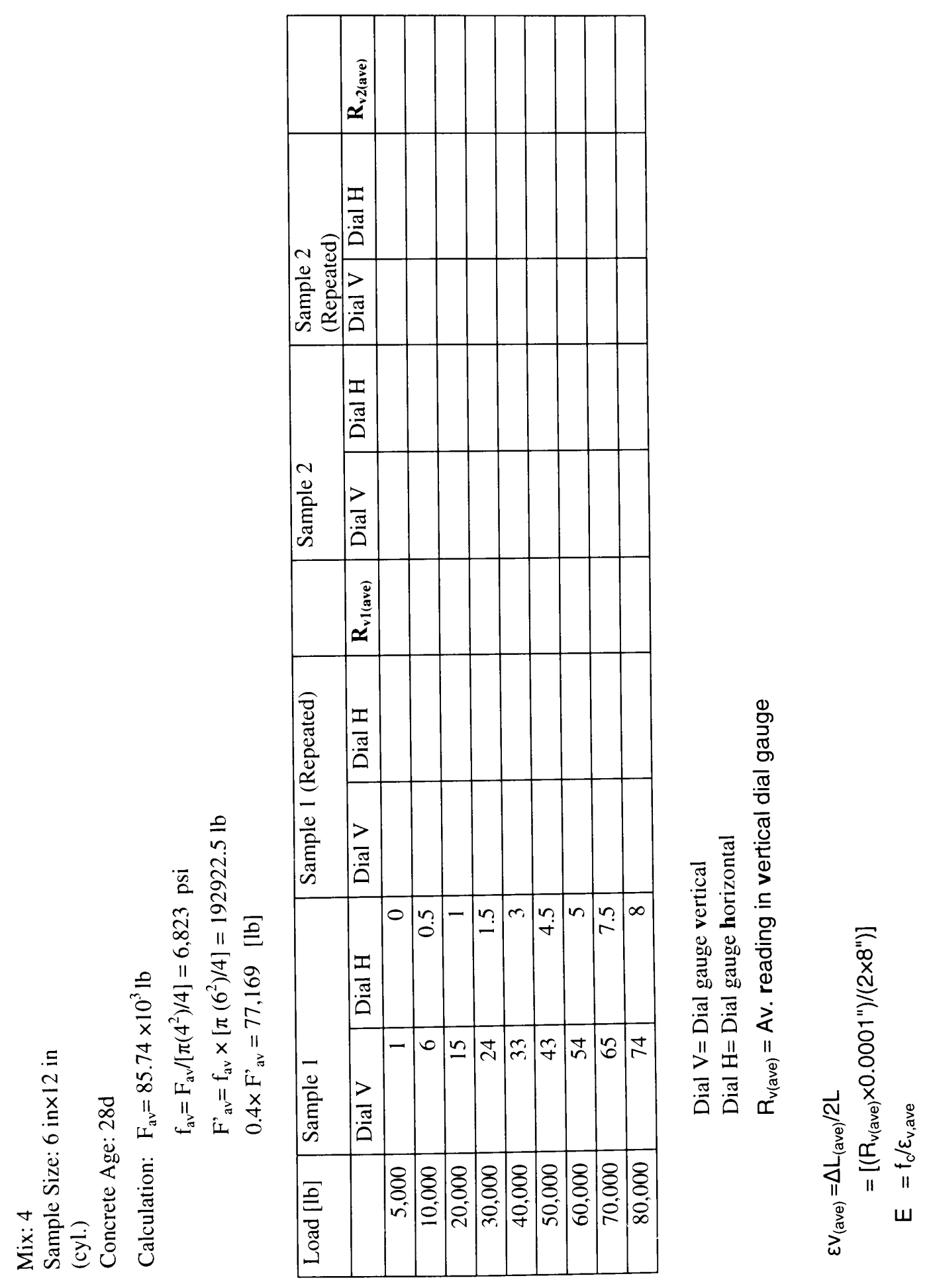



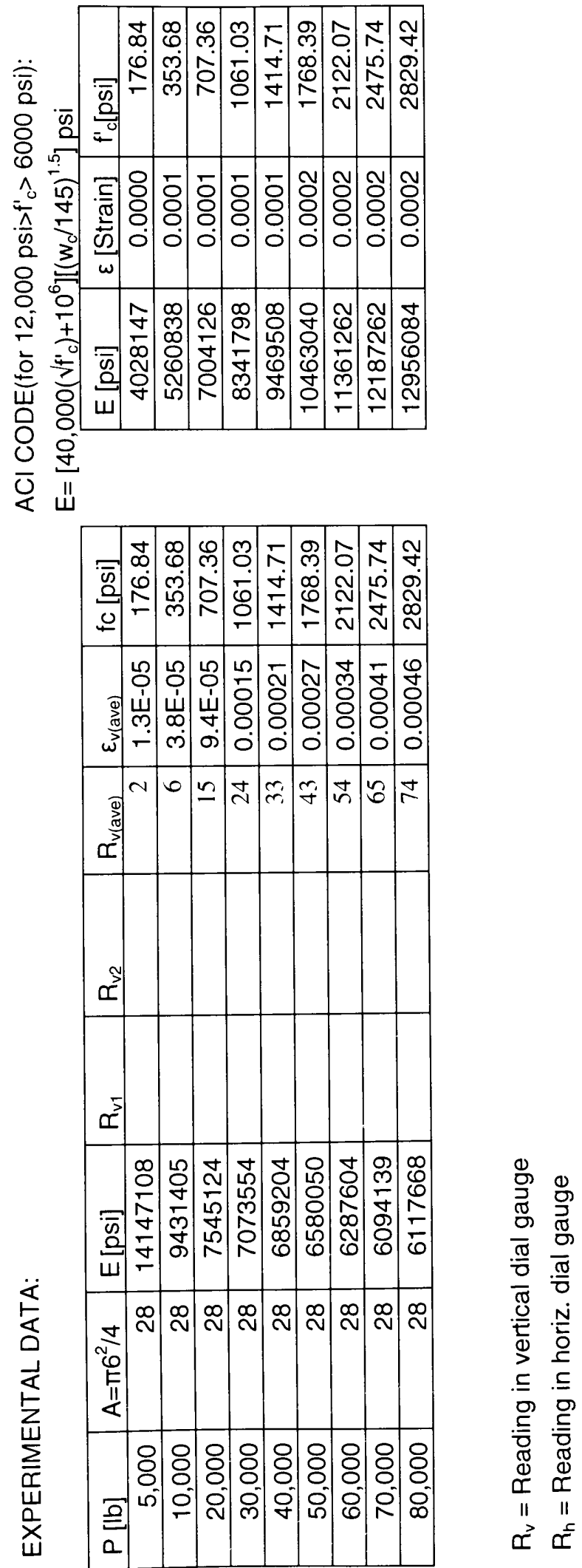


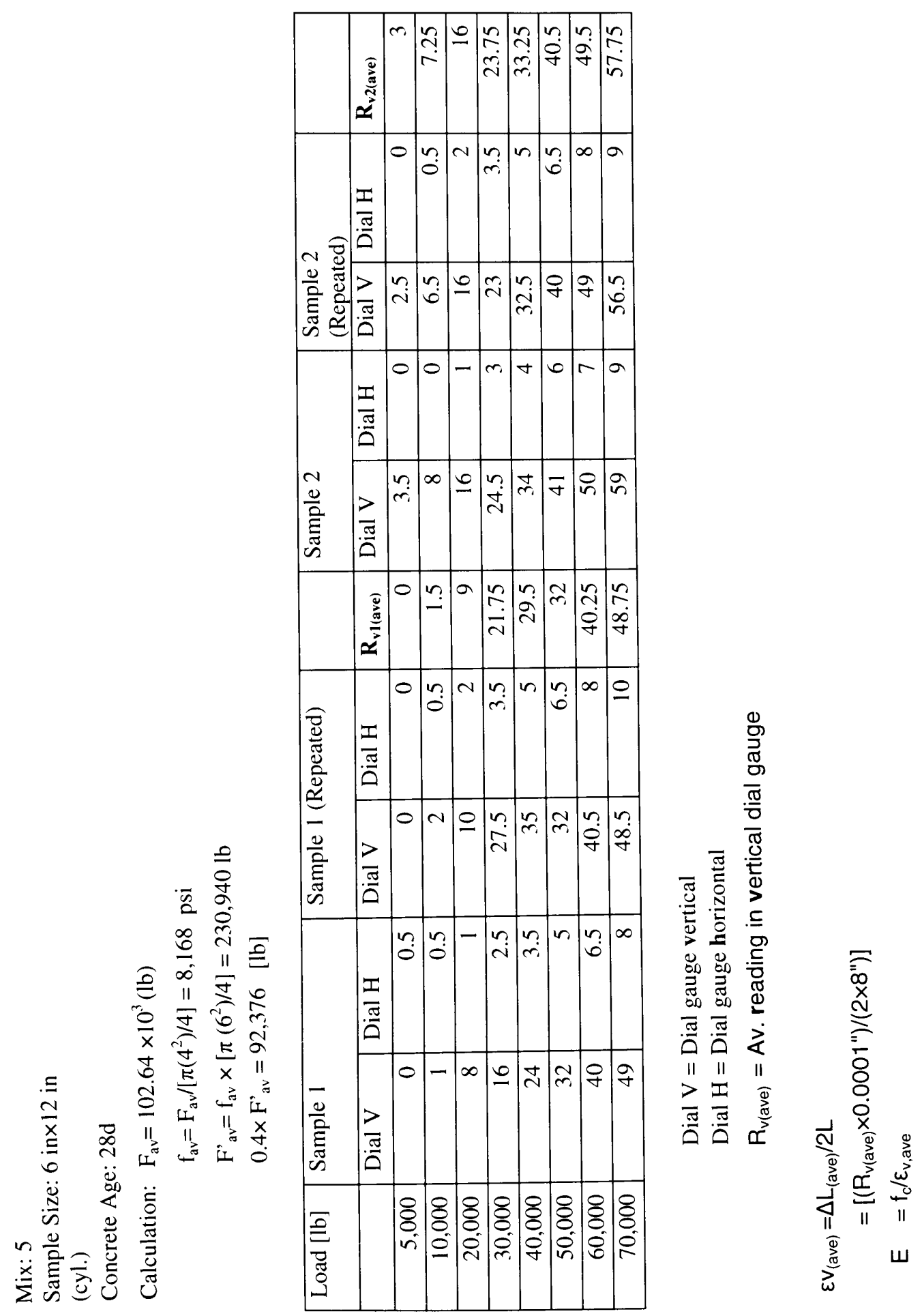



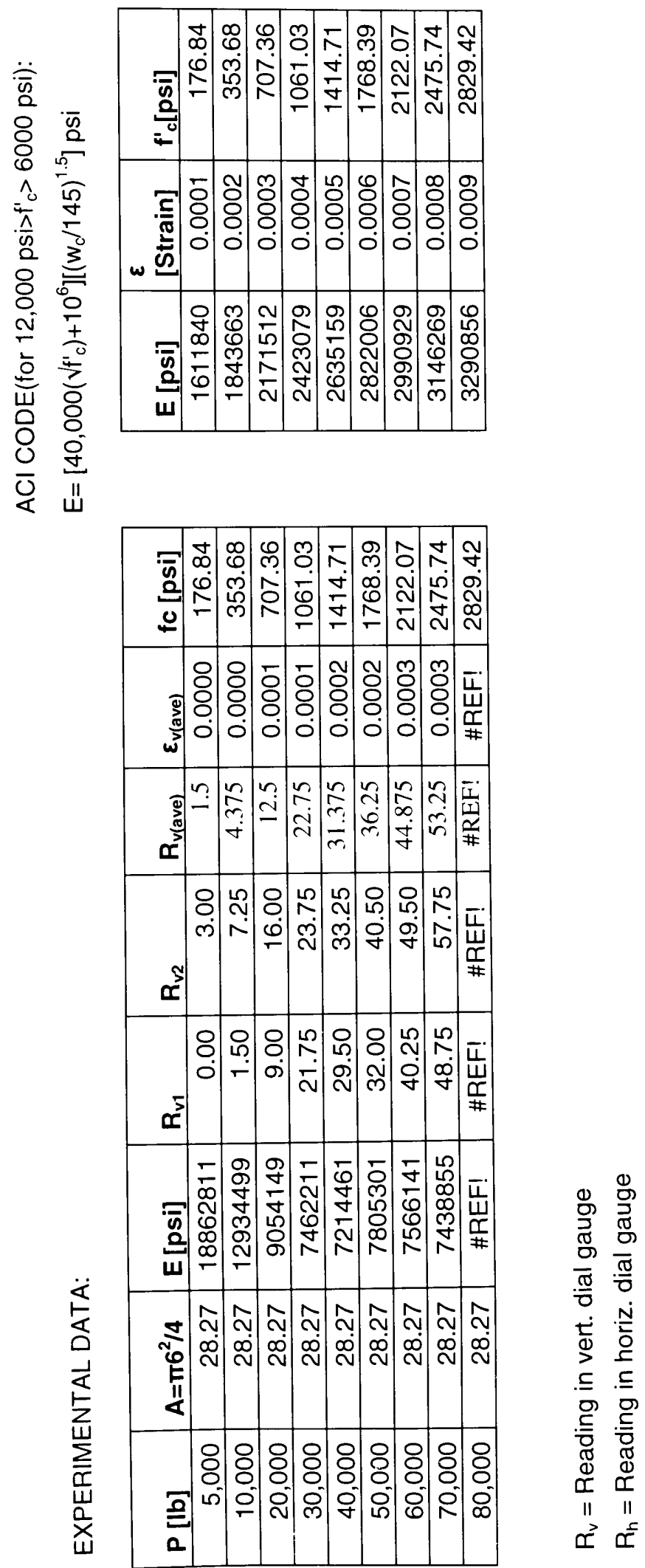


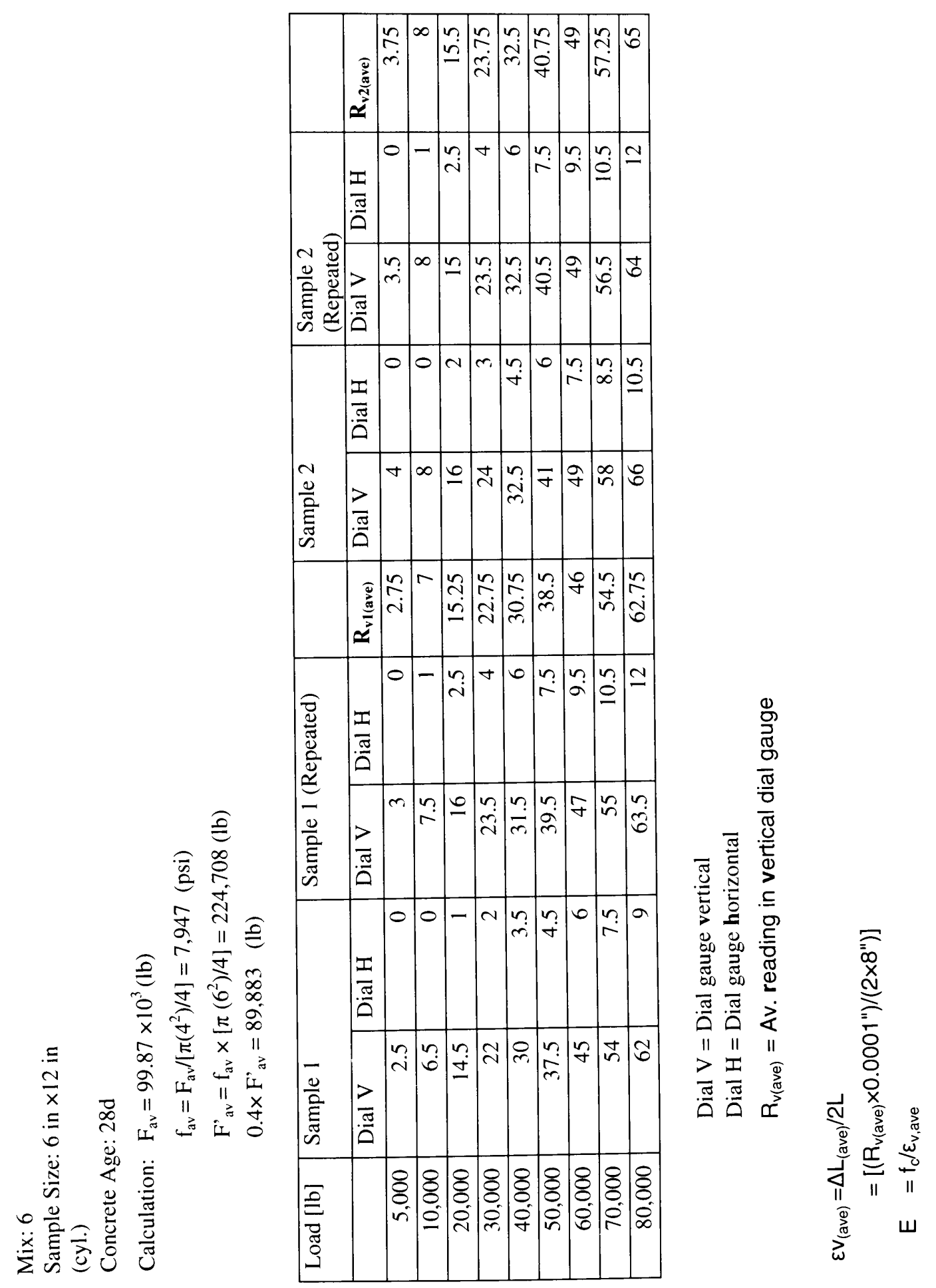



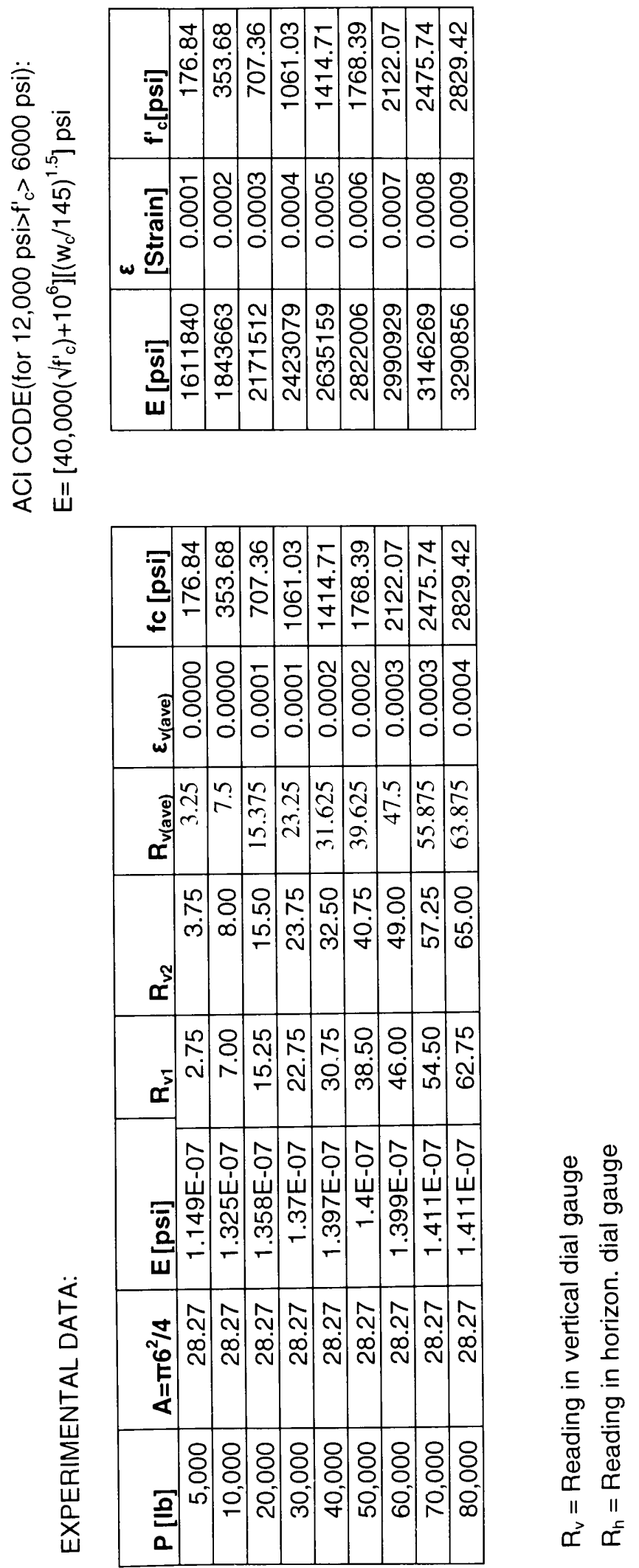
Table 5.4 Drying Shrinkage Test Results

Mix: 1

\begin{tabular}{|r|r|r|r|r|r|r|}
\hline \multicolumn{1}{|l|}{ Date } & Sample 1 & \multicolumn{1}{l|}{ Rod 1 } & Sample 2 & \multicolumn{1}{l|}{ Rod 2 } & \multicolumn{1}{l|}{ Sample 3 } & \multicolumn{1}{l|}{ Rod 3 } \\
\hline 29-Jan & 0.2243 & 0.1406 & 0.1618 & 0.1406 & 0.1781 & 0.1405 \\
\hline 1-Feb & 0.2263 & 0.1437 & 0.1708 & 0.1506 & 0.1894 & 0.1529 \\
\hline 5-Feb & 0.1671 & 0.0848 & 0.1043 & 0.085 & 0.1206 & 0.0847 \\
\hline 12-Feb & 0.1673 & 0.0852 & 0.1044 & 0.0856 & 0.1208 & 0.0862 \\
\hline & 0.1681 & 0.086 & 0.104 & 0.0851 & 0.1215 & 0.0858 \\
\hline 19-Feb & 0.1686 & 0.0871 & 0.1042 & 0.0858 & 0.1215 & 0.0867 \\
\hline & 0.1674 & 0.0869 & 0.1043 & 0.0866 & 0.1205 & 0.0864 \\
\hline 26-Feb & 0.165 & 0.0843 & 0.102 & 0.0841 & 0.1182 & 0.0844 \\
\hline & 0.1648 & 0.0841 & 0.1017 & 0.0843 & 0.1189 & 0.0842 \\
\hline 28-Apr & 0.1471 & 0.0682 & 0.0849 & 0.0682 & 0.1012 & 0.0682 \\
\hline & 0.1471 & 0.0682 & 0.0849 & 0.0682 & 0.1012 & 0.0682 \\
\hline
\end{tabular}

\begin{tabular}{|r|r|r|r|r|c|}
\hline Time (days) & Sample 1 & Sample 2 & Sample 3 & Av. Value & $\%$ Drying Shrinkage \\
\hline 0 & 0.0837 & 0.0212 & 0.0376 & 0.0475 & 0 \\
\hline 3 & 0.0826 & 0.0202 & 0.0365 & 0.0464 & 2.2 \\
\hline 7 & 0.0823 & 0.0193 & 0.0359 & 0.0458 & 3.5 \\
\hline 14 & 0.0821 & 0.0189 & 0.0352 & 0.0454 & 4.5 \\
\hline 21 & 0.0810 & 0.0181 & 0.0345 & 0.0445 & 6.3 \\
\hline 28 & 0.0807 & 0.0177 & 0.0343 & 0.0442 & 6.9 \\
\hline 90 & 0.0789 & 0.0167 & 0.0330 & 0.0429 & 9.8 \\
\hline
\end{tabular}

Mix : 2

\begin{tabular}{|r|r|r|r|r|r|r|}
\hline Date & Sample 1 & \multicolumn{1}{l|}{ Rod 1 } & Sample 2 & Rod 2 & Sample 3 & \multicolumn{1}{l|}{ Rod 3 } \\
\hline 31-Jan & 0.2407 & 0.1403 & 0.138 & 0.1547 & 0.2315 & 0.1577 \\
\hline 3-Feb & & & & & & \\
\hline 7-Feb & 0.1844 & 0.0859 & 0.0664 & 0.0857 & 0.1579 & 0.0857 \\
\hline & 0.1842 & 0.0857 & 0.0663 & 0.0857 & 0.1578 & 0.0856 \\
\hline 14-Feb & 0.1847 & 0.0864 & 0.0658 & 0.0862 & 0.1576 & 0.0862 \\
\hline & 0.1836 & 0.086 & 0.0665 & 0.0858 & 0.1577 & 0.086 \\
\hline 21-Feb & 0.1835 & 0.0865 & 0.0654 & 0.0864 & 0.1582 & 0.0866 \\
\hline & 0.1834 & 0.0864 & 0.0664 & 0.0866 & 0.1576 & 0.0863 \\
\hline 28-Feb & 0.1805 & 0.0849 & 0.0637 & 0.0846 & 0.1549 & 0.0845 \\
\hline & 0.1807 & 0.085 & 0.0638 & 0.0843 & 0.1554 & 0.0845 \\
\hline 30-Apr & 0.1633 & 0.0681 & 0.0464 & 0.0681 & 0.1378 & 0.0681 \\
\hline & 0.1633 & 0.0681 & 0.0464 & 0.0681 & 0.1378 & 0.0681 \\
\hline
\end{tabular}




\begin{tabular}{|r|r|r|r|r|r|}
\hline Time(days) & Sample 1 & Sample 2 & Sample 3 & Av. Value & $\%$ Drying Shrinkage \\
\hline 0 & 0.1004 & -0.0167 & 0.0738 & 0.0525 & 0 \\
\hline 3 & & & & & \\
\hline 7 & 0.0985 & -0.0194 & 0.0722 & 0.0505 & 3.9 \\
\hline 14 & 0.0980 & -0.0199 & 0.0716 & 0.0499 & 5.0 \\
\hline 21 & 0.0970 & -0.0206 & 0.0715 & 0.0493 & 6.1 \\
\hline 28 & 0.0957 & -0.0207 & 0.0707 & 0.0485 & 7.6 \\
\hline 90 & 0.0952 & -0.0217 & 0.0697 & 0.0477 & 9.1 \\
\hline
\end{tabular}

Mix: 3

\begin{tabular}{|r|r|r|r|r|r|r|}
\hline \multicolumn{1}{|l|}{ Date } & \multicolumn{1}{|l|}{ Sample 1 } & \multicolumn{1}{l|}{ Rod 1 } & \multicolumn{1}{l|}{ Sample 2 } & Rod 2 & \multicolumn{1}{l|}{ Sample 3 } & \multicolumn{1}{l|}{ Rod 3 } \\
\hline 2-Feb & 0.1923 & 0.1467 & 0.2293 & 0.1512 & 0.1938 & 0.1444 \\
\hline 5-Feb & 0.1283 & 0.0849 & 0.1622 & 0.0847 & 0.1335 & 0.0852 \\
\hline 9-Feb & 0.1287 & 0.086 & 0.1618 & 0.0854 & 0.1335 & 0.0855 \\
\hline & 0.1288 & 0.0856 & 0.1623 & 0.0855 & 0.1334 & 0.0854 \\
\hline 16-Feb & 0.1283 & 0.0872 & 0.1615 & 0.086 & 0.1334 & 0.0866 \\
\hline & 0.1285 & 0.0867 & 0.1623 & 0.0858 & 0.1341 & 0.0865 \\
\hline 23-Feb & 0.1278 & 0.0857 & 0.1607 & 0.0856 & 0.1321 & 0.0854 \\
\hline & 0.1272 & 0.0866 & 0.1605 & 0.0858 & 0.1311 & 0.0855 \\
\hline 1-Mar & 0.1264 & 0.0854 & 0.1594 & 0.0845 & 0.1301 & 0.0844 \\
\hline & 0.126 & 0.0851 & 0.1591 & 0.0844 & 0.13 & 0.0835 \\
\hline 2-May & 0.1077 & 0.0682 & 0.1414 & 0.0682 & 0.1127 & 0.0682 \\
\hline & 0.1077 & 0.0682 & 0.1414 & 0.0682 & 0.1127 & 0.0682 \\
\hline
\end{tabular}

\begin{tabular}{|r|r|r|r|r|c|}
\hline Time (days) & Sample 1 & Sample 2 & Sample 3 & Av. Value & \% Drying Shrinkage \\
\hline 0 & 0.0456 & 0.0781 & 0.0494 & 0.0577 & 0.0 \\
\hline 3 & 0.0434 & 0.0775 & 0.0483 & 0.0564 & 2.3 \\
\hline 7 & 0.0430 & 0.0766 & 0.0480 & 0.0559 & 3.2 \\
\hline 14 & 0.0415 & 0.0760 & 0.0472 & 0.0549 & 4.9 \\
\hline 21 & 0.0414 & 0.0749 & 0.0462 & 0.0541 & 6.2 \\
\hline 28 & 0.0410 & 0.0748 & 0.0461 & 0.0540 & 6.5 \\
\hline 90 & 0.0395 & 0.0732 & 0.0445 & 0.0524 & 9.2 \\
\hline
\end{tabular}


Mix : 4

\begin{tabular}{|r|r|r|r|r|r|r|}
\hline \multicolumn{1}{|l|}{ Date } & \multicolumn{1}{|l|}{ Sample 1 } & \multicolumn{1}{l|}{ Rod 1 } & Sample 2 & Rod 2 & Sample 3 & Rod 3 \\
\hline 6-Feb & 0.1546 & 0.0855 & 0.0612 & 0.0854 & 0.1521 & 0.0853 \\
\hline 9-Feb & 0.1537 & 0.0856 & 0.0611 & 0.0854 & 0.1506 & 0.0851 \\
\hline & 0.1531 & 0.0848 & 0.0605 & 0.0856 & 0.1514 & 0.0853 \\
\hline 13-Feb & 0.1519 & 0.084 & 0.0589 & 0.0849 & 0.1498 & 0.0852 \\
\hline & 0.1519 & 0.0843 & 0.0587 & 0.0855 & 0.1497 & 0.0849 \\
\hline 20-Feb & 0.1538 & 0.0874 & 0.0594 & 0.0869 & 0.1508 & 0.0868 \\
\hline & 0.1536 & 0.0872 & 0.0602 & 0.0869 & 0.1499 & 0.0862 \\
\hline 27-Feb & & & & & & \\
\hline & & & & & & \\
\hline 5-Mar & 0.1504 & 0.0844 & 0.0566 & 0.0845 & 0.1477 & 0.0844 \\
\hline & 0.1506 & 0.0846 & 0.057 & 0.0845 & 0.1467 & 0.0842 \\
\hline 6-May & 0.1329 & 0.0682 & 0.0391 & 0.0682 & 0.1298 & 0.0682 \\
\hline & 0.1329 & 0.0682 & 0.0391 & 0.0682 & 0.1298 & 0.0682 \\
\hline
\end{tabular}

\begin{tabular}{|r|r|r|r|r|r|}
\hline Time(days) & Sample 1 & Sample 2 & Sample 3 & Av. Value & $\%$ Drying Shrinkage \\
\hline 0 & 0.0691 & -0.0242 & 0.0668 & 0.0372 & 0 \\
\hline 3 & 0.0682 & -0.0247 & 0.0658 & 0.0364 & 2.1 \\
\hline 7 & 0.0678 & -0.0264 & 0.0647 & 0.0354 & 5.1 \\
\hline 14 & 0.0664 & -0.0271 & 0.0639 & 0.0344 & 7.7 \\
\hline 21 & & & & & \\
\hline 28 & 0.0660 & -0.0277 & 0.0629 & 0.0337 & 9.4 \\
\hline 90 & 0.0647 & -0.0291 & 0.0616 & 0.0324 & 13.0 \\
\hline
\end{tabular}

Mix : 5

\begin{tabular}{|c|c|c|c|c|c|c|}
\hline Date & Sample 1 & Rod 1 & Sample 2 & Rod 2 & Sample 3 & Rod 3 \\
\hline \multirow[t]{2}{*}{ 11-Feb } & 0.1409 & 0.0861 & 0.1306 & 0.0851 & 0.1413 & 0.0858 \\
\hline & 0.1412 & 0.0856 & 0.1306 & 0.0862 & 0.1415 & 0.0858 \\
\hline \multirow[t]{2}{*}{ 14-Feb } & 0.1406 & 0.0855 & 0.1299 & 0.0865 & 0.1405 & 0.0856 \\
\hline & 0.1408 & 0.0857 & 0.1301 & 0.0845 & 0.1415 & 0.0863 \\
\hline \multirow[t]{2}{*}{ 18-Feb } & 0.1411 & 0.0869 & 0.1307 & 0.0864 & 0.141 & 0.0865 \\
\hline & 0.1407 & 0.0859 & 0.1306 & 0.0867 & 0.1406 & 0.0866 \\
\hline \multirow[t]{2}{*}{$25-F e b$} & 0.137 & 0.0845 & 0.1276 & 0.0842 & 0.1367 & 0.084 \\
\hline & 0.1381 & 0.0833 & 0.1277 & 0.0842 & 0.1375 & 0.084 \\
\hline \multicolumn{7}{|l|}{ 3-Mar } \\
\hline & & & & & & \\
\hline \multirow[t]{2}{*}{ 10-Mar } & 0.0639 & 0.0121 & 0.0545 & 0.0116 & 0.0635 & 0.0117 \\
\hline & 0.0637 & 0.0119 & 0.054 & 0.0115 & 0.0643 & 0.0119 \\
\hline \multirow[t]{2}{*}{ 11-May } & 0.1199 & 0.0683 & 0.1096 & 0.0682 & 0.1199 & 0.0682 \\
\hline & 0.1199 & 0.0683 & 0.1096 & 0.0682 & 0.1199 & 0.0682 \\
\hline
\end{tabular}




\begin{tabular}{|r|r|r|r|r|r|}
\hline Time(days) & Sample 1 & \multicolumn{1}{|c|}{ Sample 2 } & Sample 3 & Av. Value & $\%$ Drying Shrinkage \\
\hline 0 & 0.0552 & 0.0450 & 0.0556 & 0.0519 & 0 \\
\hline 3 & 0.0551 & 0.0445 & 0.0551 & 0.0516 & 0.7 \\
\hline 7 & 0.0545 & 0.0441 & 0.0543 & 0.0510 & 1.9 \\
\hline 14 & 0.0537 & 0.0435 & 0.0531 & 0.0501 & 3.6 \\
\hline 21 & & & & & \\
\hline 28 & 0.0518 & 0.0427 & 0.0521 & 0.0489 & 5.9 \\
\hline 90 & 0.0516 & 0.0414 & 0.0517 & 0.0482 & 7.1 \\
\hline
\end{tabular}

Mix : 6

\begin{tabular}{|r|r|r|r|r|r|r|}
\hline Date & Sample 1 & \multicolumn{1}{|l|}{ Rod 1 } & Sample 2 & Rod 2 & Sample 3 & Rod 3 \\
\hline 14-Feb & 0.1162 & 0.0871 & 0.0731 & 0.0861 & 0.1579 & 0.0853 \\
\hline & 0.1159 & 0.0869 & 0.0723 & 0.0866 & 0.1585 & 0.0866 \\
\hline 17-Feb & 0.1149 & 0.0864 & 0.0719 & 0.0861 & 0.1566 & 0.0857 \\
\hline & 0.1149 & 0.0861 & 0.0721 & 0.0863 & 0.1567 & 0.0859 \\
\hline 21-Feb & 0.1149 & 0.0869 & 0.072 & 0.0862 & 0.1569 & 0.0864 \\
\hline & 0.1149 & 0.0864 & 0.072 & 0.0865 & 0.1564 & 0.0866 \\
\hline 28-Feb & 0.1122 & 0.0844 & 0.0699 & 0.0802 & 0.1548 & 0.0846 \\
\hline & 0.1121 & 0.0843 & 0.0699 & 0.0801 & 0.1543 & 0.0844 \\
\hline 6-Mar & 0.0401 & 0.0119 & 0.0002 & 0.0118 & 0.0813 & 0.0118 \\
\hline & 0.0392 & 0.012 & 0.0001 & 0.0116 & 0.0815 & 0.0117 \\
\hline 13-Mar & 0.0402 & 0.0126 & 0.0001 & 0.0157 & 0.0821 & 0.0125 \\
\hline & 0.0399 & 0.0129 & 0 & 0.0158 & 0.0822 & 0.0126 \\
\hline 14-May & 0.0946 & 0.0688 & 0.052 & 0.0688 & 0.1371 & 0.0689 \\
\hline & 0.0946 & 0.0688 & 0.052 & 0.0688 & 0.1371 & 0.0689 \\
\hline
\end{tabular}

\begin{tabular}{|r|r|r|r|r|c|}
\hline Time(days) & Sample 1 & Sample 2 & Sample 3 & Av. Value & \% Drying Shrinkage \\
\hline 0 & 0.0291 & -0.0137 & 0.0723 & 0.0292 & 0 \\
\hline 3 & 0.0287 & -0.0142 & 0.0709 & 0.0284 & 2.7 \\
\hline 7 & 0.0283 & -0.0144 & 0.0702 & 0.0280 & 4.1 \\
\hline 14 & 0.0278 & -0.0154 & 0.0701 & 0.0275 & 5.9 \\
\hline 21 & 0.0277 & -0.0157 & 0.0697 & 0.0272 & 6.8 \\
\hline 28 & 0.0273 & -0.0157 & 0.0696 & 0.0271 & 7.4 \\
\hline 90 & 0.0258 & -0.0168 & 0.0682 & 0.0257 & 11.9 \\
\hline
\end{tabular}




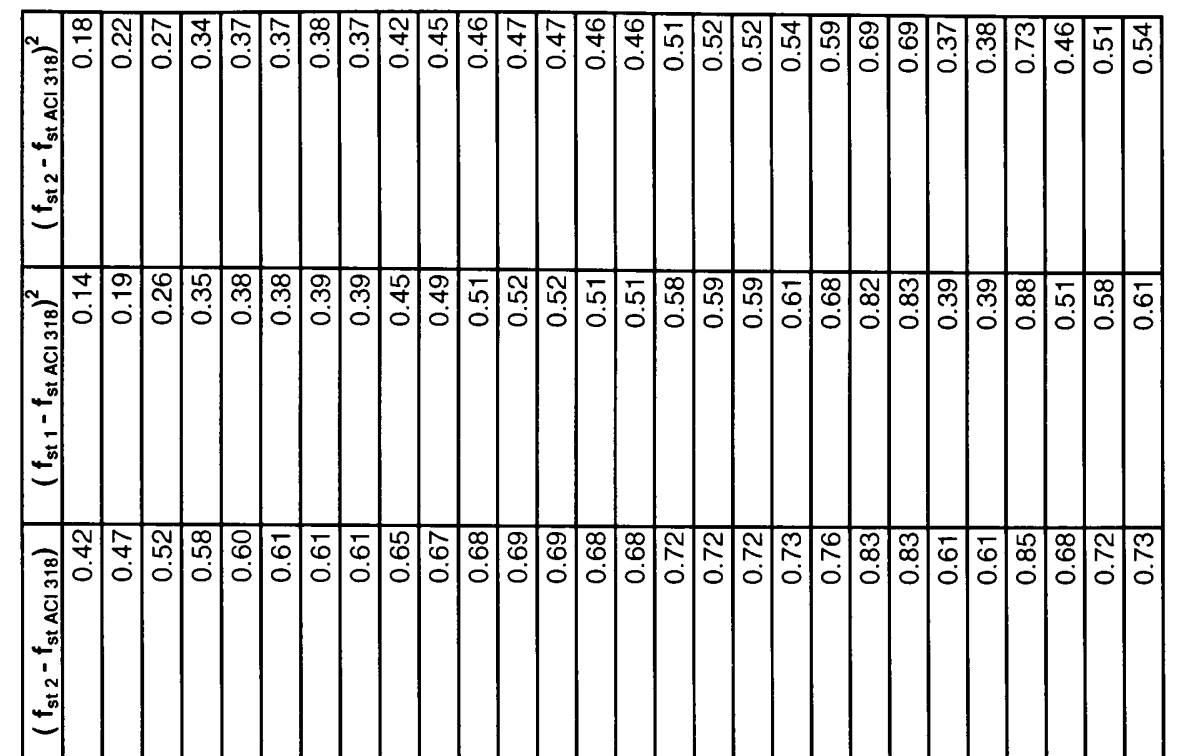

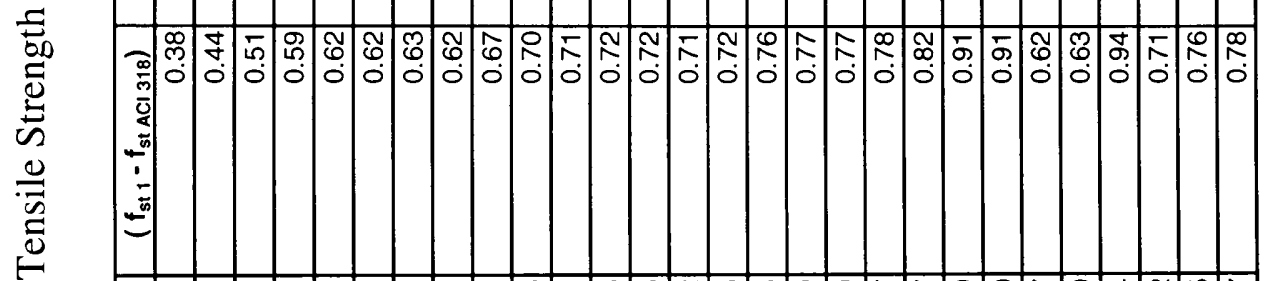

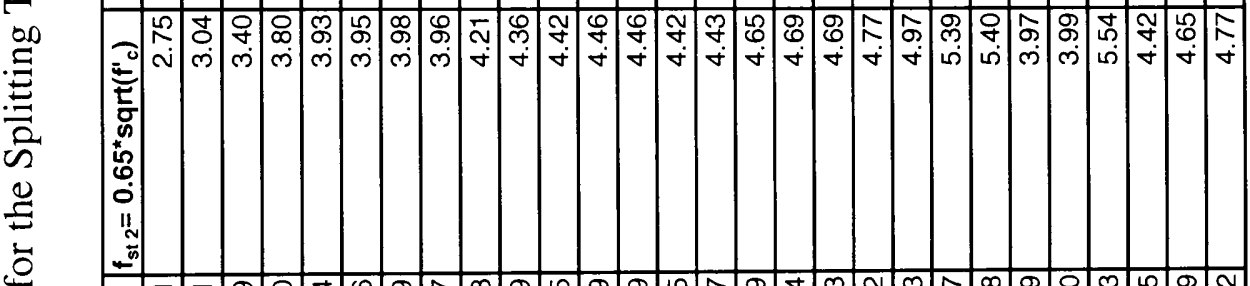

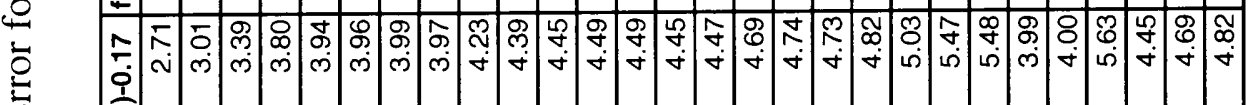

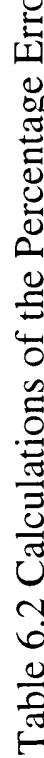

(1)

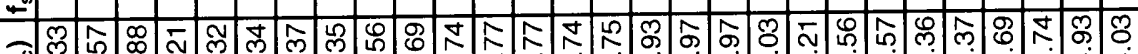
$=$ 시 N 约

草

10

लं

$\frac{\bar{a}}{\sum_{\bar{m}}^{\pi}}$

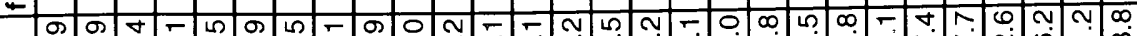
离

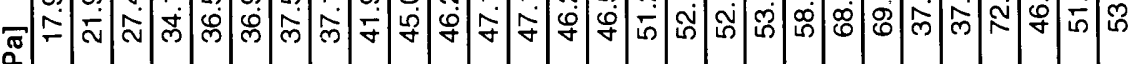




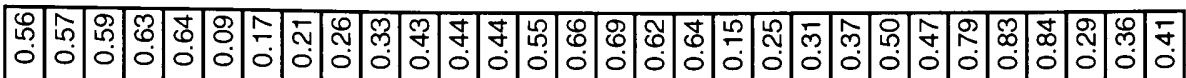

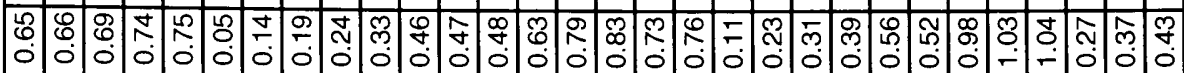

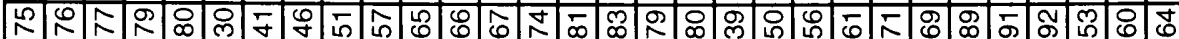

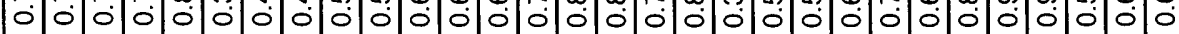

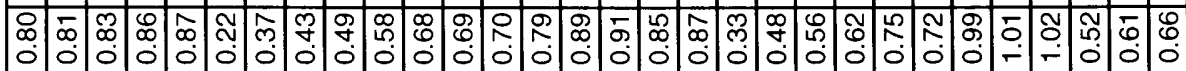

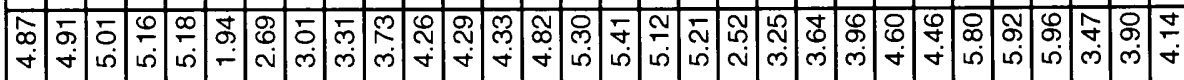

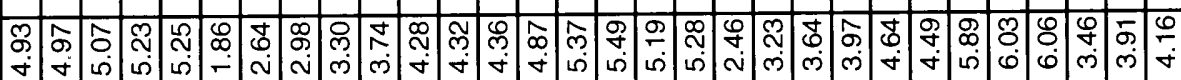

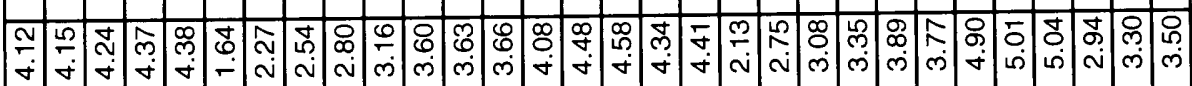

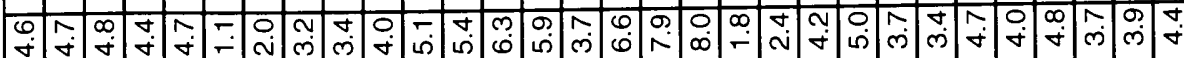

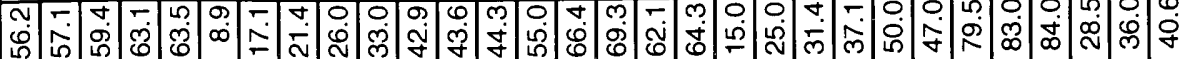




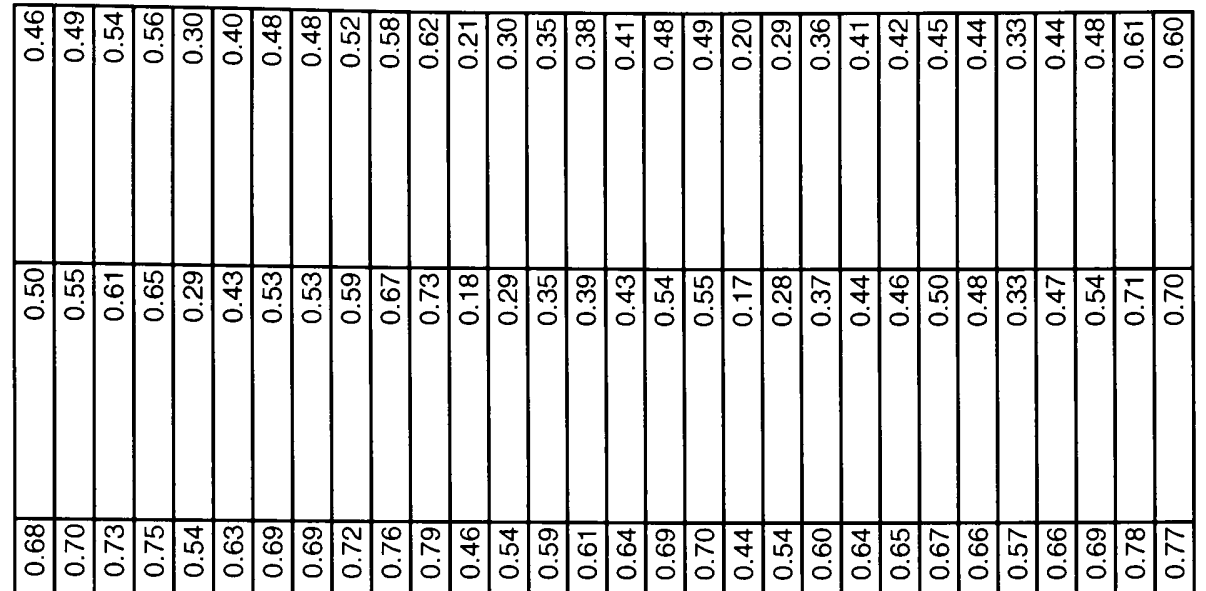

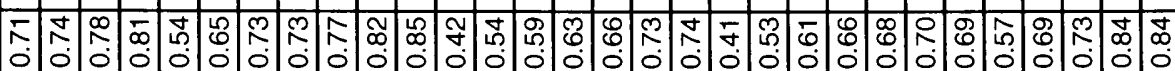

की

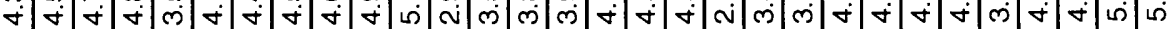

สำ

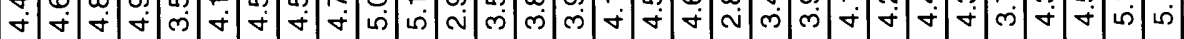

Гர்

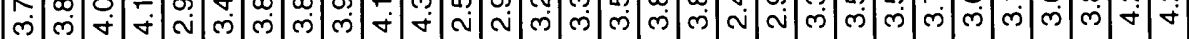

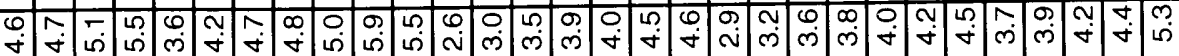

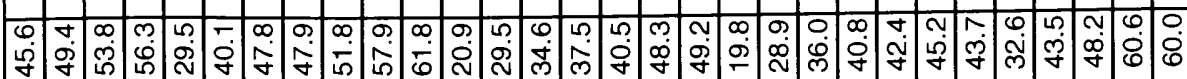

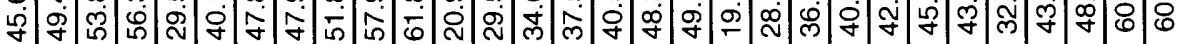




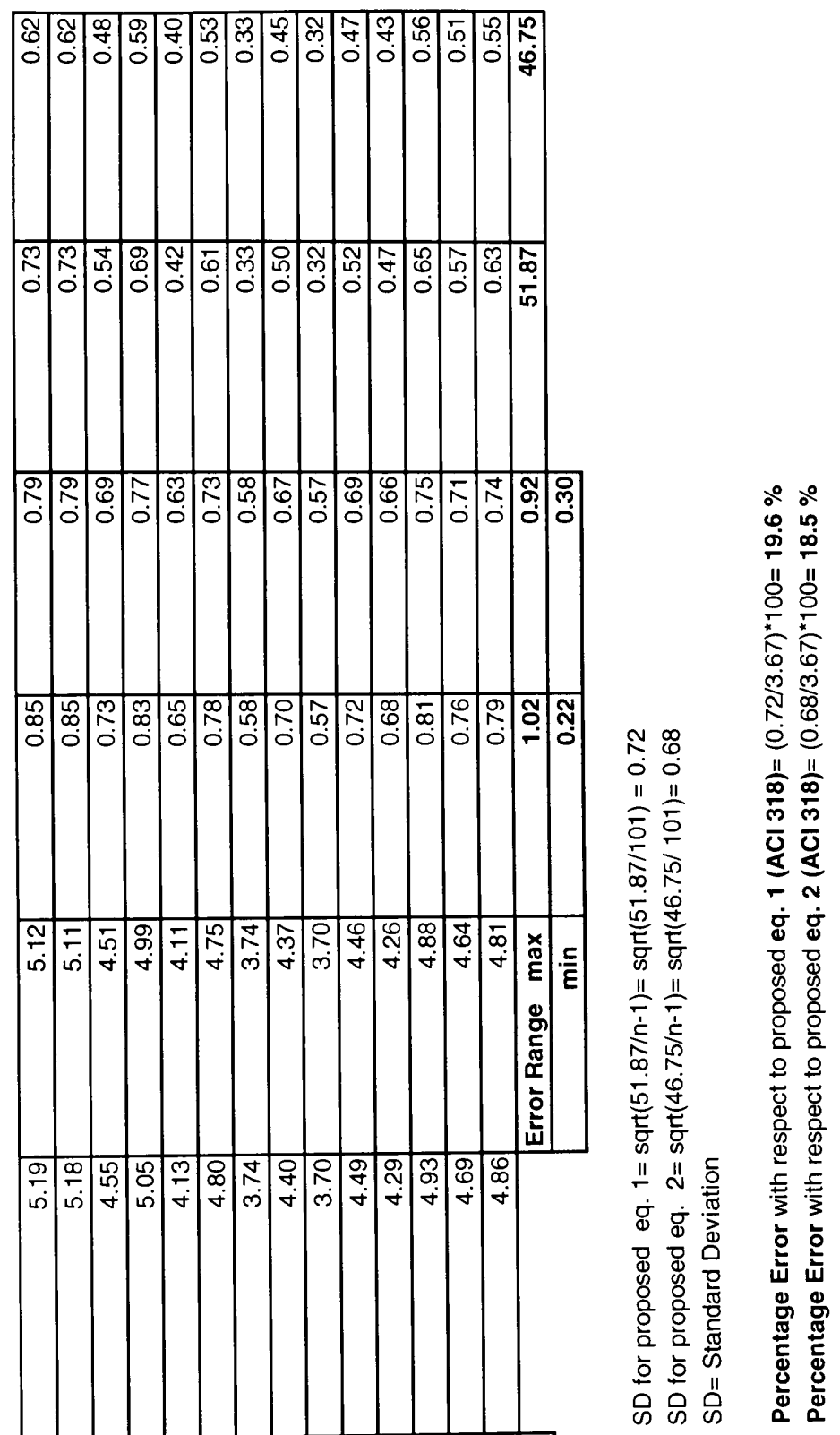

लำ

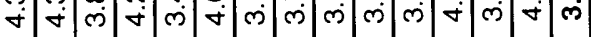

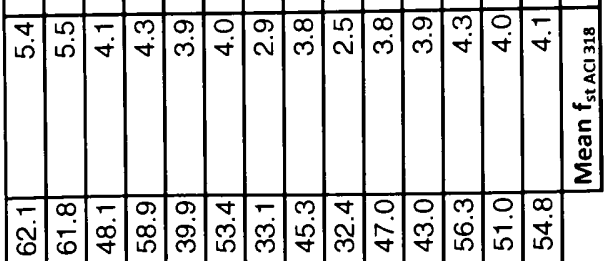




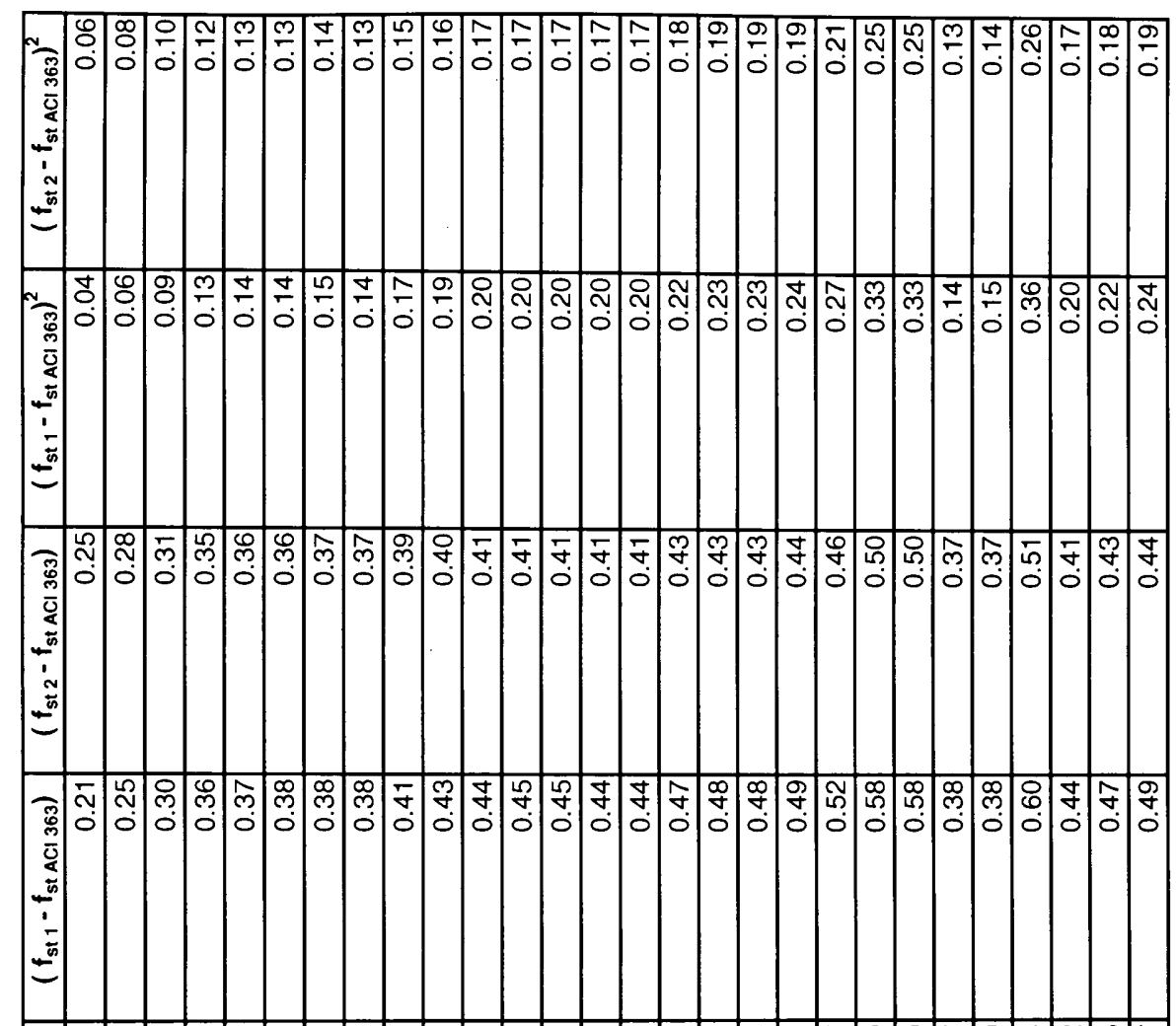

గొ

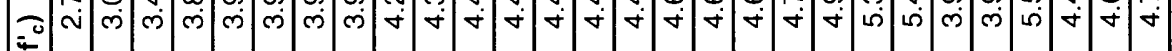

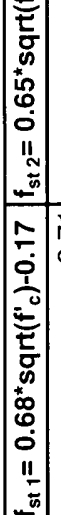

-

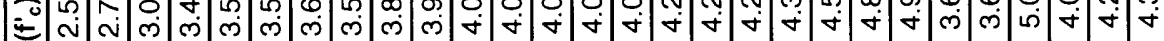
.

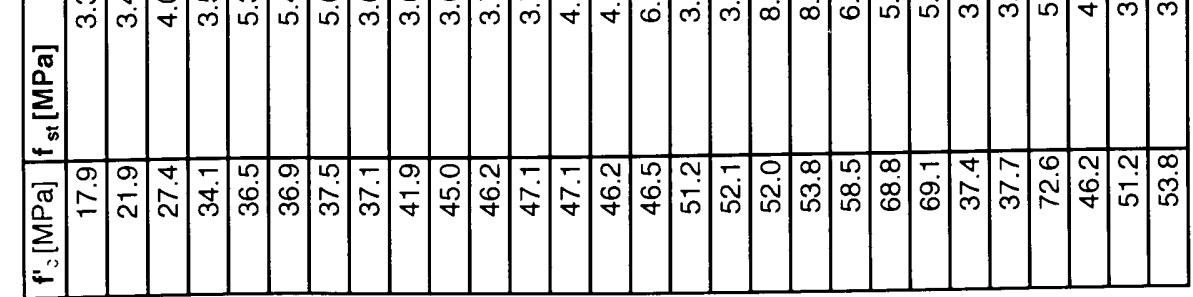




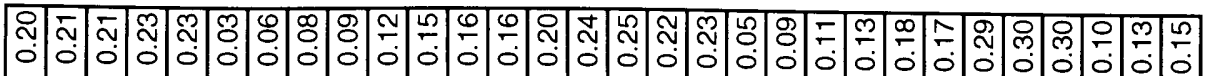

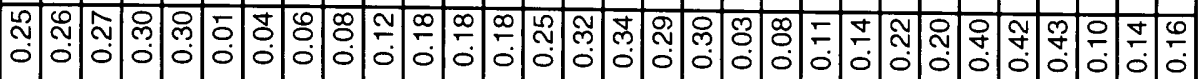

ケৃ

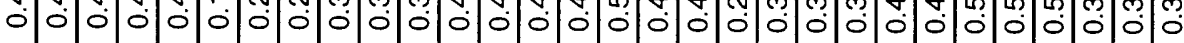

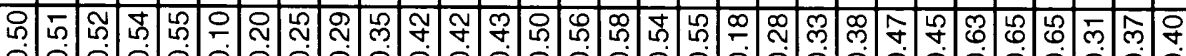

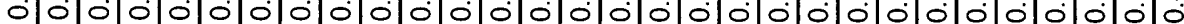

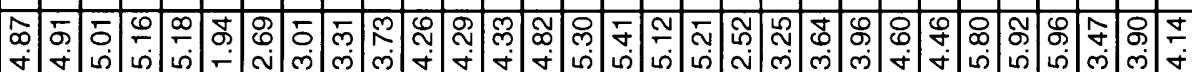

S. పे

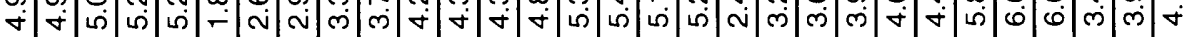

ๆण

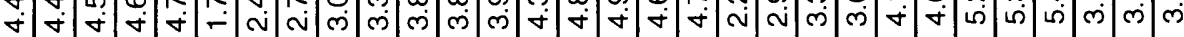

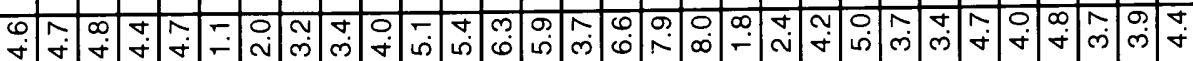

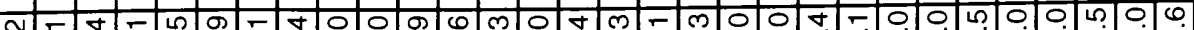
穴 


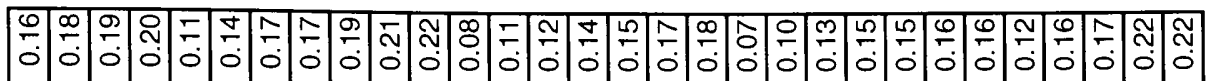

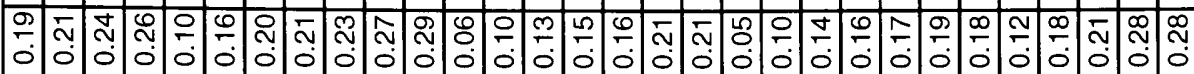

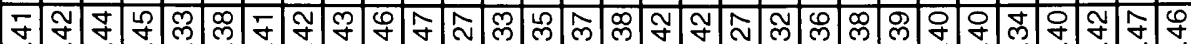

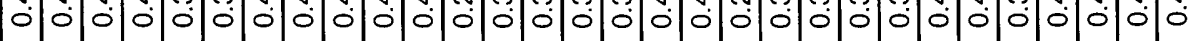

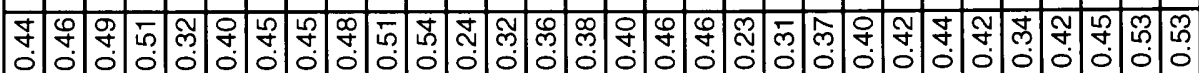

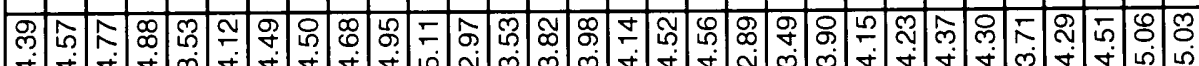

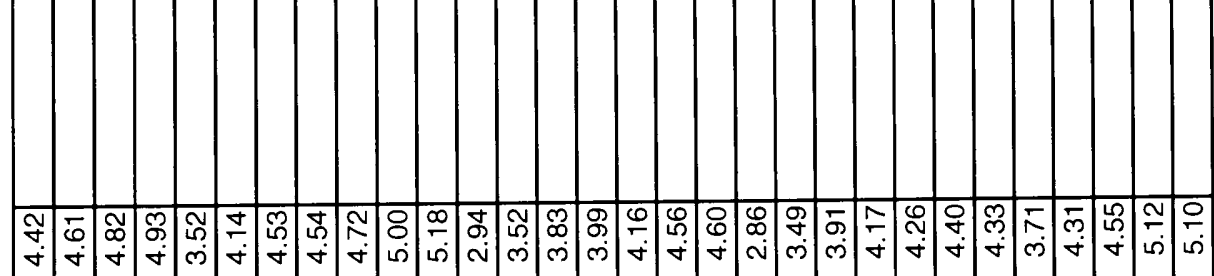

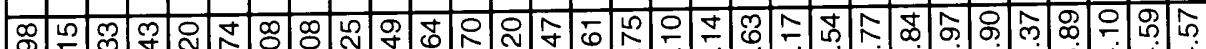

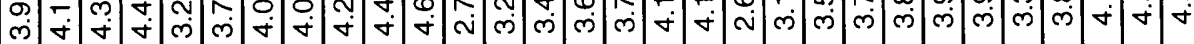

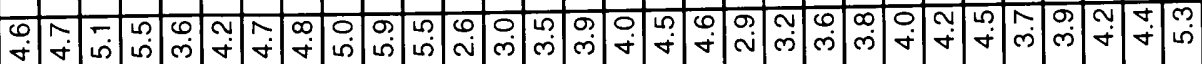

ம 守守 


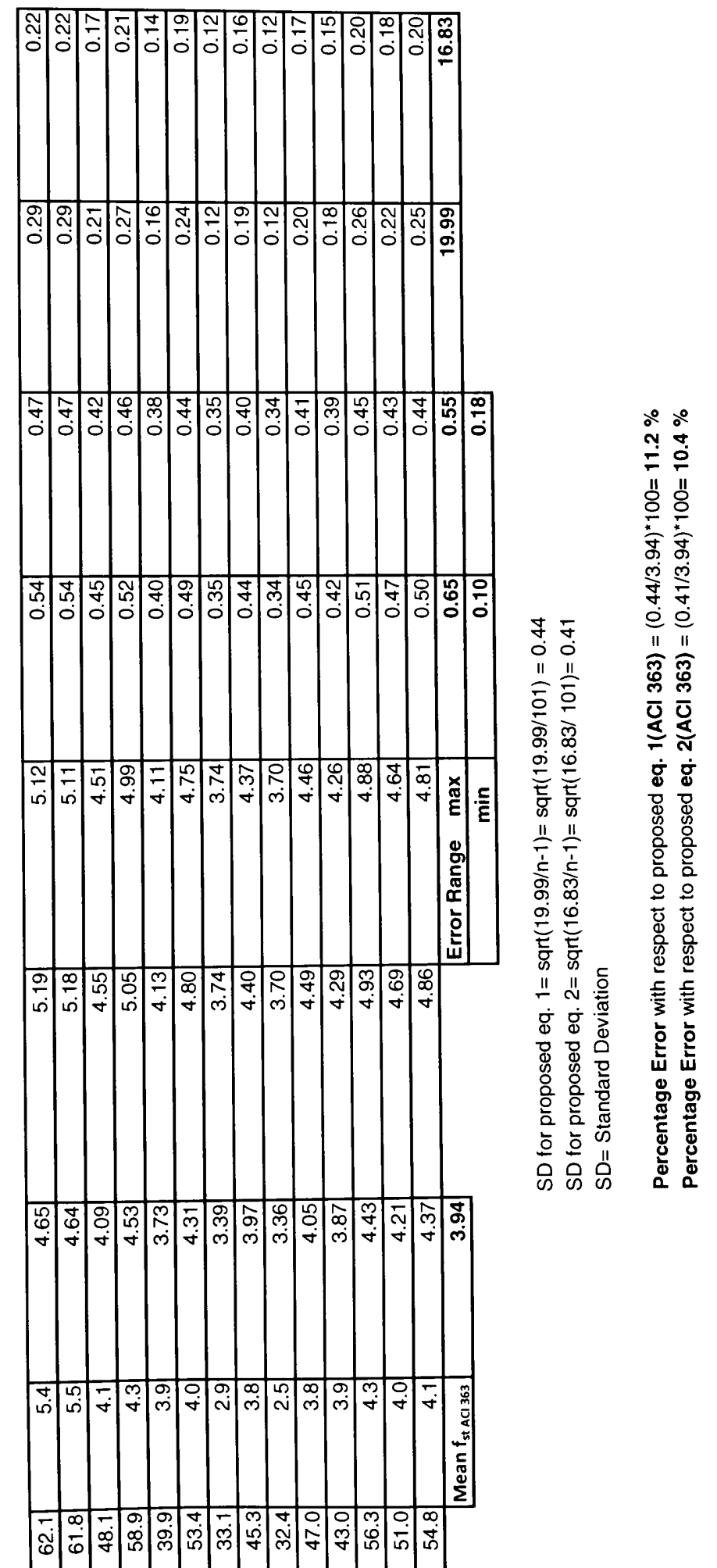




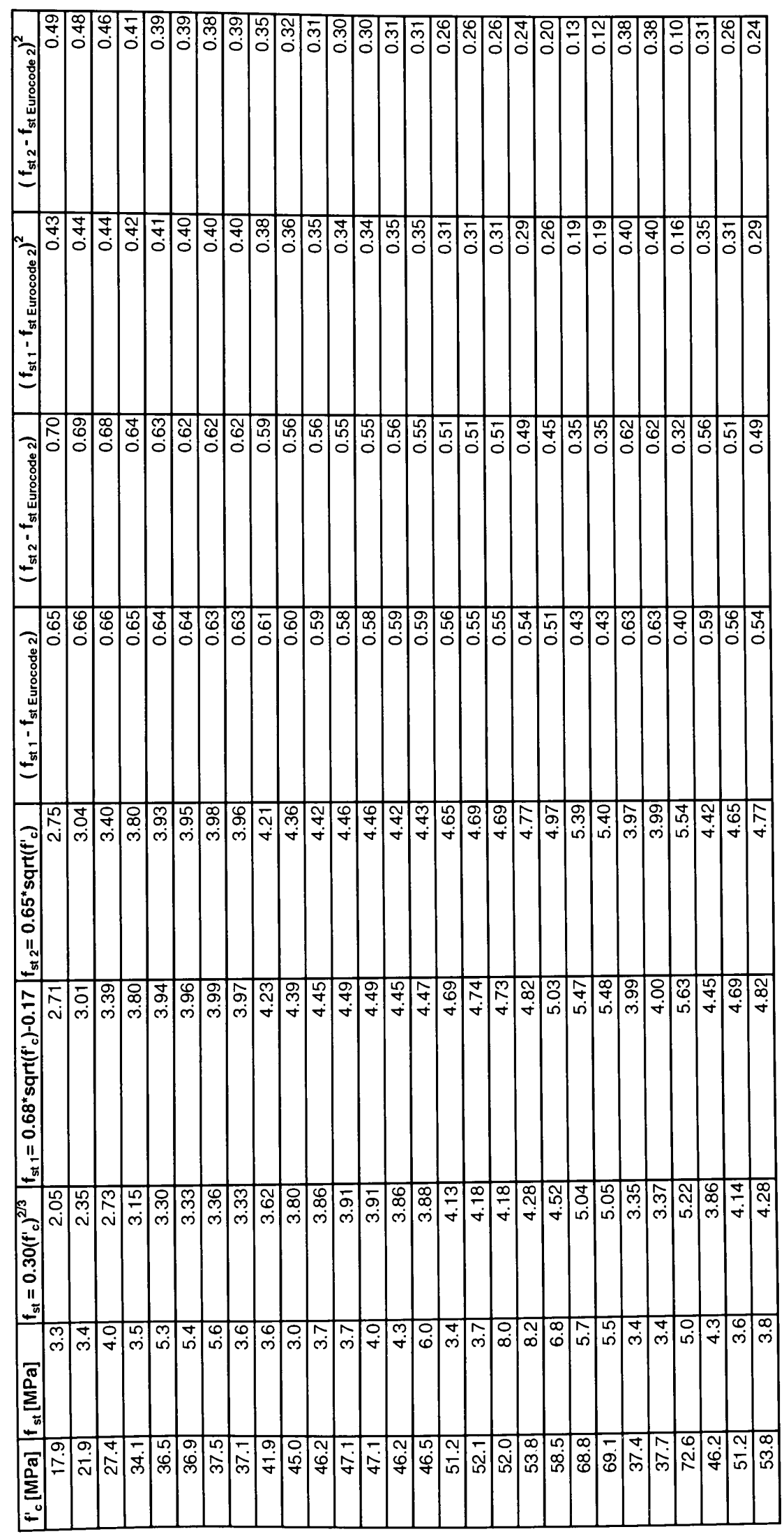




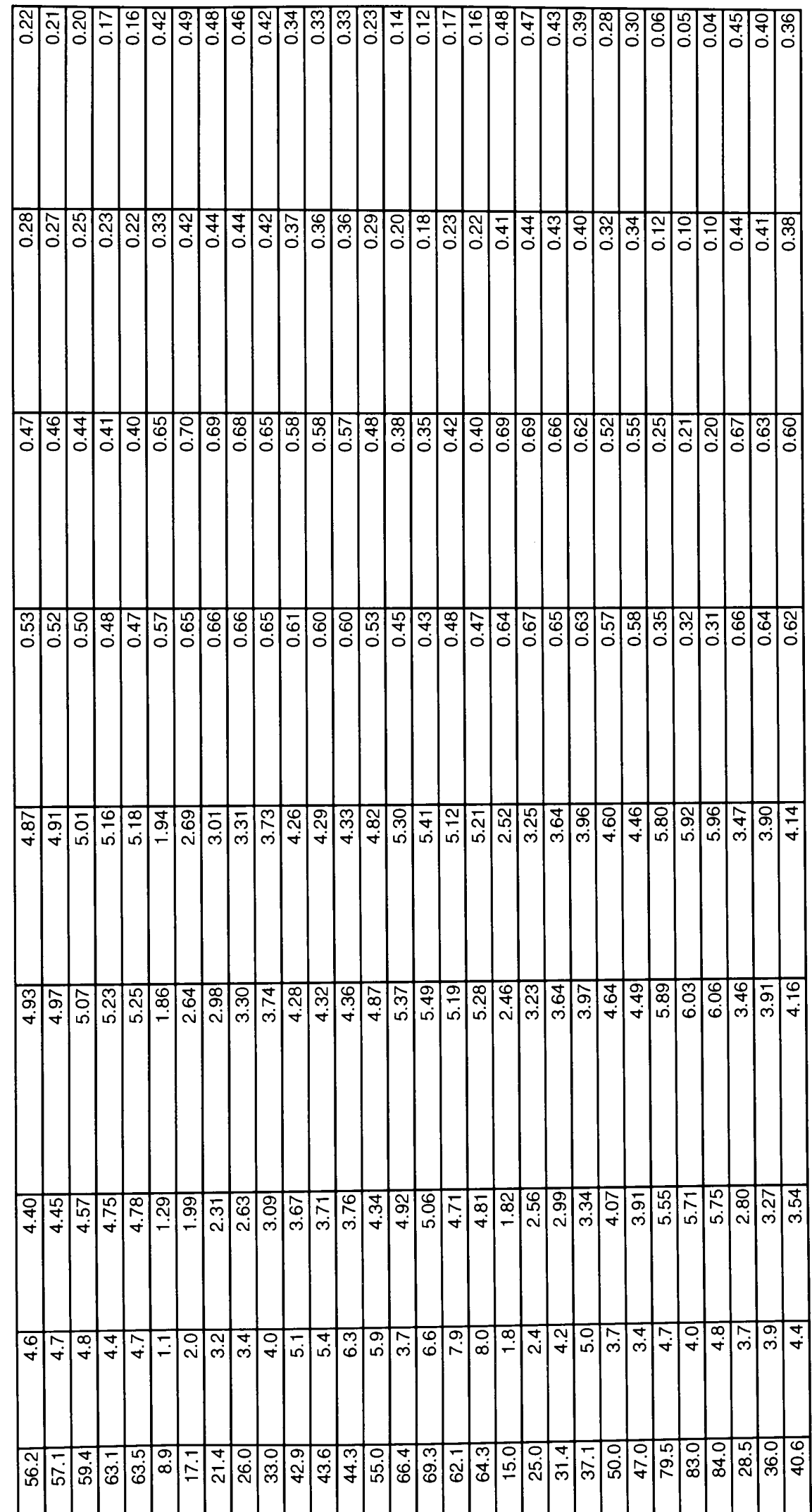




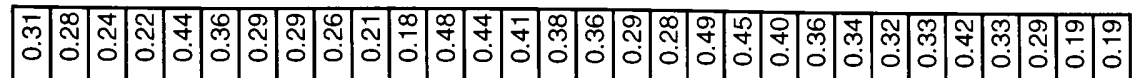

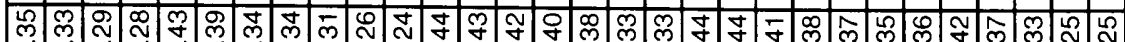

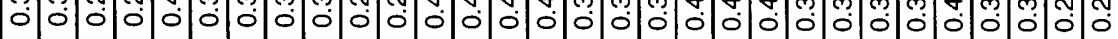

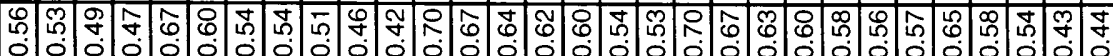

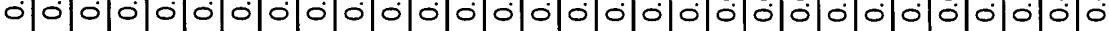

윳

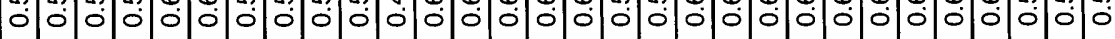

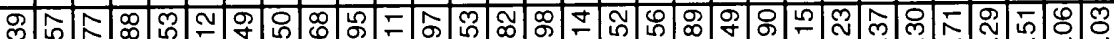

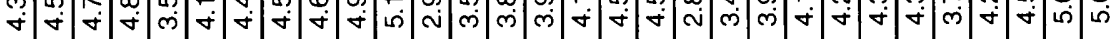

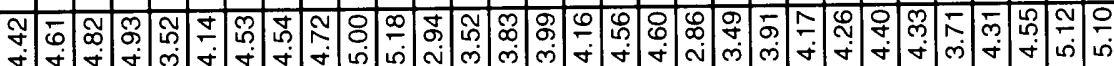

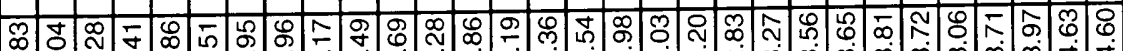

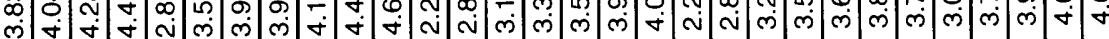

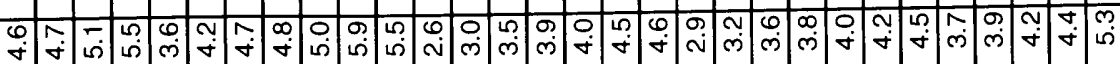

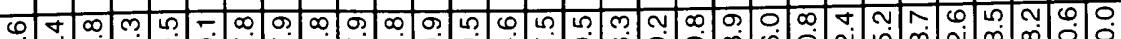

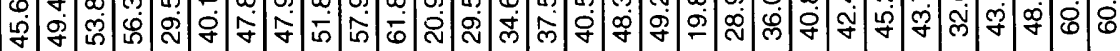




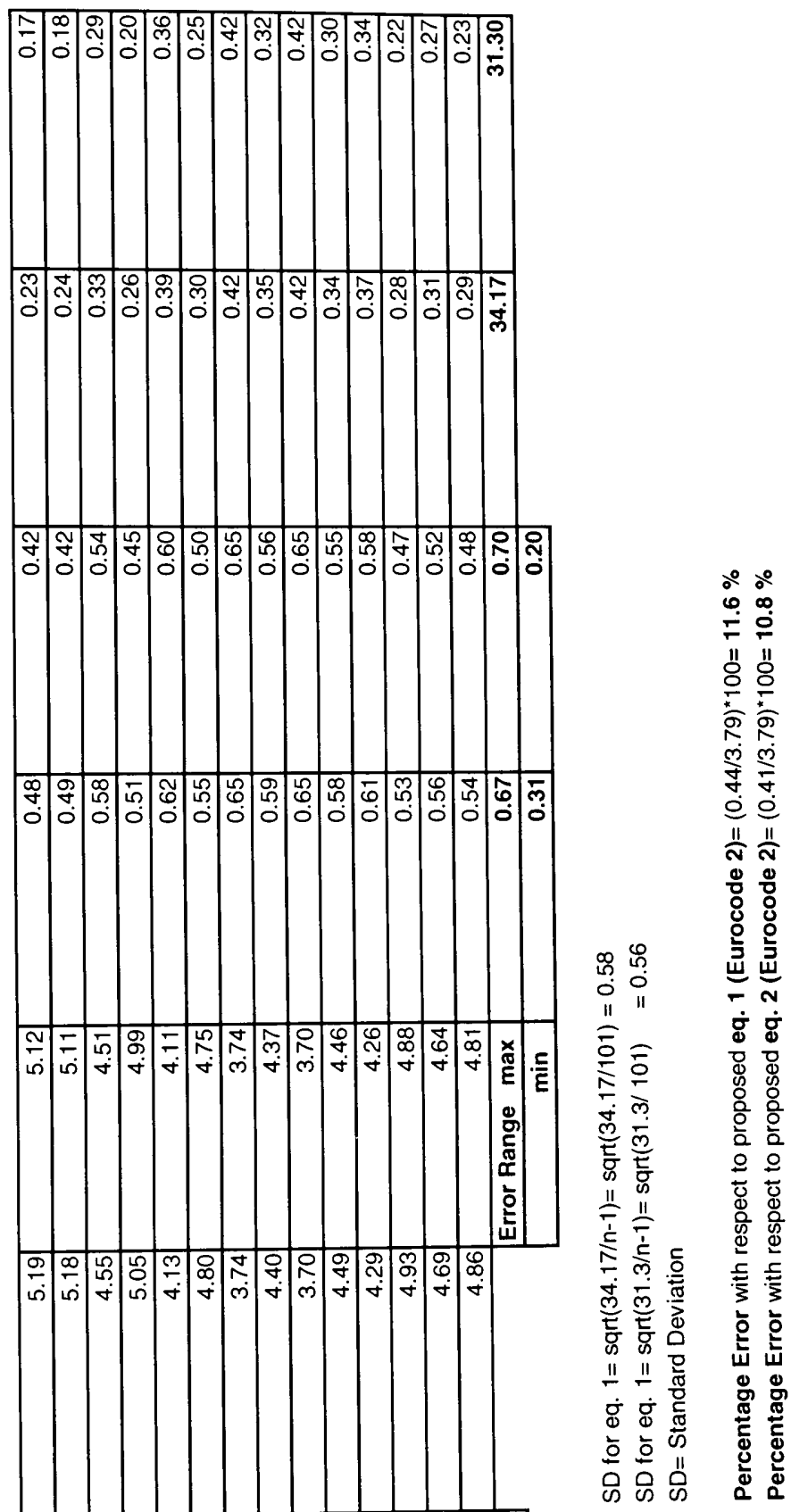

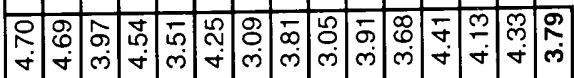

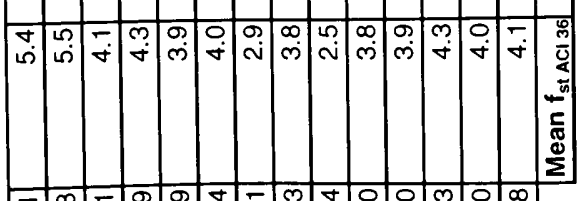

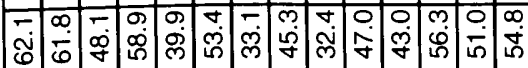




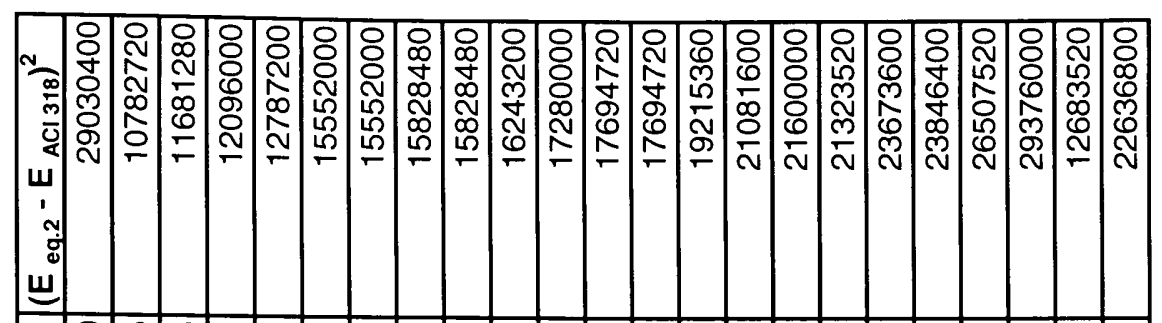

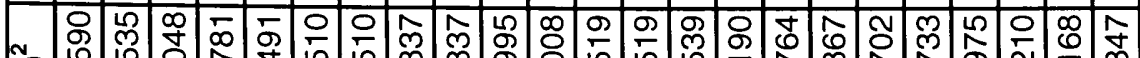
\% 彳亍 w

:-

ш)

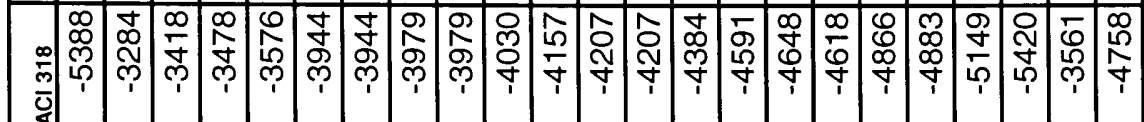

w

บับ

ш

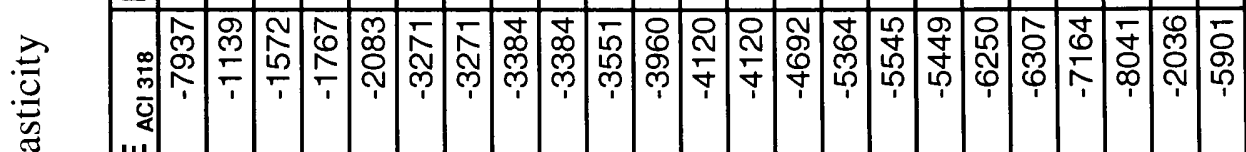

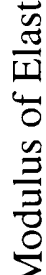

$\Xi$ :

:

ш

w.

ш

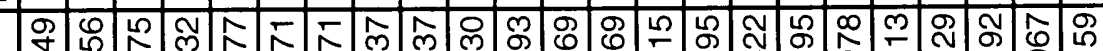
రे 守

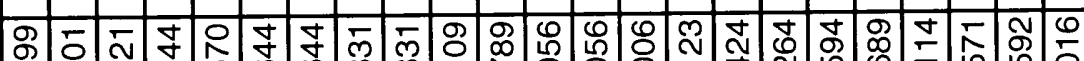

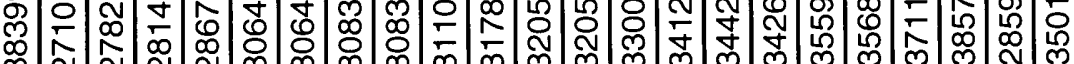
$-$

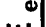

ш)

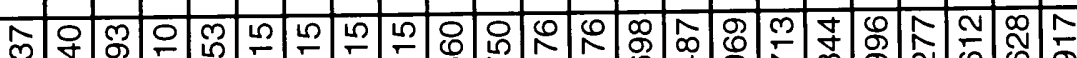

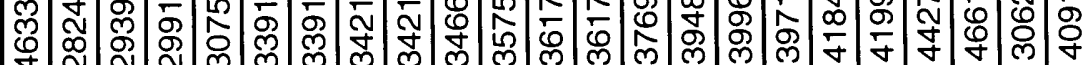

के

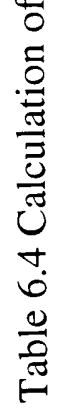

计

(2)

ш

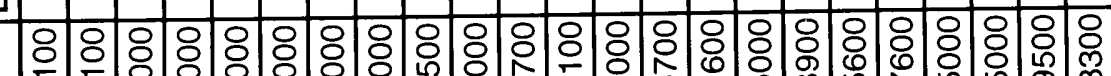

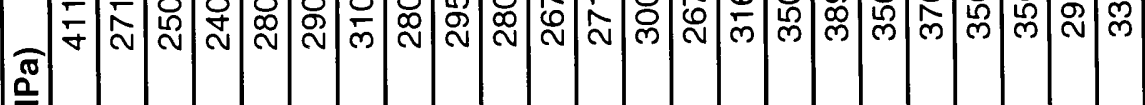

$\frac{\pi}{\Sigma}$

要 


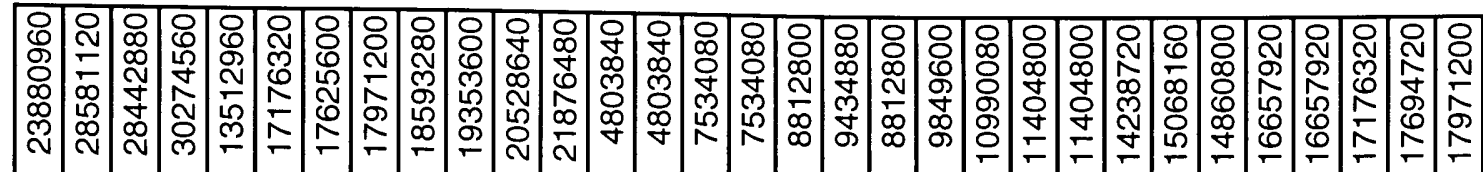

군

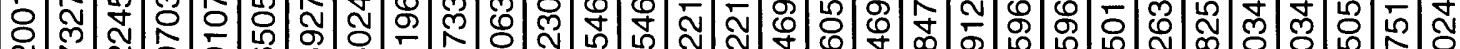
网 ల) 0 : 0 :

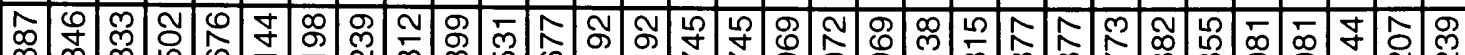

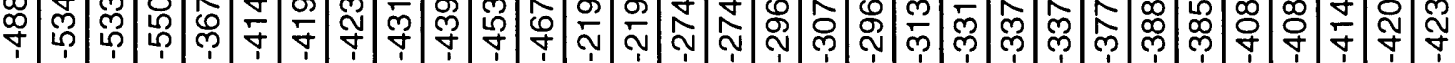

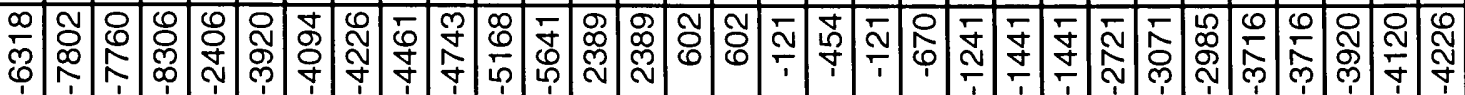

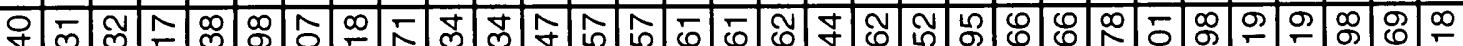

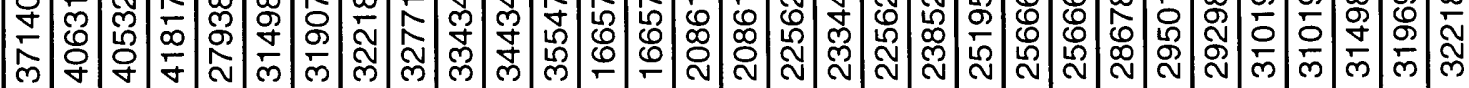

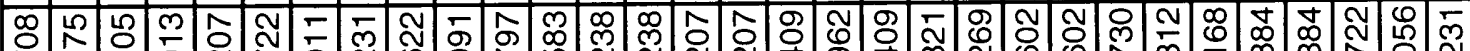

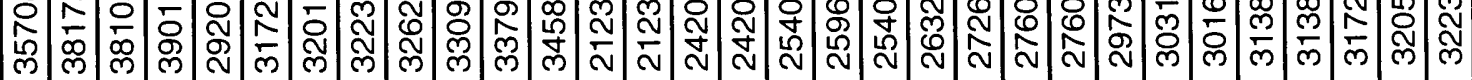

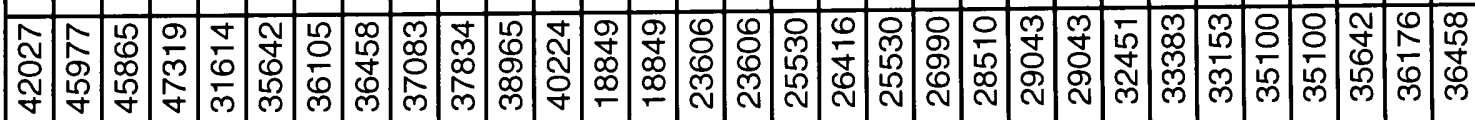

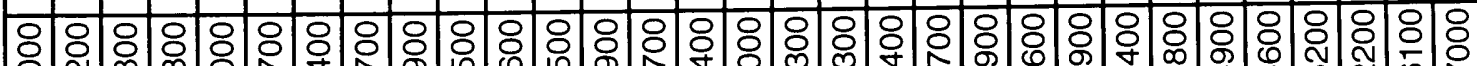

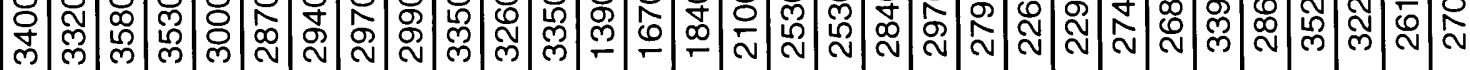

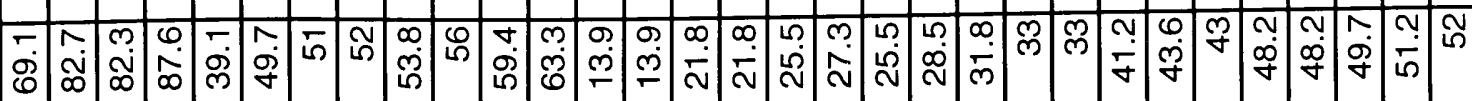




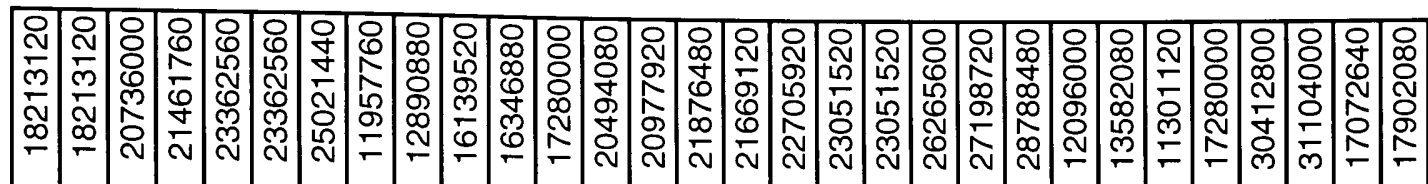

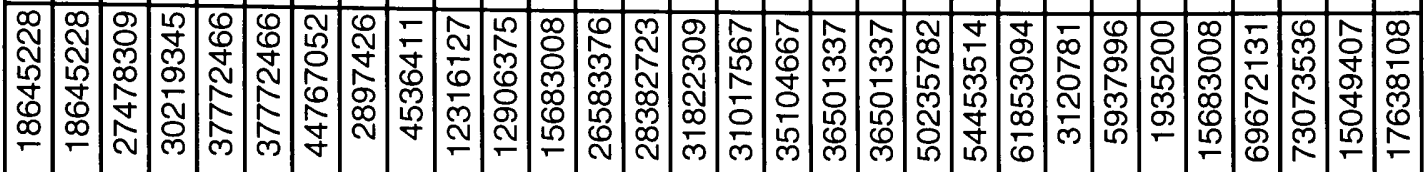

ஜ

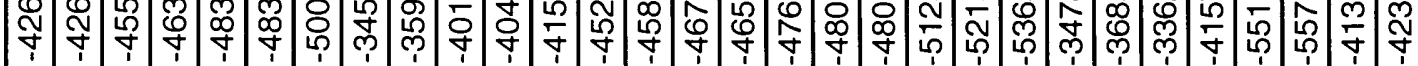

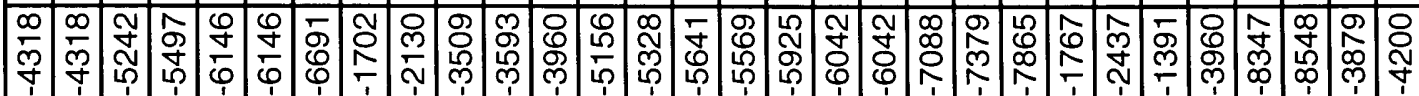

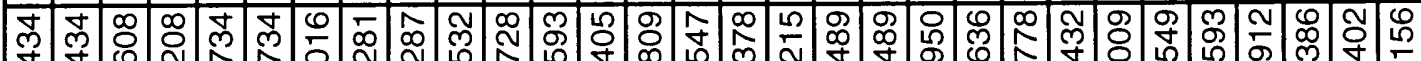

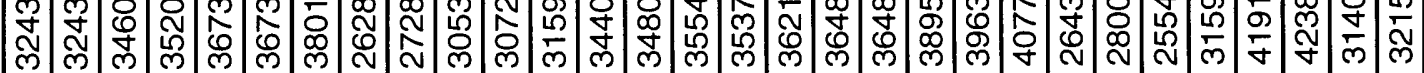

ম 雨

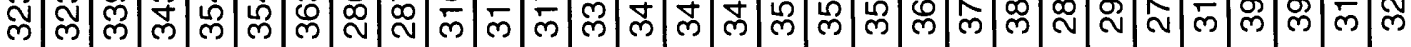

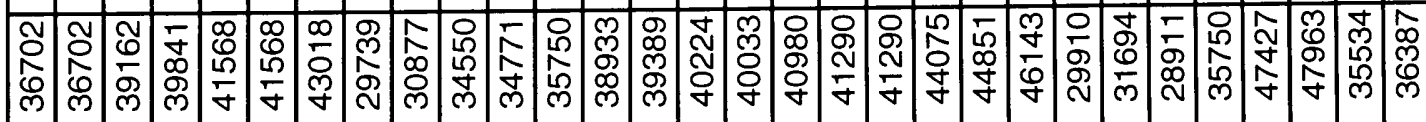

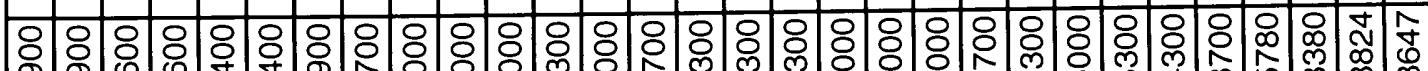
m I กิ่ กิ 


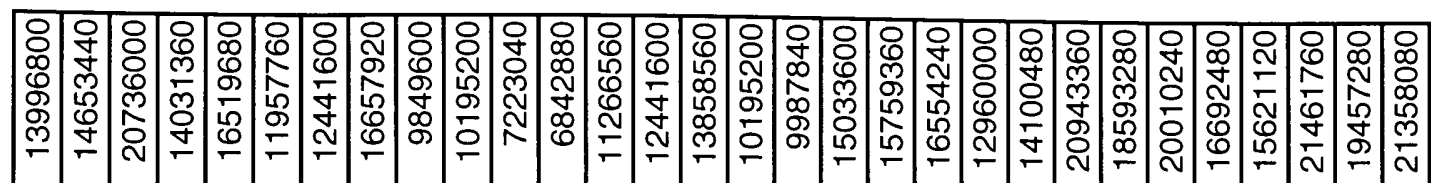

\} సิ

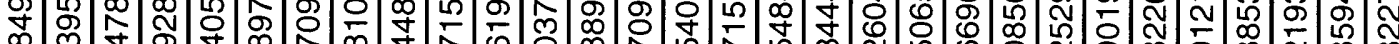
:

广 冞

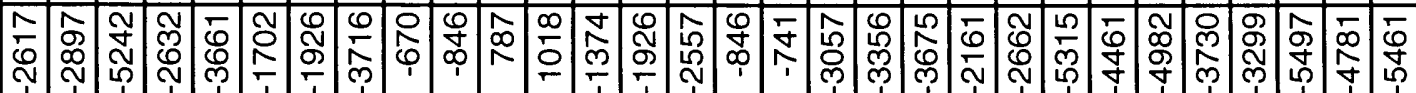

mுలூ 唄

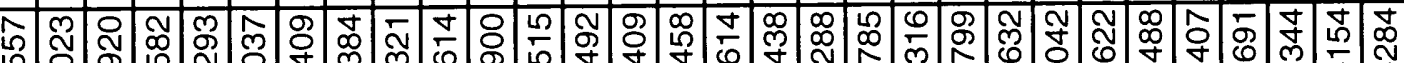
令号

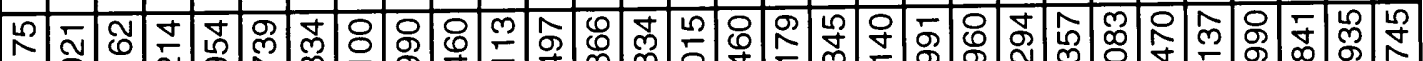

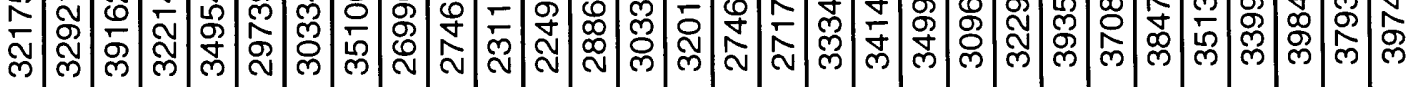

을 స్లెల ம

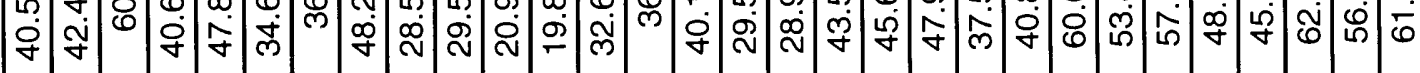




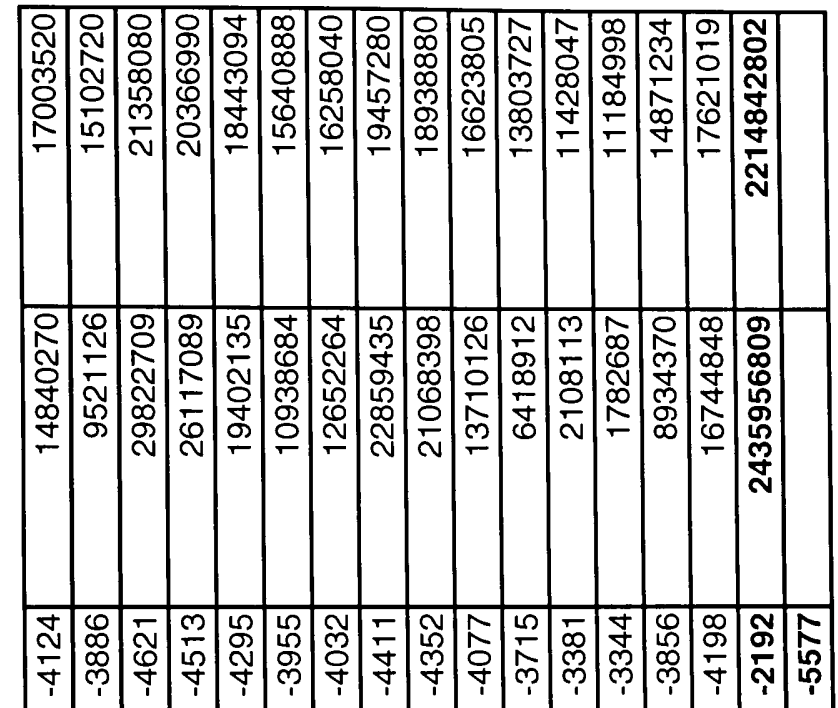

$\sum_{11}^{n} \frac{m}{4}$

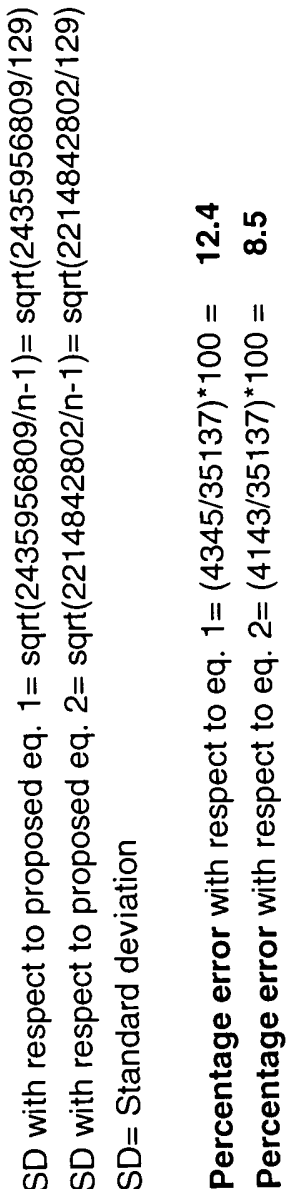

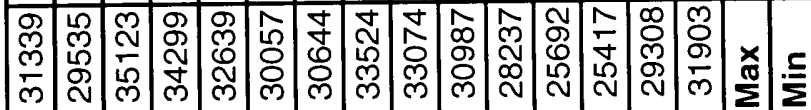

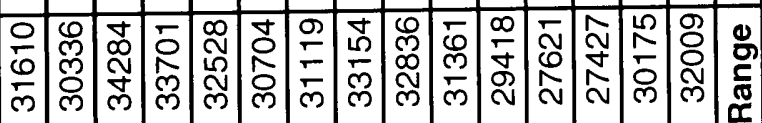

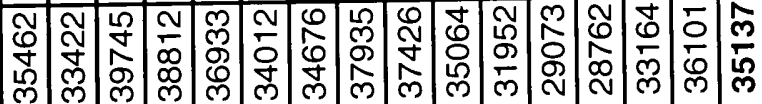

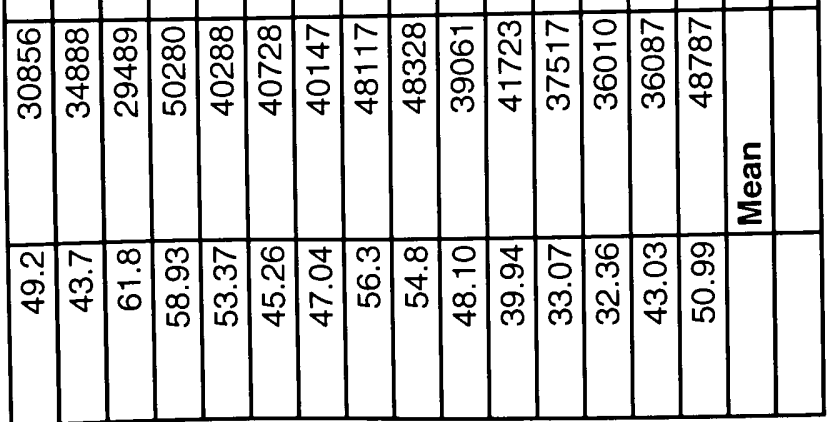




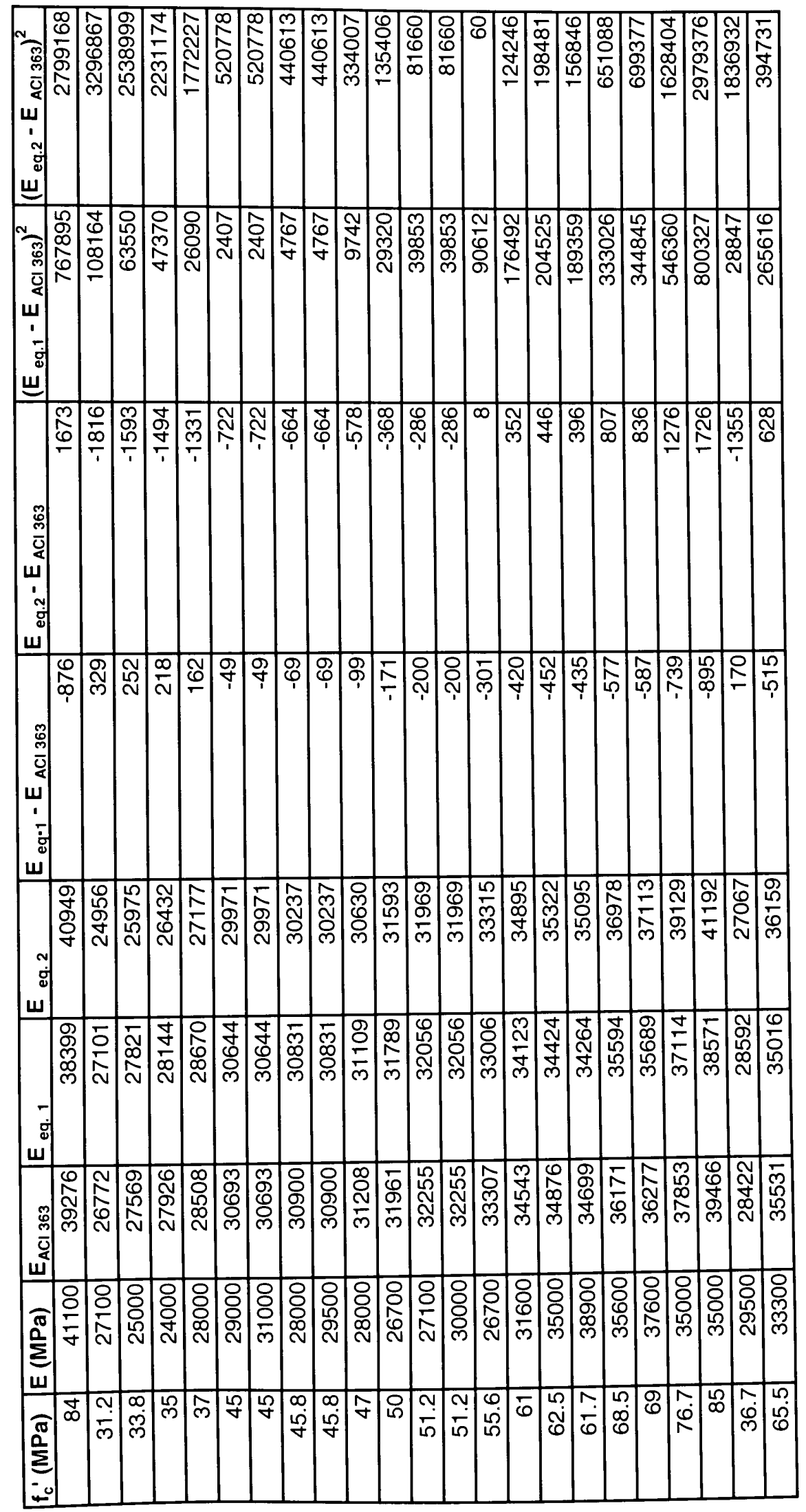




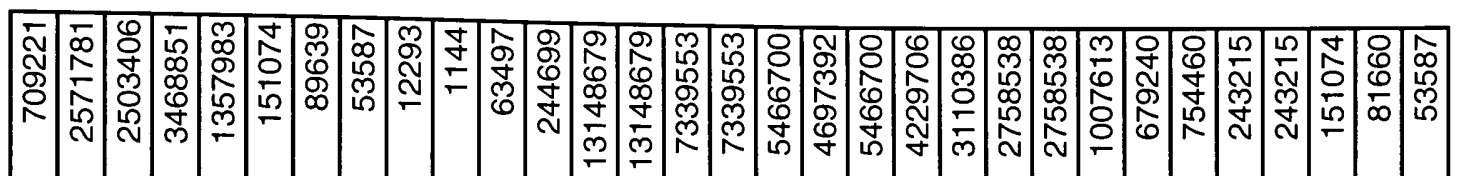

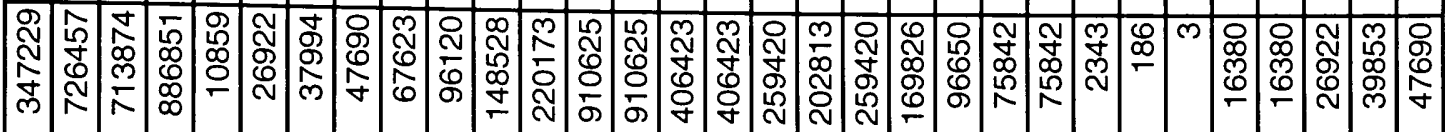

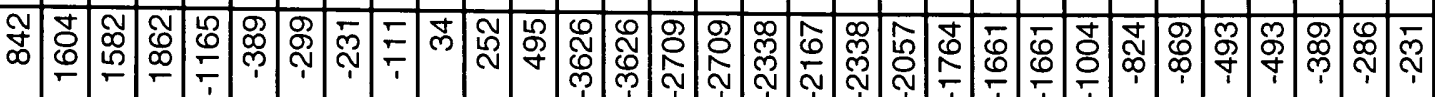

ஜ

守

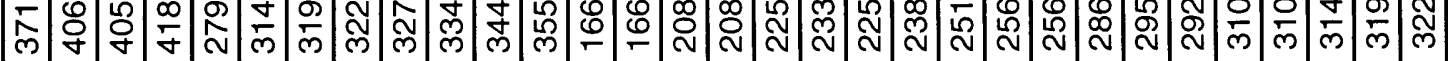

ஜ

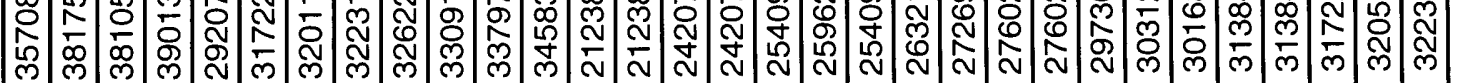

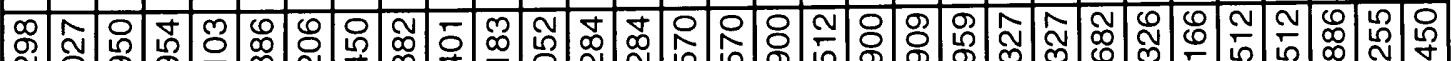
స్లి

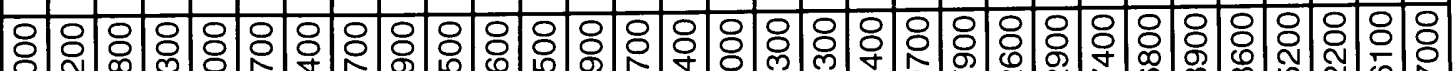
m.

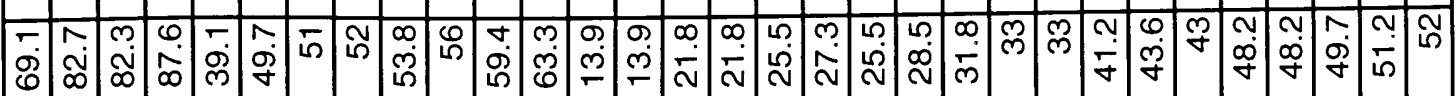




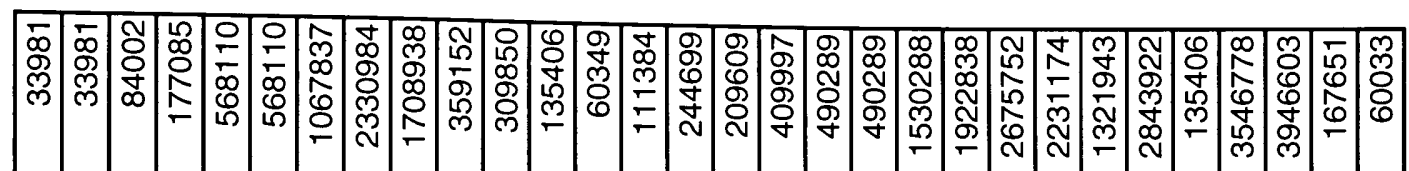

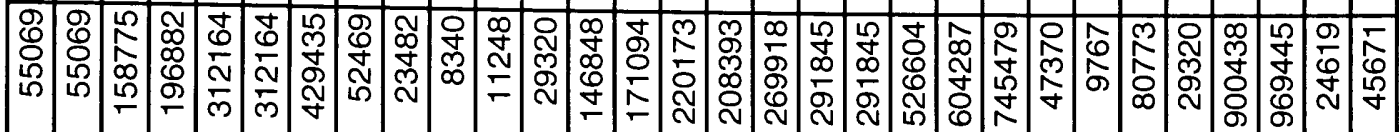

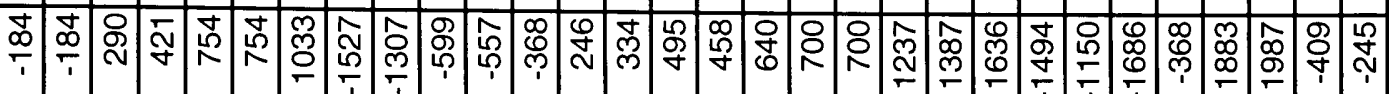

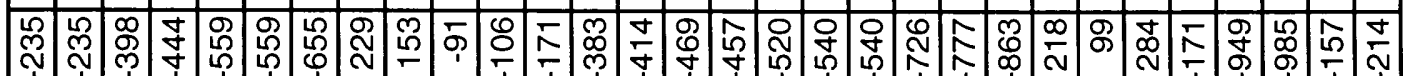

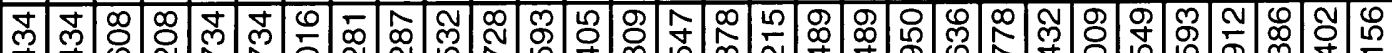

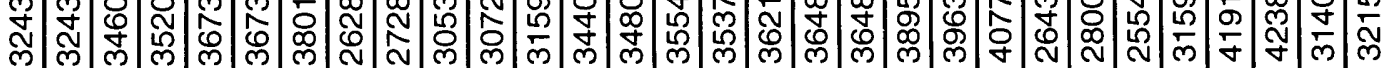

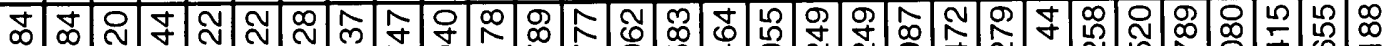

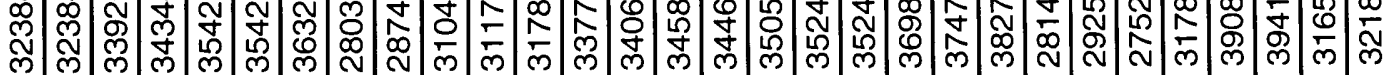

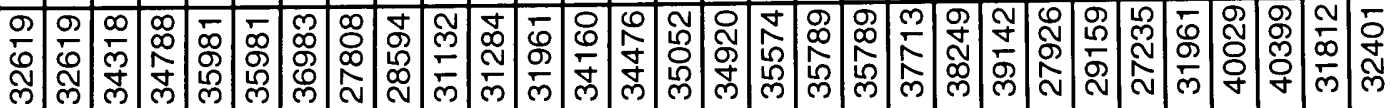

ㅇㅇㅇㅇㅇㅇㅇㅇㅇㅇㅇㅇㅇㅇㅇㅇㅇㅇㅇㅇㅇㅇㅇㅇㅇㅀ $\frac{\Phi}{m}$ 市

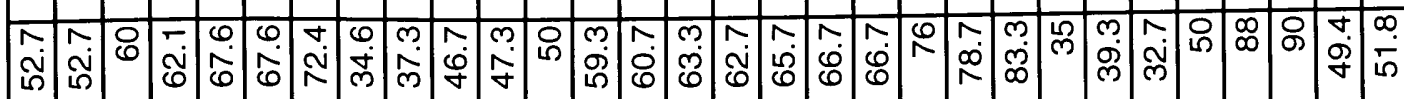




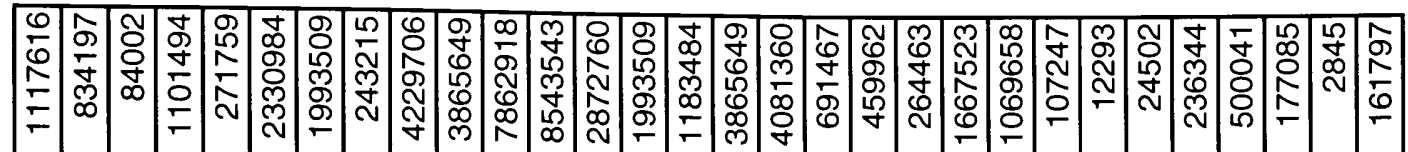

ஜ

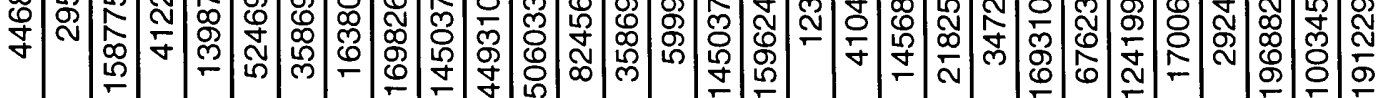

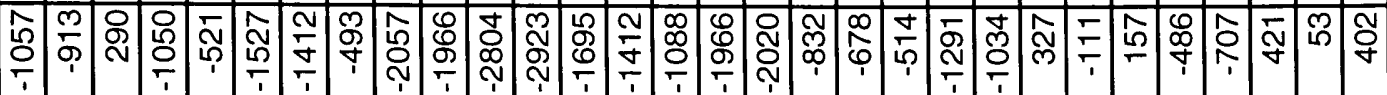

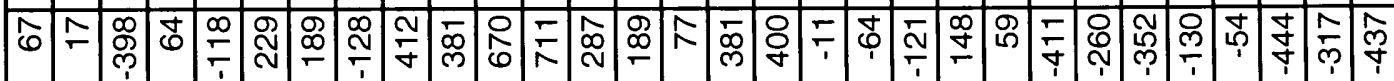

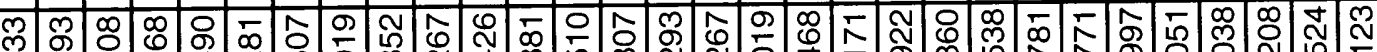
品

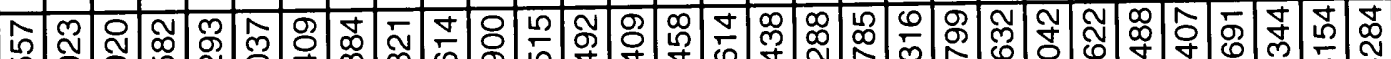
స్స

Б் N)

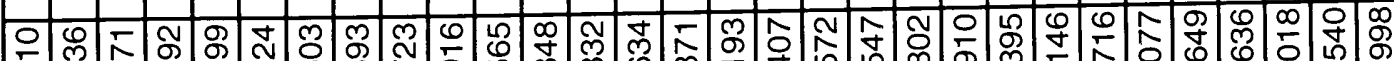
స్లి ம f 


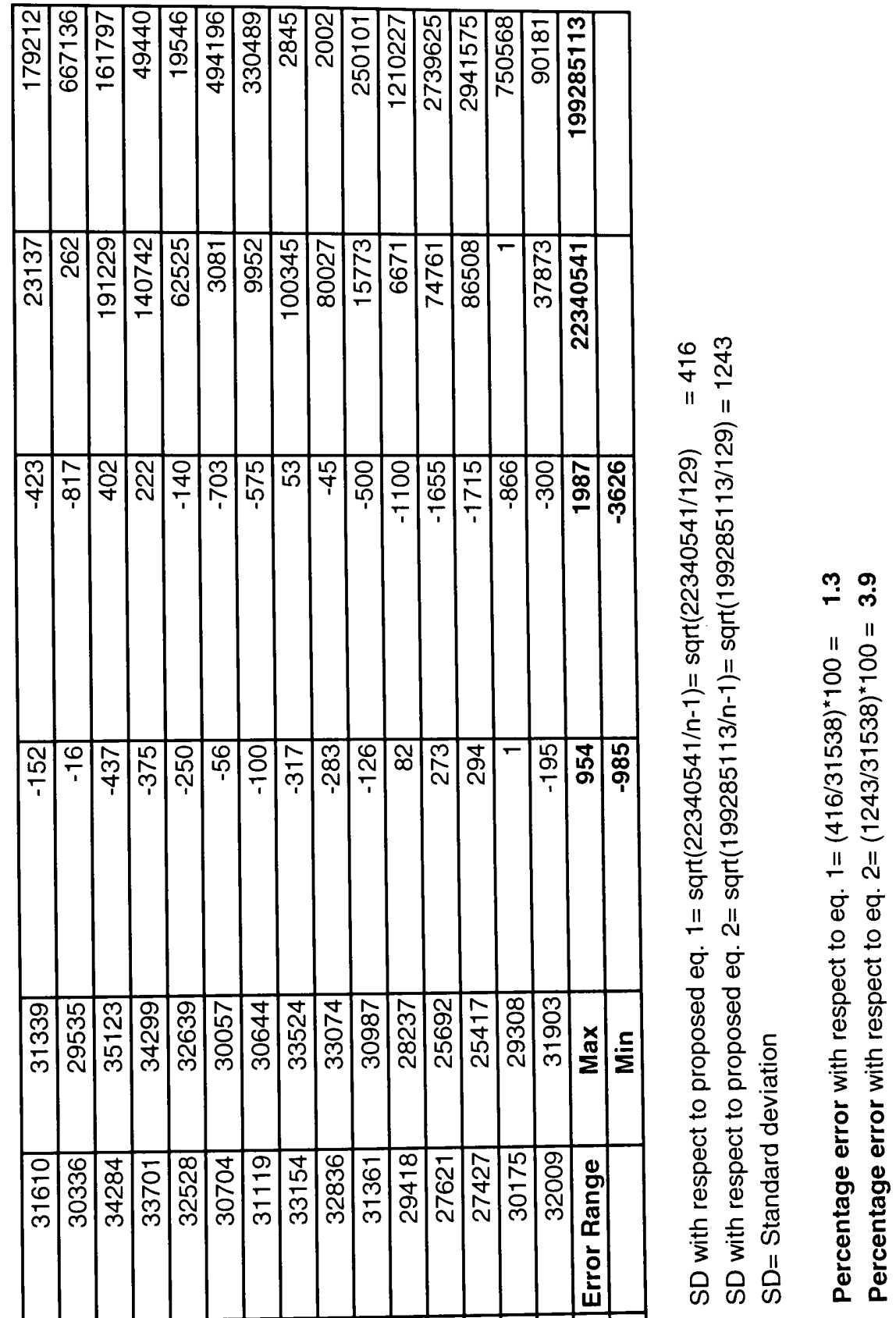

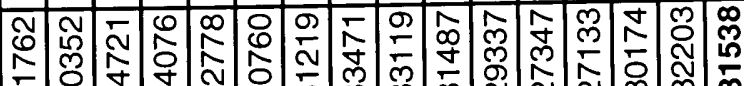

ल)

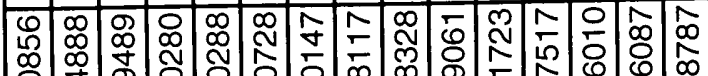

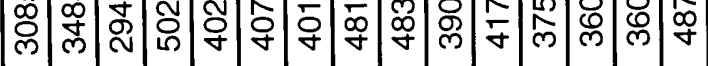

$\frac{5}{\mathbb{0}}$

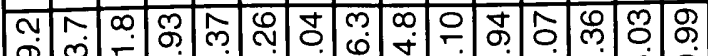

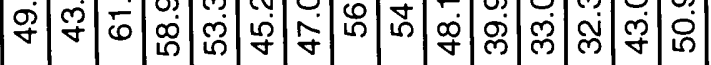




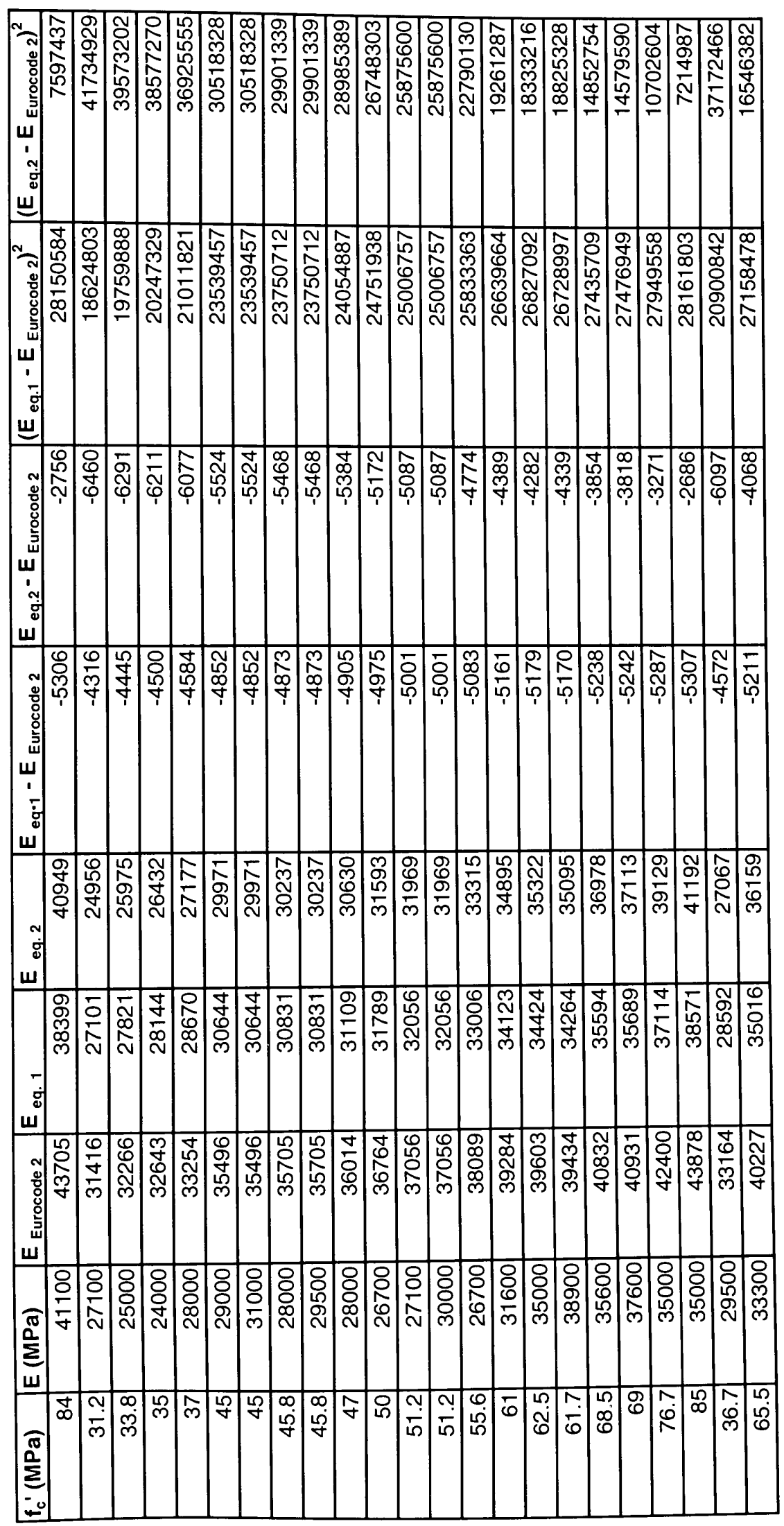




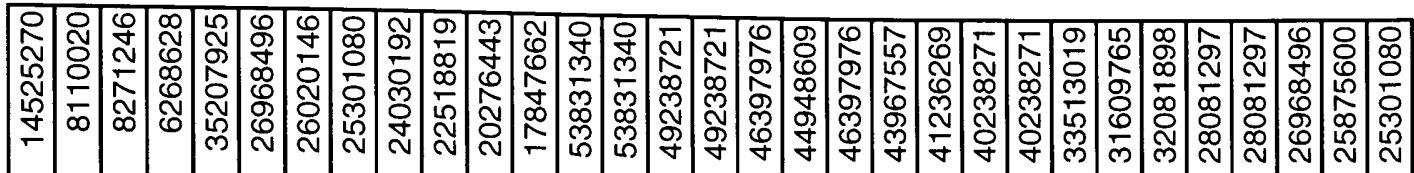

ల్లా

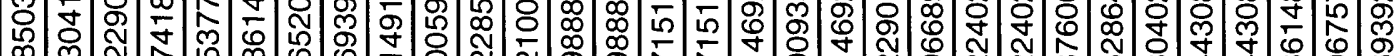

年 $N$ N

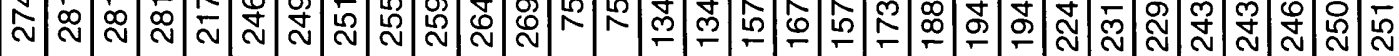

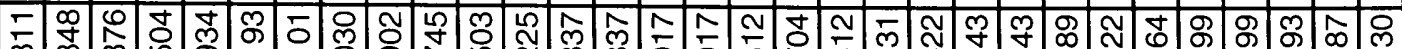

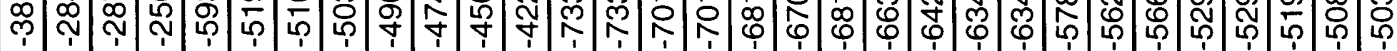

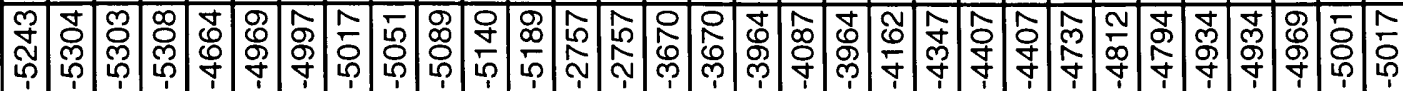

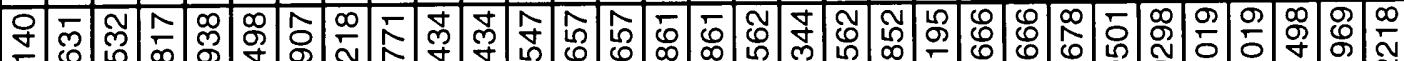

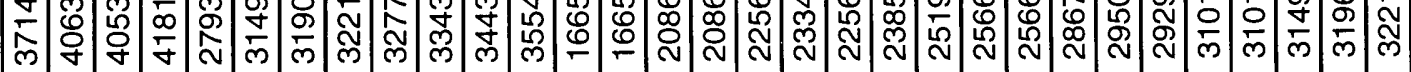

வ 挛

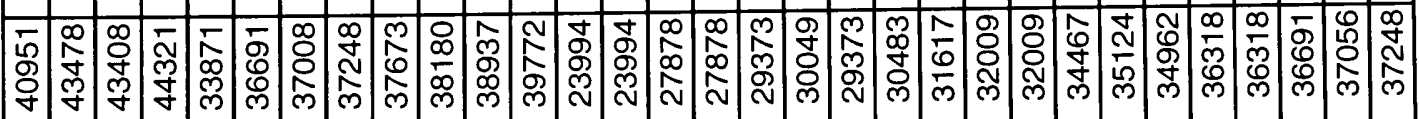

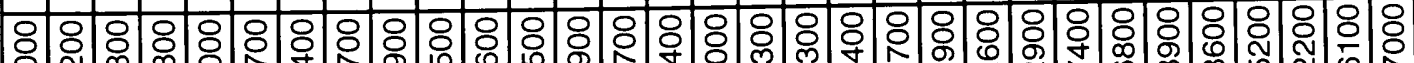

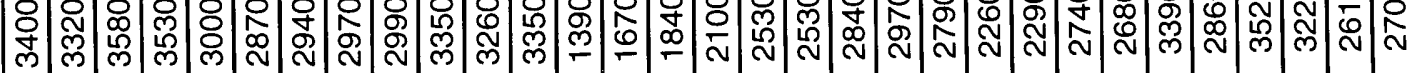

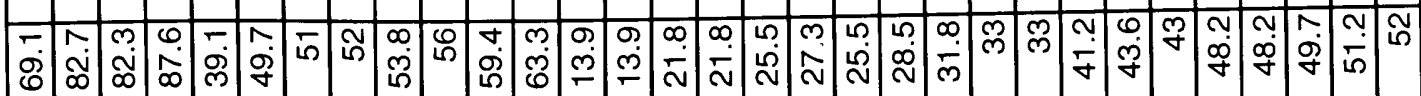




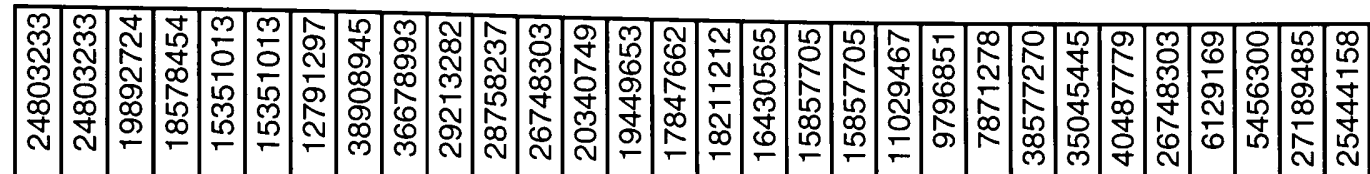

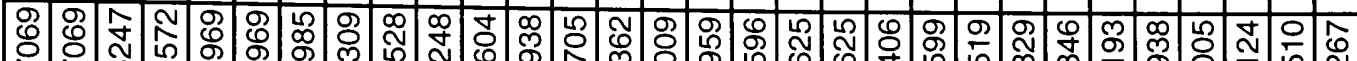

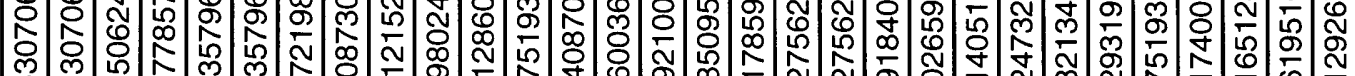

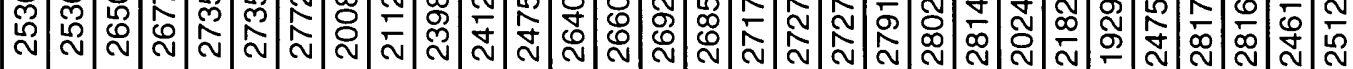

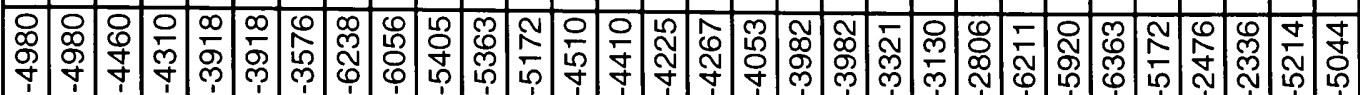

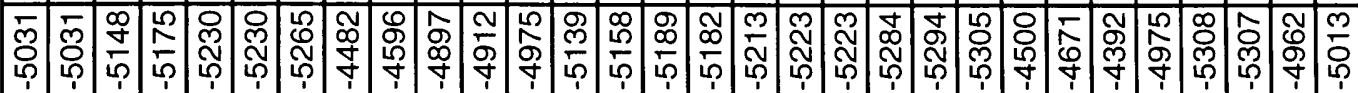

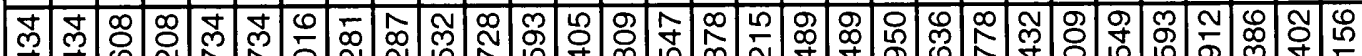

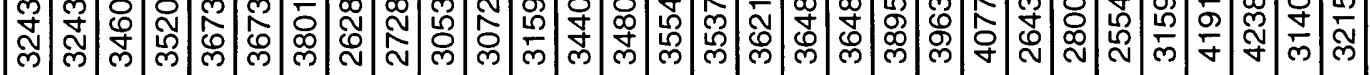

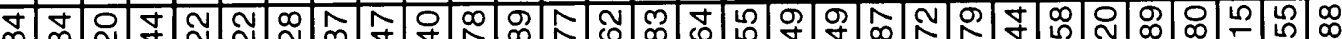

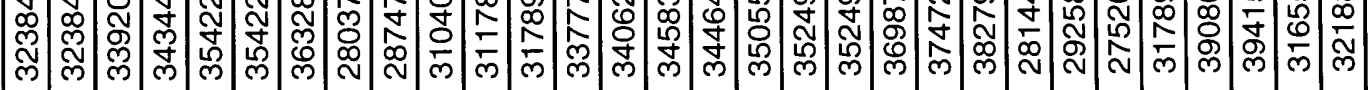

느응유.

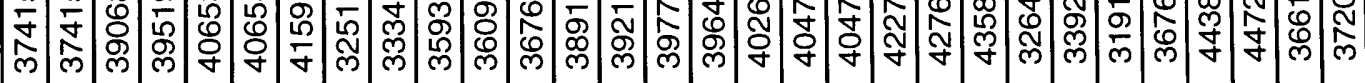

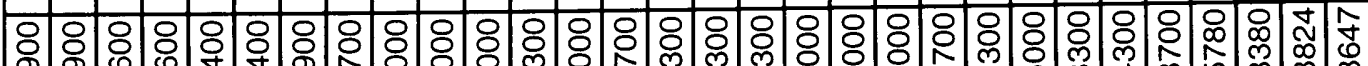

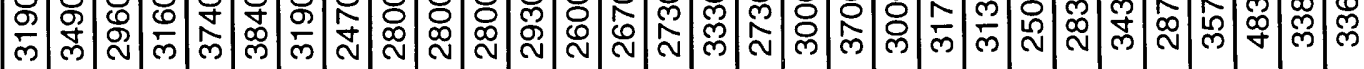

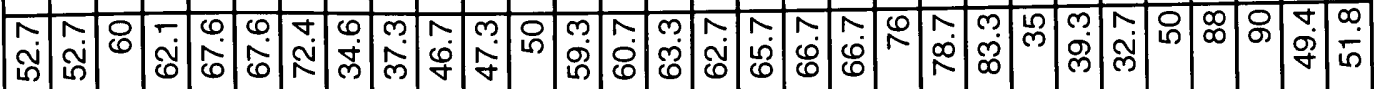




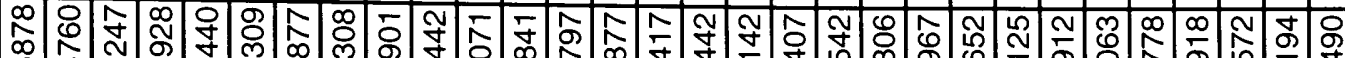
萑 స N

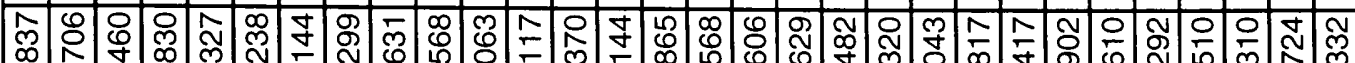

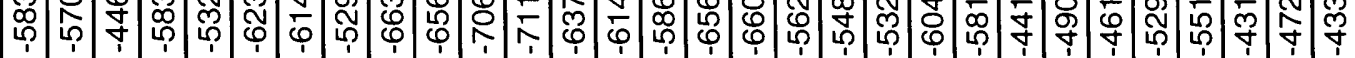

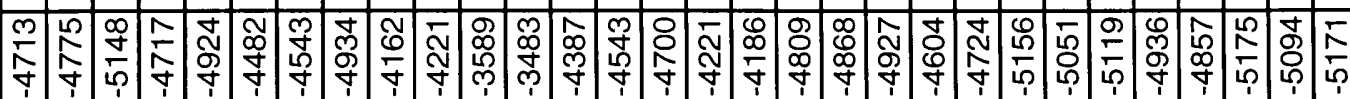

স্লিপి:

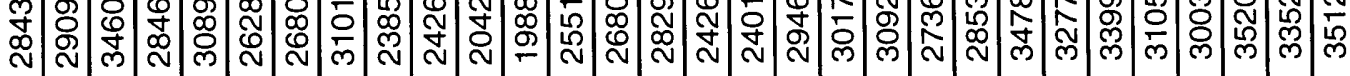

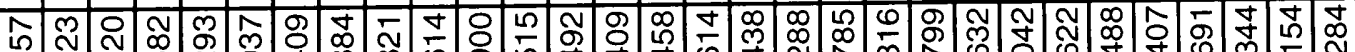
N)

テ๐

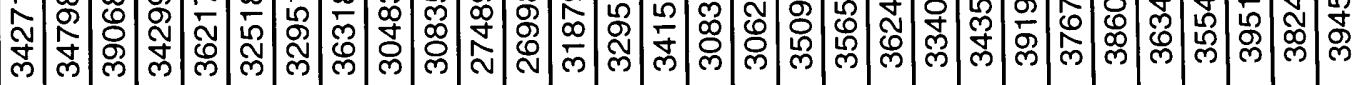
O స్ల.

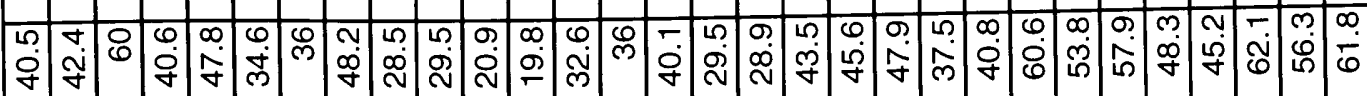




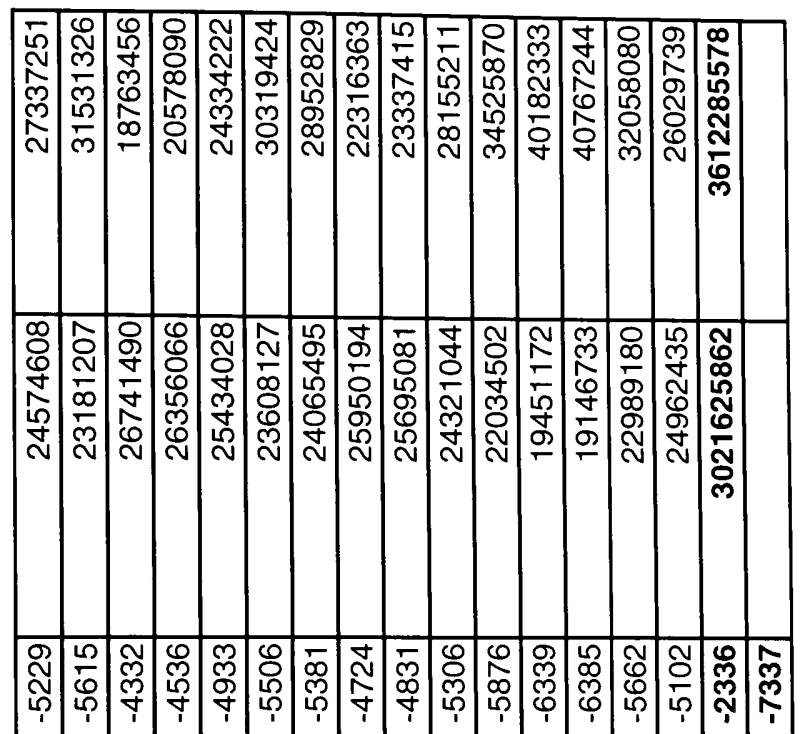

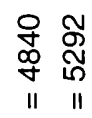

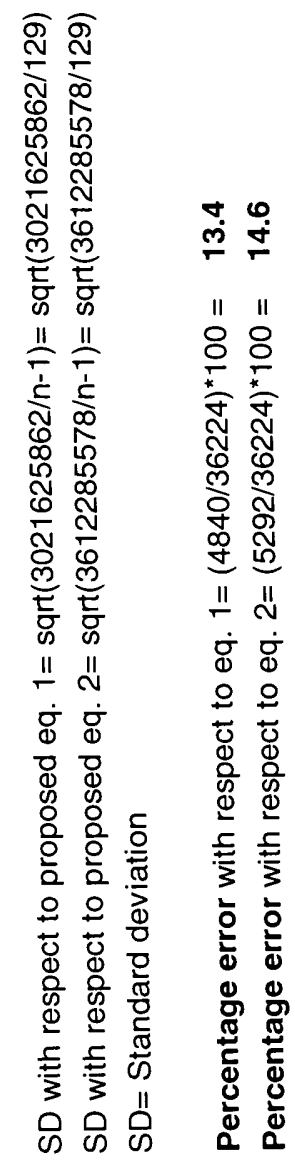

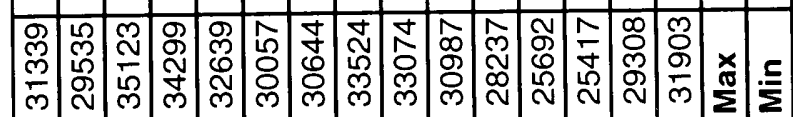

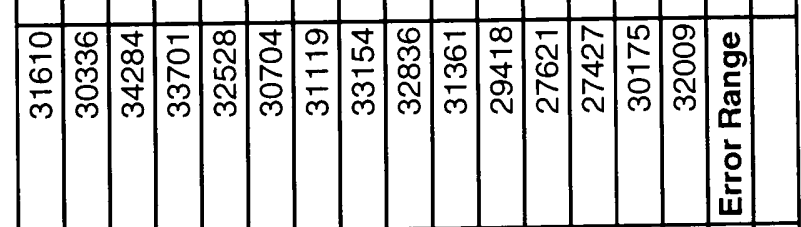

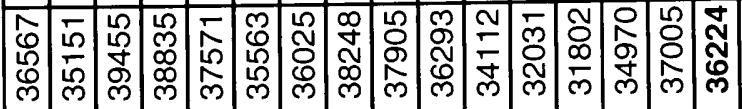

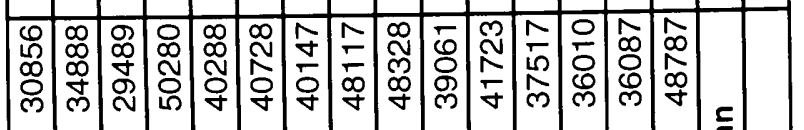

空

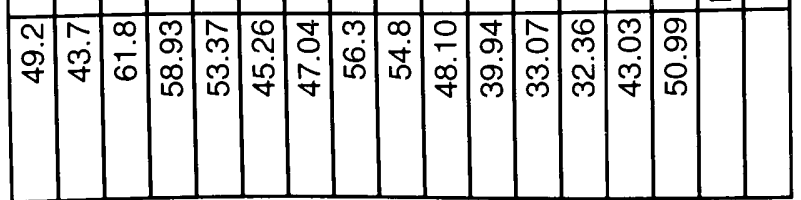

